NBSIR 81-2348

\title{
Materials for Instrumentation for Fossil Energy Technologies
}

(A Review and Program Plan of R\&D Needs Conducted by the National Bureau of Standards)

U.S. DEFARTMENT OF COMMERCE

National Bureau of Standards

Washington, DC 20234

August 1981

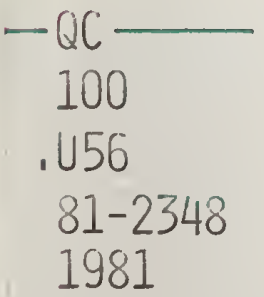

Prepared for

Department of Energy

Washington, DC 20545 



\section{MATERIALS FOR INSTRUMENTATION FOR FOSSIL ENERGY TECHNOLOGIES}

(A Review and Program of R\&D Needs Conducted by the National Bureau of Standards)

H.P.R. Frederikse and P.K. Schenck*

G.W. Burns**

R.R. Dils and J.R. Whetstone***

U.S. DEPARTMENT OF COMMERCE

National Bureau of Standards

Center for Materials Science*

Center for Absolute Physical Quantities**

Center for Chemical Engineering **

Washington, DC 20234

Prepared for

Department of Energy

Washington, DC 20545

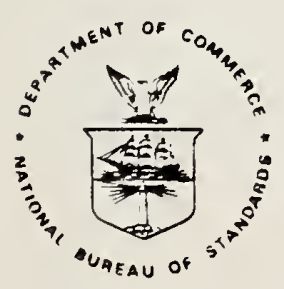

U.S. DEPARTMENT OF COMMERCE, Malcolm Baldrige, Secretary NATIONAL BUREAU OF STANDARDS, Ernest Ambler, Director 
1 


\section{MATERIALS FOR INSTRUMENTATION FOR FOSSIL ENERGY TECHNOLOGIES}

A Review and Program Plan of R\&D Needs

Conducted by the National Bureau of Standards

for

The Department of Energy - Fossit Energy (AR\&TD)

under contract No. EA-77-A-01-6010

Task No. A002-MER

by

the National Bureau of Standards

Washington, DC 20234

August 1981

H. P. R. Frederikse and P. K. Schenck

Center for Materials Science

G. W. Burns

Center for Absolute Physical Quantities

R. R. Dils and J. R. Whetstone

Center for Chemical Engineering

"This report was prepared for the internal use by the National Bureau of Standards and the Department of Energy as a planning document. Neither the United States nor the U.S. Department of Energy and the National Bureau of Standards, nor any of their employees, nor any of their contractors, subcontractors, or their employees, makes any warranty, expressed or implied, or assumes any legal liability or responsibility for the accuracy, completeness, or usefulness of any information, apparatus, product or process disclosed, or represents that its use would not infringe privately owned rights". 
EXECUTIVE SUMMARY. . . . . . . . . . . . . . i

ACKNOWLEDGEMENTS ......................

CHAPTER 1. Introduction................ 1

1.1 Objectives. . . . . . . . . . . . . . . 1

1.2 Approach. . . . . . . . . . . . . . . 2

1.3 Scope . . . . . . . . . . . . . . 3

1.4 Present Activities. . . . . . . . . . . . . 4

CHAPTER 2. Measurement Needs \& Materials Requirements . . . . 7

2.1 Process Parameters. . . . . . . . . . . . . . 7

a. Multi-component Flow ........... 7

b. Pressure ............... . 9

c. Temperature. . . . . . . . . . . . 9

d. Composition - Chemical .......... 14

e. Composition - Phases, Particulates ...... 15

f. Composition - Emissions. . . . . . . . . . 16

2.2 Erosion and Hot Corrosion . . . . . . . . . . . 17

2.3 Fuel Characterization . . . . . . . . . . . . 18

2.4 Instrumentation for Thermal \& Mechanical Properties . . 21

2.5 Testing Procedures and Facilities.......... 24

2.6 Data Centers. . . . . . . . . . . . 26

CHAPTER 3. Suggested Program Plan . . . . . . . . . . 28

3.1 General Considerations. . . . . . . . . . . . . 28

3.2 Rationale and Recommendations.......... . 29

3.3 Level of Effort. . . . . . . . . . . . . . . 29

3.4 Coordination and Impiementation.......... . 34

3.5 Recommended Projects. . . . . . . . . . . . . 37

REFERENCES ................. . 75

APPENDICES

I. Review of Major Fossil Energy Processes

II. Present Activities in the Area of Materials/Instrumentation for Fossil Energy

II . Case Studies

a. Flow Measurement Research for Coal Slurry Flows - J. R. Whetstone

b. Acoustic Char-Flow Monitors for the BI-GAS Pilot Plant - T. P. Mulcahey

c. Temperature Measurement in Coal Gasifiers - G. W. Burns

d. High Temperature Gas Turbine Erosion/Corrosion Thin Fi?m Sensors and Related Devices - R. R. Dils

e. Analysis by High Pressure Sampling Mass Spectrometry - P. K. Schenck

f. Measurement of Heat Conductivity - H. P. R. Frederikse

IV. Miniworkshop 


\section{Executive Summary}

This report is an assessment of the materials research needed to address the instrumentation problems in the various Fossil Energy Technologies. The study was conducted by the National Bureau of Standards on request of the Department of Energy (Fossil Energy Program).

Reliable operation of Fossil Energy plants requires knowledge, and hence measurement, of essential parameters like temperature, flow, heat transfer, liquid and gas composition, etc. Furthermore it is essential to sample and/or monitor possible erosion, hot corrosion, and mechanical degradation of plant components. The equipment needed for these measurements must be able to operate under extremely harsh conditions, and consequently, the selection of proper materials is a major problem. The main theme of this report is that the problems of accurate measurements and reliable materials are intimately connected and that the design of instrumentation in the field of Fossil Energy should go hand-in-hand with carefully planned materials research.

The review of research needs in this area has lead to a suggested Program Plan presented at the end of this report. Possible avenues of approach are discussed. Priorities and levels of effort are indicated. (See Tables 1, 2 and 3 on pages 31-34).

As the title of this report indicates the research is aimed at "Materials for Instrumentation". In some of the recommended work the emphasis is somewhat more on the materials aspect, while in other cases the measurement angle receives at bit more attention.

The plan divides the proposed research in 38 projects covering 4 major research areas:

I. Materials Research for Sensors

A. Erosion/Hot Corrosion: slurries, particulates in gas, erosion/ corrosion sensors.

B. Thermal/Mechanical Properties: heat transfer, thermal expansion, heat capacity, mechanical strength, NDE for cracks and voids, etc.

C. Materials Problems in Process Parameter Measurement: flow, temperature, pressure, composition, coatings, adhesion, electrochemical cells, windows and spool pieces.

II. Fuel Characterization: chemistry and physics of coal, flyash 
III. Testing and Data: test methodology, test facilities for liquids, slurries and gas streams, test rigs for combustion, erosion/corrosion; data banks on materials and instrumentation

IV. Exploratory Research: new ideas in materials for measuring equipment. It is felt that the above listing expresses the order of importance of the research areas under consideration. Yet, even a minimum program should conta in some elements of areas II, III and IV.

The authors of this report realize that a considerable amount of materials research is being performed which is relevant to the problems of Fossil Energy Instrumentation. However, the connection is not always obvious. Much of the work is either aimed at solving some particular, immediate problem in coal conversion plants, or the research is general and basic in nature and does not apply to the specific Fossil Energy needs. The goal of the present program recommendations is to conduct applied research focussed on generic materials problems related to instrumentation in coal conversion or coal combustion facilities.

The report does not devote much space to an expose of the instrumentation requirements as such. These needs have been listed and analyzed systematically in a number of reports to the Department of Energy. [e.g., Technical Memoranda 1-10, Argonne National Laboratory (refs. 6 and 7) and the series of Proceedings of I\&C Symposia (ref. 5, p. 84)].

Detailed discussions of half a dozen selected problems (Case Studies) have been collected in Appendix III. 


\section{Acknowledgements}

The authors want to thank a number of colleagues for their help and cooperation in putting together this report. The Instrumentation and Control Group at Argonne National Laboratory (especially Nancy D'Fallon, Paul Raptis and Tom Mulcahey) has given valuable assistance in familiarizing us with the field of Instrumentation for Fossil Energy. Special thanks are due to our colleagues at NBS; to Sam Schneider, Taki Negas and Ken Kreider for critical reading of the manuscript, and to Greg Rosasco, Jim Schooley and John Hastie for important information in the areas of temperature measurement and gas analysis, respectively.

Discussions with experts at several research laboratories, pilot plants, as well as at trade and professional organizations have provided important input to this report: Bob Eustis, Sidney Self and their colleagues at the Gas Dynamics Laboratory of Stanford University, J. R. Hightower and others of Oak Ridge National Laboratory, several engineers at the SRC-II pilot plant in Ft. Lewis, Washington (Dennis Canfield, et al.), John Walsh (JPL) and various members of SCIEP (Society for Control and Instrumentation of Energy Processes), as well as Bob Jaffee (among others) at EPRI. Special thanks are due to W. M. Roquemore of the Aero Propulsion Laboratory of the Air Force, who provided valuable comments on the report, especialiy in the area of optical instrumentation.

Valuable assistance was received from the participants in a one-day discussion of the report's recommendations, which was held immediately after its completion in June 1981 (Appendix IV). 
1 
CHAPTER 1. Introduction

1.1 Objectives

In late spring of 1980 the National Bureau of Standards was approached by representatives of the AR\&TD-branch of the Department of Energy (Fossil Energy) with a request to review the needs for research on Materials as related to Instrumentation in Fossil Energy Facilities and to make recommendations with respect to appropriate Research and Development activities in this area.

The Department of Energy, together with a sizable number of private corporations, is deeply involved in a variety of programs to develop and expand several new Fossil Energy processes from the laboratory through the test-, pilot- and demonstration stages to full commercial application. At each of these stages, in nearly every component of the system, there is a great need for measuring certain control parameters and product properties. This in turn means development of instrumentation and selection of appropriate materials for the measuring equipment that can withstand the harsh environments in fossil energy systems.

At the same time the designers of fossil energy conversion facilities and power plants need reliable data on material properties under hitherto unexplored conditions of temperature, pressure or chemical attack. The novel approaches employed in the fossil energy field dictate the use of some new compounds and substances (e.g., special coatings, composites), and therefore the development of improved or redesigned equipment for the determination of material characteristics in extreme environments. The above discussion can be summarized as follows: Better measurements require better materials, and new materials need new measurement techniques. In contrast to the prevailing view that the measurement equipment and the construction materials required in these technologies can be taken "off-the-shelf" it is becoming increasingly clear that both these ingredients require new approaches and advanced research efforts.

The objective of this study is to review the needs for materials research as related to the development of instrumentation for Fossi? Energy, and to outline an appropriate program to satisfy these needs.

The work is divided into several Tasks:

a. The study will assess the requirements for instrumentation to measure and record essential process and product parameters (such as 
temperature, pressure, flow and mechanical properties) and indicate the materials development necessary for the design and operation of such instrumentation.

b. The study will review the measuring capabilities with respect to the chemical and structural analysis of both active and passive substances (gas, liquid and solids) in fossil energy facilities.

c. The study will pinpoint the needs for new and modified techniques to obtain the materials data that are essential for the proper performance and design of facility components.

d. These reviews and assessments will be the basis of a suggested R\&D program on "materials for instrumentation in fossil energy" with indications of priorities and staffing levels.

1.2 Approach. In order to perform these tasks, NBS formed a group of 5 scientists and engineers with thorough knowledge in various aspects of materials science, fluid mechanics, temperature and pressure control and chemical analysis. The group gathered information from many different sources involved in Fossil Energy development, discussed and analyzed the difficulties in presently used instrumentation and materials, and suggested possible avenues of research that can lead to modifications or alternatives in measuring techniques and material usage. Some of these suggestions are of an engineering nature, others are more basic-scienceoriented. In some cases the recommendations are very specific and oriented towards one problem in one particular process. In other cases, the suggested research effort is broad and generic and addresses several problems encountered in a number of technologies not necessarily limited to the Fossil Energy field.

The report is organized as follows: This introduction (Chapter 1) indicates the objectives and scope of the review and touches on the approach being taken and the present activities in the area of measurement and related materials needs.

Chapter 2 reviews the Materials and Instrumentation problems and briefly discusses promising areas of research and development. Chapter 3 contains the actual Program Plan listing the various areas that require attention. A few general remarks about implementation have been added. 
Additional information is presented in three Appendices. Appendix I briefly describes the major Fossil Energy Technologies. Two tables indicating present research and development work in the instrumentation/materials field are tabulated in Appendix II. A number of specific examples have been chosen for an in-depth discussion of the technical aspects, in order to illustrate the close relationship between measurement, materials and design. These 6 case Studies have been coliected in Appendix III.

\subsection{Scope}

The Program of the Fossil Energy Administration can be divided in 3 major categories: Coal, Petroleum and Gas. Because the main goal of these programs is to diminish the nation's dependence on oil and gas, it is logical that the emphasis is on coal conversion. At the same time, it should be kept in mind that the potential resources in oil shale are enormous; most recently there are indications that interest in oil shale exploitation is again increasing. In addition, more attention is being focussed on enhanced oil recovery schemes.

Over the last few years the administrative organization of the various Fossil Energy Programs within the Department of Energy has crystallized to some extent. Besides branches dealing with mining and preparation, gasification and liquefaction, there are departments concerned with direct combustion, gas turbines, MHD, fuel cells, in-situ gasification, environmental control, as well as a division devoted to Advanced Research and Technology.

The absolute financial support for each of these activities has fluctuated considerably over the years, and even the relative ranking of these technologies is difficult to assess, especially at this particular point in time, May 1981.

It is obvious, therefore, that planning for research and development is a difficult task. As a result, planners, engineers and scientists try to find shortcuts, trying to show that this or that approach will work. In the process they seem to overlook the fact that they do not possess the necessary information on process conditions or the required design data to guarantee successful operation. Needed as an adjunct to present efforts is a research and development program - especially with respect to materials and instrumentation - that is somewhat more oriented towards long range benefits. Such a program has to be geared to the severe environment in most components of Fossil Energy facilities. Brief descriptions of some of the major processes and the physical and chemical conditions existing in these systems are presented in Appendix I. 
Considering the harsh atmospheres one has to deal with, it is not realistic to expect complete solutions overnight. A somewhat more basic and long range approach has definite advantages. This ties in with the atmosphere of uncertainty described above. A considerable number of problems in fossil energy plants and test rigs are caused by high temperatures and pressures, erosion and corrosion, and by the complexity of the process fluids and gases. These problems often require the use of new or modified materials, and improved or novel measurement techniques. Although the problems are specific, in many cases the needed research is generic, and the solution can be applied in several technologies. For instance, the question of how to control chemical attack by molten slag is not limited to MHD, but appears in similar ways in the operation of slagging gasifiers and coal combustors.

This report is focused on the materials-for-instrumentation problems encountered in gasification, liquefaction, direct combustion and gas turbines. Very little will be said about the other Fossil Energy technologies for a number of different reasons.

\subsection{Present Activities (in Materials and Instrumentation for}

\section{Fossil Energy Processes)}

Instrumentation for fossil energy has begun to receive some attention in the last 4 or 5 years. Most of the development work is aimed at the solution of special measurement problems that arise in particular subsections of coal conversion facilities.

The same can be said for materials research. The corrosion rates of various metals and alloys are being compared by means of test runs on representatịve coupons in a "standard gasification environment". la * Certain mechanical tests are being performed on liner refractories in "typical gasifier atmospheres". " Th There is, however, very little systematic research of a generic nature, aimed at understanding the degradation process and solving the problem by proper material selection or modification.

Most of the materials and instrumentation development work is shortrange in nature: the conventional measuring equipment is being modified to fit the more strenuous plant conditions. A material is replaced on the basis of the very scant data of its behavior at the high temperature and/or high pressure of the coal plant component. One often overlooks that the presence of small amounts of water, hydrogen, sulfur or particular

*The references for the main body of the report are 1 isted on pages 75-77. 
metals (e.g., Ti), radically changes the durability of the material and hence the service life of the instrument. The result of this attitude was wel1-stated in a recent DoE report: ${ }^{2}$

"Coal conversion process development units (PDU's) and

pilot plants have repeatedly experienced disproportionate problems with components compared with apparently similar applications in industry. This poor record has been attributed to the philosophy that PDU's and pilot plants are intended primarily to validate process chemistry, with limited consideration given to reliability. Frequently, pilot plant construction does not reflect the best or even reasonable materials selection for commercial plants......"

What is needed is better contact and cooperation between workers in the field, including plant engineers, instrument manufacturers and laboratory researchers. of course, continuity of effort in this area is of prime importance.

We do not want to leave the reader with the impression that the amount of materials research pertinent to the Fossil Energy field is negligible. However, the connection between this research and the materials problems in coal technologies is not always realized. Many R\&D organizations are involved in basic investigations of material properties in severe environments sponsored not only by the Department of Energy, but also by the Department of Defense, the National Science Foundation, NASA and many other government or private funding institutions. A list of some of the laboratories that are active in these areas is presented in Table a. of Appendix II.

In this connection we should mention the activities of the Energy Materials coordinating Committee (EMCC). This committee was set up to exchange information and to promote materials research within the Department of Energy. Its annual report ${ }^{3}$ summarizes the materials research projects supported by the Department, including those of the major programs (Nuclear, Fossil, Solar, Conservation, etc.) and of the Office of Energy Research. An appreciable number of these projects deal with problems that are relevant - but not necessarily specific - to the subject of this report, Materials for Instrumentation in Fossi 1 Energy.

The word "materials" has a broad meaning as used in the present report; it includes materials for meters and sensors, construction materials, as well as process solids and fluids such as coal char, coal slurries, coal slag and kerogen.

In the area of instrumentation there has been an interesting development in 1980, namely the establishment of an organization that aims to be a forum for the exchange of ideas in the many areas of fossit energy where better 
measurement equipment is urgentiy needed. This group, the Society for Control and Instrumentation of Energy Processes (SCIEP), is still in its infancy but is growing rapidly. It now is one of the co-sponsors of the Annual symposium on Instrumentation and Control for Fossil Energy Processes together with the Department of Energy and Argonne National Laboratory. Nearly a dozen subgroups have been organized ${ }^{4}$ and many of these groups have held very useful workshops during 1980 (see Appendix II-b). 
CHAPTER 2. Measurement Needs and Materials Requirements

\subsection{Process Parameters 5}

a. Multi-component Flow

One of the most crucial measurements in nearly all Fossil Energy Processes is the determination of the rate of flow of solids, liquids and gases, separate and mixed with each other. This measurement is difficult experimentally because of the need to detect the concentration and the flow velocity of each component. Another reason is the very aggressive environment which produces uncertainties in the metering device and degradation of the equipment being used. At the same time, intelligent design of flowmeters and interpretation of their response is hampered by the lack of fundamental understanding and mathematical description of two- and three-phase flow. (See Case Study a - Appendix III).

One can divide flowmeters in two categories: intrusive and nonintrusive. The former is often abandoned in favor of the latter because many designers and operators believe that by switching to a nonintrusive flowmeter, materials problems can be avoided. This is not aiways true, because the latter type may depend on the proper material and design of special windows or wall sections.

The kind of flowmeter that can be employed is dictated mostly by the prevailing process parameters (temperature, pressure, chemical environment, etc.), and by the physical characteristics of the process material. A rather complete list of flow metering devices includes more than two dozen different types of which some 6 to 10 are still under development. ${ }^{6 *}$ Among the intrusive flowmeters the orifice plate and the Venturi type flow sensors are the most popular. These two can be used both with gas and liquid and both are being tried for multicomponent flows, but fail to provide an accurate measurement.

An acoustic device for determining the presense or absence of the flow of char (mixed with steam) entering a gasifier reactor is being developed at ANL (Case Study b).

Several new nonintrusive flowmeters are commercially available or under development. An example is the ultrasonic flow sensor, based on a time-delay effect. ${ }^{7}$ A number of these devices are available for use at or just above room temperature. Although some encouraging results have been reported ${ }^{7}$

\footnotetext{
*In the present report, we will often refer to this "Overview of Coal Conversion Process Instrumentation". It is a compact review of the major commercial instruments that can be used, in principle, to measure the following parameters: flow, temperature, level, pressure, composition, viscosity and heat content.
} 
when used to measure high temperature slurries, a considerable amount of development work will have to be done before a reasonably-priced, reliable, instrument for this regime will have reached full commercialization.

Other non-intrusive flowmeters that need considerable R\&D efforts are the tracing types (e.g., pulsed neutron activation ${ }^{8}$ ), meters based on capacitance or thermal mass flow, and devices that use laser light scattered by small particles in the stream (Doppler shifted). The latter method is particularly interesting for dilute, high temperature, particle-laden gas streams because one can measure not only the flow velocity but also obtain information about the gas temperature and the size and size distribution of the particles (see below).16,22 All these non-intrusive methods depend on the capability of injecting the radiation (or neutrons) into the flow and of detection of the reflected or transmitted signal inside or outside the pipe, tube or chamber. Hence, a window, pipe segment or spool piece sufficiently transparent to the radiation or particles is required. In most cases this "window problem" can be solved by using a temperature and chemically resistant ceramic or metallic disc a short distance away in a side arm of the main pipe or reactor. This side arm is purged regularly either mechanically or by a flowing gas.

Materials research is needed to determine the appropriate "window" or spool piece material for particular applications in various severe environments.

In general the two most important factors that lead to degradation of intrusive flowmeters are erosion and corrosion. Orifice plates could be used for high temperature slurries if the material of the plate (and the shape of the orifice) were designed to withstand the enormous erosion caused by the solid particles in the liquid. Similar considerations hold for this kind of flowmeter in high temperature gas streams containing particulates. In many cases erosion is accompanied by corrosion and the combined effect is even more disastrous. The result of either or both effects is rapid deterioration of the orifice and a deviation from the true calibration often in a matter of hours.

Of course, other flowmeters also are subject to this erosion/corrosion damage: again, any significant change in the dimensions of the critical component of the device produces unacceptable variations in the calibration. 
b. Pressure $^{6}$

Fossil energy facilities require a variety of reliable pressure measurements in several stages of the processes. In some applications, quick response is of prime importance as a sudden pressure change may be a precursor to explosion or fire. When pressure instrumentation is used for process control, long term repeatability and stability is the main concern. In the case where pressure measurement is aimed at materials accountability, then accuracy is most important.

Piezoelectric pressure sensors have the fastest response time...on the order of microseconds. Certain crystals without a center of symmetry produce a surface potential difference when they are stressed in appropriate directions which can be used to indicate a change of pressure. Quartz, Rochelle salt, barium-titanate and lead-zirconate-titanate all exhibit usable piezoelectricity. There is a need for improved piezoelectric materials having greater signal output, less sensitivity to temperature and light, and better repeatability within a given unit and from lot to lot.

Pressure control instrumentation normally involves monitoring the mechanical distortion of some elastic element such as a spiral tube, bellows, capsule, or diaphragm. Many varied schemes are used to convert these distortions into controlling electrical signals. Response times for such equipment are on the order of milliseconds. The principal materials problems in these sensors can be remedied by developing elastic element materials with lower mechanical hysterisis, greater resistance to chemical attack, and above al1, greater high temperature durability.

Very slow response times are generally adequate when pressure measurements are used for materials accountability. As these measurements are normally done in a benign environment, currently available instrumentation is usually acceptable.

Overall, the greatest need is to develop materials for pressure sensors in high temperature environments. There is a great dearth of instrumentation for application above $200{ }^{\circ} \mathrm{C}$.

c. Temperature ${ }^{6}$

The determination of the temperature is one of the most essential measurements to be made in all energy technologies. In fossil energy processes the range is very large, extending up to $2500{ }^{\circ} \mathrm{C}$ in MHD combustors. In general the measurement of the temperature, be it by means of thermometers, pyrometers or other 
temperature sensors, is severely hampered by the harsh environment encountered in coal conversion facilities. Just as with other measuring devices (for flow, pressure composition, etc) the intrusive instruments (such as thermocouples) are subject to very high temperatures and pressures, extraordinary reactive atmospheres, as well as highly erosive particulate streams.

The available temperature sensors can be divided in 2 classes:

1. contact thermometers and 2. non-contact thermometers. Class 1 can be subdivided in about 5 categories: First of all, there are thermocouple thermometers, which are probably the most generally used type of temperature sensor, due to their simplicity, versatility, and general reliability. As measuring instruments, they are found as devices that are simply constructed at almost no cost, or as expensive devices constructed with painstaking care. Their thermoelements consist of metals or alloys used in a variety of configurations, typically as wires, ribbons, rods, tubing, or as vapor-deposited thin films.

While approximately three hundred different types of temperature measuring thermocouples have been identified and studied, only a few types, having the more favorable characteristics, are in general use. These favorable types include, ${ }^{9} \mathrm{Cu}$ and Fe-constantans used to $760{ }^{\circ} \mathrm{C}$, Chromel/Alumel couples used to $1200{ }^{\circ} \mathrm{C}$, several types comprised of $\mathrm{Pt}$ and $\mathrm{Pt}-\mathrm{Rh}$ alloys used to $1750^{\circ} \mathrm{C}$, and several $\mathrm{W}$-Re types that extend the range up to above $2800^{\circ} \mathrm{C}\left(5570{ }^{\circ} \mathrm{F}\right)$. There are also special alloy combinations, such as $\mathrm{Ni}-9 \% \mathrm{Cr}$ and $\mathrm{Au}-0.07$ at $\% \mathrm{Fe}$, available for use at very low temperatures, down to $1 \mathrm{~K}$.

For the reliable use and performance of thermocouples, it is essential that the thermocouple materials be protected from contamination caused by the environment in which they are employed by selecting and using the proper materials for their insulation and protection. In harsh chemical environments at elevated temperatures, the thermocouple wires are often insulated by a metal oxide and shielded by a metal tube that is placed within a primary thermowe 11 which in turn is inserted directly into the process environment. Of course, when the protection gets heavier, the time response becomes longer. Consequently, it is important to select the strongest and lightest material for the primary thermowell. Much research can and should be done to improve the material choices for thermocouple protection, both in general environmental regimes and for specific applications (see Case Study c). 
Other contact thermometers are based on physical properties such as electrical resistance, thermal expansion, sound velocity, and viscosity. One kind of resistance thermometer is based on the temperature dependence of the resistance of metals, such at $\mathrm{Pt}$ or $\mathrm{Ni}$. These devices cover a wide temperature range from -250 to $1000{ }^{\circ} \mathrm{C}$. Their advantage is that they can be made sma 17 and therefore respond very quickly. Such sensors can be made in the form of thin films and hence can be deposited exactly at the spot on the surface where the temperature reading is desired. They can be protected by the most desirable insulators. Research needs to be conducted in determining how these metallic sensors are degraded by impurities from the insulating material, and the results should determine the appropriate insulator to be used.

A different type of resistance thermometer is the thermistor, a ceramic semiconductor, available as beads, bead-in-glass probes, rods, discs, flakes, etc. They are composed primarily of $\mathrm{Mn}$ and $\mathrm{Ni}$ oxides, with dopants of $\mathrm{Cu}-$, Co-, Fe-, or other metal oxide. The oxide mixture is normally sintered at about $1200{ }^{\circ} \mathrm{C}$ and the devices are useful thermometers over the temperature range $1 \mathrm{~K}$ to $1100 \mathrm{~K}$. Because these oxides are semiconductors, the temperature coefficient of resistance is unusually large. Again, these oxides can be produced as thin films and thus make a small, fast temperature device. The stability of thermistors at high temperatures has not been investigated.

The use of both kinds of resistance thermometers can be advanced by a combination of basic thermometry studies, proper materials selection and a wide ranging testing program.

The ultrasonic thermometer is based on the temperature dependence of the velocity of sound in a solid rod $^{5 a}$. This velocity is derived from the measured time interval between reflections of a sound pulse from the end surface and from a "neck" in the rod. The time delay of this sound pulse is measured by a transducer. The use of this thermometer is limited by the maximum temperature and the environment which the transducer is able to endure.

The bi-metallic strip operates on the principle of differential expansion between two different metals bound together at one end. When heated, the strip will bend and hence be used as a temperature indicator. Unfortunately, the range is limited and the displacement is non-linear. 
More promising is the fluidic thermometer based on the temperature dependence of the viscosity of a gas flowing through a capillary. This thermometer has considerable possibilities when the use of thermocouples becomes very difficult: contact with aggressive molten substances (such as iron or slag), and cases in which the thermometer has to operate in electric or electromagnetic fields, or in strongly reactive atmospheres (e.g., $\left.\mathrm{O}_{2}, \mathrm{H}_{2}, \mathrm{~s}\right)^{10}$. Application of the fluidic thermometer in fossil energy experiments and pilot plants requires further studies and tests of materials appropriate for each particular need.

Recent years have seen an increased interest in non-contact thermometers, especially for use at very high temperature, in strongly corrosive and erosive environments and in cases where immediate response is mandatory.

The radiation pyrometer (spectral or total) has been used for a long time. However, these instruments are not without difficulties. One of the problems is the uncertainty of the exact location where the temperature is being measured, especially when the optical path is transversed by a stream of gases, particulates or droplets. Other difficulties are the accuracy (often photometrically limited in field applications) of the measurement and the emissivity of the surface and gases being observed. Although two-color pyrometry appears to be a useful approach, experimental tests of the "grayness" of the relevant surfaces needs to be made. Radiometric measurements should be included in any complete instrumentation system, and the experience of past researchers ${ }^{11}$ must be brought to the solution of the practical problems which will be encountered.

A second method is the line reversal technique for gas temperature measurement. In this approach the gas or plasma of which the temperature has to be determined is seeded with a small amount of $\mathrm{Na}$ or $\mathrm{K}$. The gas or plasma is illuminated with a tungsten ribbom lamp of known brightness temperature $T_{L}$. The Na or $K$ will emit light (usually the resonance lines at 589 or $767 \mathrm{~nm}$, respectively) with an intensity corresponding to the gas or plasma temperature $T_{p}$. The latter temperature can be compared with that of the tungsten lamp by varying $T_{L}$ until the alkali emission peak "reverses" to an absorption dip. Several variations of this basic approach are possible to increase the speed of the measurements and to localize the volume of gas or plasma where the temperature is determined. This technique has been successfully utilized in MHD experiments. 12 
A technique capable of both high speed measurement and high spatial resolution in temperature measurement is the two line fluorescence technique. ${ }^{13}$ In this technique atoms are seeded into the gas stream and excited alternately at two different (laser) wavelengths. The atomic system is selected to have levels with an energy difference appropriate to the temperature range of interest; these levels are coupled by a third intermediate level. The difference in fluorescence yield from the two levels is a measure of the electron temperature via the Boltzmann factor.

The rotational and vibrational temperature can be determined using the inelastic scattering from polyatomic molecules, $\mathrm{N}_{2}, \mathrm{CO}, \mathrm{CO}_{2}, \mathrm{H}_{2} \mathrm{O}, \mathrm{OH}^{-}$. Raman scattering, involving either linear or non-linear (Raman gain or coherent anti-Stokes Raman scattering) interactions, has been applied in many combustion environments. ${ }^{14-15}$ Millimeter spatial resolution and nanosecond temporal resolution can be achieved. Accuracies of $5 \%$ for the temperature range $77 \mathrm{~K}$ to $2500 \mathrm{~K}$ are claimed for laboratory and practical combustion systems. Application to many fossil energy systems will require significant new efforts.

In order to assess the accuracy of the measurement of temperature and to better understand the processes involved in advanced fossil energy systems, intercomparisons among the various techniques is required. Spatial profiles, fluctuations in local temperature and non-equilibrium conditions should be investigated.

The subject of non-contact thermometry is only briefly discussed above; a fairly complete review of the methods and instrumentation is presented in the Proceedings of the 10th Materials Research Symposium ${ }^{16}$ and the review by Eckbreth, et a7. 17

How to introduce a light beam into the gas or plasma, and how to collect the emitted, transmitted or scattered light onto a detector present several tough material problems. However, solutions have been found and temperatures have been determined by means of optical techniques in MHD experiments at the High Temperature Institute in Moscow and at the University of Tennessee Space Institute.

Some attention has been paid to the possibility of periodic rather than continuous measurement. The idea is to insert the probe (fiber, thermocouple, etc.) for a short period into the reaction chamber, the channel or the pipe, perform the measurement, and retract the probe back 
into the wall or side arm. 18 This requires the movement of a rod or cylinder through a tight seal in the wall. This way the optical fiber or the thermocouple would be exposed only for a short period and hence could survive for periods 10 or 100 times longer. The principle can be extended, of course, to many other sensors (pressure gauges, strain gauges, sampling devices, particulate collectors, etc.). The problem is that this approach would not solve the sensing of temperatures and pressures at locations where continuous recording is required for process control and/or safety.

d. Composition - Chemical

As mentioned before, coal conversion plants have a variety of extremely harsh environments ( $\mathrm{T}>1000^{\circ} \mathrm{F}, \mathrm{P}>100 \mathrm{~atm}$ ) which tax the capabilities of currently available instrumentation for chemical composition analysis of solids, liquids and gases. Analytical measurements in the process stream will be important for control, safety, and pollution monitoring.

There is currently a wide variety of conventional analytical instruments ${ }^{6}$ being considered for use in coal conversion plants. In addition to these conventional techniques, Raman scattering, laser-induced fluorescence, optogalvanic spectroscopy, and optical absorption have been suggested. 19 Nuclear techniques such as Neutron activation analysis ${ }^{20}$ and Mbssbauer spectroscopy 21 are also possible in situ techniques for certain analyses. Although these less conventional techniques will require additional development, they will serve an important purpose not only in the early stages of pilot and demo plant activities, but they also may find occasional application in full-scale commercial plants.

The materials problems associated with the analytical instrumentation can be divided into three major categories: direct samplers (or side arm ports), in situ probes, and windows (optical and nonoptical). The design of successful samplers is a materials problem in coal conversion plants both in terms of probe survival in the harsh environment (materials durability), and in terms of sample accuracy. Catalytic and wall reaction effects may very well affect the sampler-based measurements (see Case Study e). Watercooled, self-purging, and/or automatically cleaned sampling probes have been suggested for use with mass spectrometers, (Case Study e), Tiquid and gas chromatographs 21 , and other sampling based analytic devices. New materials will have to be developed for both the sampler and internal workings of the instruments, for exampie, the column in the chromatographs. 
Chromatographs will also have to be modified to remove particulates or other phases from the process stream. The intermittent nature of chromatograph measurements couples well with the probe purge/cleaning cycle which may be required.

In situ probes have been suggested for ions, moisture, and some gaseous species. A good example is the case of carbon monoxide detection. CO is important for process control, safety, and pollution management. Solid state detectors utilizing a surface effect could profit from basic materials research on the sensor materials. ${ }^{19}$ The development of high temperature PZT devices would benefit moisture analysis in the gas flow of gasifiers. The possible use of ion selective probes, capable of withstanding the process stream environment, will require considerable materials and design studies.

Development of window materials may also contribute to improved non-intrusive, in situ measurement techniques. Neutron activation analys is promises to provide a multi-element capability for an on-line analysis of the process stream. The use of NAA and other nuclear-based analytical techniques will require special materials for spool pieces either in the direct process stream or in the auxillary side arm. The materials selected will have to be transparent to the incident and reradiated radiation and be able to survive the erosive and corrosive environment of the process stream. In addition, better detector materials may be required to survive the thermal environment in the proximity of the process stream.

Optical window design will present materials problems because of the high pressures ( $>100 \mathrm{~atm}$ ) likely to be encountered. Whether laser or nonlaser optical techniques are used, the window will have to be stable to prevent pressure changes from altering the optical path of the device. Recessed,gas-purged windows have been used with moderate success in MHD environments. New window materials with good IR transmission should also be developed in support of dispersive IR analyzers. These instruments show promise in multispecie detection, i.e., $\mathrm{SO}_{x}, \mathrm{NO}_{x}, \mathrm{CO}_{x}$ and even particulates (see below) --- The use of protected, water-cooled, fiber-optic devices coupled to UV, visible, and IR instruments for analysis will also require materials research into more durable fibers. 12,18 .

e. Composition - Phases, Particulates

Many of the general considerations of section 2.1.d. are also applicable to the measurement of the relative amounts of physical phases (solid, liquid, gas) and particulates. The nuclear-based techniques have been suggested not 
only as composition analyzers but also for devices to measure flow and separate phases. This multiple capability further supports the materials research required for appropriate spool pieces.

The use of ultrasound techniques for physical phase measurement will require the development of high temperature ceramic transducers to be mounted on the inside or the outside of pipes and reactors. In the latter case, there will be a need for the development of suitable materials for acoustic windows.

In the gas phase an accurate measurement of the particulate loading and size distribution of particles in the stream is critical. The NSF workshop on particle sizing 22 serves as a good source for potential techniques. Sampling techniques generally are not on line and require further operator analysis. The lack of adequate size Standard Reference Materials for scanning electron microscope calibration, typically used in analyzing the particulates on a wire mesh or filter, is also a problem.

Because of the need for on-line information on particulate loading in devices such as turbines, only optical techniques seem reasonable. If more detail than average size and/or loading is required, laser-based Mie scattering may be used. If less information is required, simple single and dual wavelength transmissometers may be used. ${ }^{23}$ Such devices will be adequate for monitoring the effectiveness of cyclones and other particulates precipitators. These devices share the "window" problems associated with optical chemical composition analyzers (2.1.d.). The design and materials choice of the window is again a research problem.

These transmissometer techniques also lend themselves to incorporation with the fiber optic probe detection scheme.

f. Composition - Emissions

EPA standards for $\mathrm{SO}_{x}, \mathrm{NO}_{x}, \mathrm{CO}_{x}$ and particulate emissions from coal conversion plants will at least be as strict as those prescribed for the exhaust from conventional plants. The instrumentation for monitoring these emissions and compliance with the EPA standards are generally closely tied together. The emission monitoring is presumed to be at the end of the process stream (or power plant in a combined conversion power plant). In this case the materials problems become less crucial than if active process control with monitoring earlier in the process stream is required. In the latter case the materials problems identified in sections 2.1.d. and 2.7.e. are also applicable to emission instrumentation. 
The window problem still exists in either case. Emission-monitoring equipment is generally designed to be specific to a species (or total particulates in the case of the transmissometer or turbidity monitor). Simple devices like the NBS $\mathrm{SO}_{2}$ monitor ${ }^{24}$ which consist of a lamp, line filter and detector are more likely to be used than elaborate remote laser monitors. The development of more durable, alkali-resistant window materials would further enhance the application of these simpler monitors. 2.2. Erosion and Hot Corrosion

It is probably no overstatement to say that erosion and hot corrosion are the major degradation mechanisms in Fossil Energy Facilities. This allegation holds for most of the construction materials, but it also applies to the instruments that are being used to measure process parameters. This is amply illustrated by the above discussion of flow meters, thermometers and pressure metering devices (at least as far as the intrusive types is concerned).

The two phenomena, erosion and corrosion, are basically different effects. Erosion is mechanical damage caused by a gas, liquid or particle flow ${ }^{25,26}$; corrosion is chemical attack. However, in coal conversion environments, the two are so closely intermixed that separation of the damage caused by the two phenomena is practically impossible. Nevertheless, a basic study of these effects should at first focus on one and then on the other.

A major source of erosion in gasification processes is entrained solids. The damage depends on many parameters of the particle laden gas stream as well as on the properties and location of the impacted surface. These conditions should be studied systematically. It is not enough to measure the weight change; a careful study should be made of changes in the condition of the surface. In the case of metals (ductile) often a crater is formed and part of the material forms an adjacent ridge. Impact of particles on ceramic surfaces (brittle) can produce cracks.

Erosion in liquefaction systems is of a different nature because the particles are suspended in a liquid. However, due to the high concentration of solids and the appreciable flow velocities the problem still is a serious one. In many respects, less is known about the surface damage produced by solid particulates in liquids because the problem is tightly connected with the conditions of the slurry flow (laminar or turbulent, boundary layers, surface roughness, etc.). 
Corrosion in gasification and liquefaction systems is a very complex problem. ${ }^{27}$ Considering that in most cases one is dealing with (s]ightly) reducing conditions, chemical and physical changes of the wall materials might be caused more by species like S, C, alkalis, halides, $\mathrm{H}_{2} \mathrm{O}$, and $\mathrm{H}$, than by oxygen. However, during the starting up period oxygen may play an important role. Certainly, if one considers the use of oxide coatings or refractory liners to protect the metal, the possible reducing effect of the above mentioned elements should be appreciated.

Again, the possible degradation of the wall material (metal or ceramic) is very different when contacted by a liquid slurry or by a gas. Above, we referred to both chemical and physical effects. In many cases the damage is strongly dependent on the diffusion of species to and from the surface. If a gas or liquid diffuses rapidly into the material, the added atoms or molecules may cause an expansion and cracking of the solid. At the same time the absorbed gas can chemically attack the host material much more easily.

A major problem is to monitor the erosion/corrosion effect quantitatively. At present most experiments are of a testing nature. Coupons are exposed for (long) periods of time to gasification or liquefaction environments and subsequently the weight loss (or gain) is being determined. ${ }^{28}$

The question arises whether it is possible to follow the erosion/corrosion behavior by means of an in-situ measurement. Some devices are being developed with this goal in mind: one is an ultrasonic wall thickness meter used to monitor the erosion in slurry lines ${ }^{29}$, the other is a thin film sensor. ${ }^{30}$ The latter consists of an insulated thin strip of the wall material deposited on an oxide and thus insulated from the metal wall. The thinning or thickening of the film strip due to erosion and/or corrosion can be tracked by measuring its electrical resistance. Of course, one has to prove the equality of the film and the bulk material with respect to erosive/corrosive wear.

2.3. Fuel Characterization $31-33$

Coa?.

There is no doubt that a major deficiency in the development of all coal conversion processes is our lack of knowledge of the composition, structure and properties of coal. The three most important aspects of the feedstock in coal utilization are (1) coal handling (which involves many physical properties of coal), (2) the chemistry of coal reactions, and (3) emissions from coal combustion or reaction. In all three areas the 
problems are complex, involving molecular structure of the coal, trace constituents and such properties as porosity and moisture content. During the last 10-15 years a number of new or refined methods have become available, offering means to provide much previously unobtainable information.

Coal is a very reactive solid, but little is known about the relative abundance of various groups and their "organization" within the coal molecule. ${ }^{34}$ There is still considerable uncertainty about the fractions of aromatic and aliphatic groups. It should be possible by application of high resolution NMR techniques (using ${ }^{13} \mathrm{C}$ as the nuclear probe) to learn more about the nature of the carbon bond and the hydrogenation process. The resolution of the NMR technique can be increased by using ultrahigh magnetic field, pulse sequencing, and "magic angle" spinning of the sample. It is important that this spectroscopy be applied to samples both under ambient conditions and at high temperatures.

After carbon and hydrogen, the elements oxygen, sulfur and nitrogen are the most abundant atoms present in the organic part of coal. It is important to know not only the exact concentration of each of these elements but also how they are bonded. Usually oxygen is determined by subtraction after $\mathrm{C}, \mathrm{H}, \mathrm{N}, \mathrm{S}$ and the flyash constituents have been measured. Improved methods for direct oxygen determination, such as neutron activation analysis would be desirable. Furthermore one would like to find out how the oxygen is distributed over the various functional groups: hydroxyl, ether, carbonyl, carbonate, etc. A number of novel techniques and modified, older methods may be able to provide the answer: energy dispersive x-ray analysis (EDX), ESCA, NMR, IR, UV, and Raman spectroscopy all show promise. In some cases, the solution will depend on the development of entirely new experimental approaches.

Sulfur is often present in the inorganic portion of the coal as a compound with iron (pyrite). In that case the M४ssbauer technique can be very helpful. Much information can be derived from the use of the isotopes ${ }^{17} \mathrm{O},{ }^{33_{S}}$ and ${ }^{15_{N}}$ in NMR spectroscopy.

Most coals contain quite a number of trace elements in the mineral matter, but some of these elements also are bound in organo-metaliic groups. Often it is critical to determine the amount of these trace metals; a number of them are very toxic like $\mathrm{As}, \mathrm{Hg}, \mathrm{Pb}$ and $\mathrm{Cd}$, especially in the form of metal10organic compounds. Another metal that should be traced is $T i$, because it is a strong catalyst poison. 
Many techniques can be used to detect these small impurities including neutron activation analysis (NAA) and proton-induced $x$-ray emission (PIXE).

Besides chemical composition, an essential aspect of coal is its physical structure. The reactive behavior, its volatility, the forming of slurries, all depend on the pore size and pore distribution of the coal. These two quantities are closely related to the surface area, which in turn determines the various adsorption-desorption equilibria, the kinetics of many reactions, etc. Several experimental techniques can be used to . study the porosity of coal: transmission electron microscopy, modified small angle $x$-ray scattering, the adsorption of an inert gas (BET) and, of course, the measurement of mercury uptake. One should realize that these methods do not necessarily determine the same quantity. In some instances knowledge about the relative surface areas in two different environments is sufficient. Determination of absolute surface area is difficult.

The porosity is one of the major factors in determining the amount of water in coal; the moisture content can be very high. A variety of promising new methods exist for determination of moisture in coal. Consequently, a critical step in the coal handling process is drying. This has to be done very carefully, because dry pulverized coal can be pyroforic. Obviously, the oxidation of coal deserves systematic study in which surface area and porosity play an important role. Mineral matter (slag, flyash) 36

Most coals contain about 10\% inorganic material mainly in the form of oxides. The most abundant are $\mathrm{SiO}_{2}$ and $\mathrm{Al}_{2} \mathrm{O}_{3}$, ranging from $30-65 \%$ for the former and 25 to $55 \%$ for the latter. Because of the high silica content coal slag may be converted to a liquid during coal combustion and other high temperature stages of the coal conversion processes, and then solidify into a glass or "glass ceramic" when the surrounding temperature is lowered to between 1000 and $1500{ }^{\circ} \mathrm{C}$. The exact crystallization temperature $T_{C}$ varies with composition. (For relatively high silica content this temperature is about $1400{ }^{\circ} \mathrm{C}$.) This means that it is possible to define and measure a slag viscosity above $T_{c}$, but below that temperature one deals with a "glass-ceramic" and the viscosity increases in time while some crystalline minerals phase-separate from the molten material. 
In several coal conversion technologies coal slag will condense on the watercooled wall. This will be the case in combustors, MHD-channels and slagging gasifiers. It is therefore important to know the chemical and phase composition, and the physical properties like viscosity and thermal conductivity as a function of that composition. 37 As mentioned above, in many cases solid slag will consist of a glassy matrix containing small or large islands of crystallized material. It is important - not only in this case, but in other applications too - to determine the ratio of crystalline and amorphous matter and, if possible, the size and shape of the crystalline areas. This is not an easy measurement; it might involve a combination of $x$-ray-, electron- and neutron-diffraction.

Another totally different, but important aspect of the mineral matter are the particle size and composition of the flyash in the gas stream. The simple presence of these particles is detrimental in the gas stream exiting from gasifiers if this gas stream is used to power a gas turbine. Particle erosion of the turbine blades (as well as the corrosion due to alkali salts) is extremely rapid. From the emission point of view the flyash is a health hazard if it consists of glassy particles of submicron size. Consequently, it is essential to determine the concentration of flyash particulates in-situ (see 2.1.f) and to measure their size, size distribution and composition on samples collected under a wide variety of conditions.

0il Shale Kerogens

Kerogens require analytical research similar to that described for coal and coal ash. Knowledge of chemical composition, physical properties and molecular structure are essential for the development of oil shale technology. Again, determination of the nitrogen and sulfur content is important; the measurement techniques are not straightforward and require attention. Very crucial is the determination of trace impurities because a major difficulty with shale waste is toxicity and the possibility of polluting rivers and groundwater.

\subsection{Instrumentation for Thermal and Mechanical Properties}

The reliability and efficiency of coal conversion plants depend to a great extent on the proper selection of construction materials. Considering the very severe conditions, both physically (temperature, pressure, etc.) and chemically (corrosive atmosphere) that one finds in most segments of such plants, the choice of construction materials (metals, alloys and ceramics) is very limited. Aggravating the problem is the fact that reliable, accurate data on material properties in these extreme environments is rather scarce. 
One of the reasons is that the measuring methods, which are reasonably straightforward under ambient conditions, are not always easily extrapolated to the high temperatures and pressures and chemically reactive atmospheres of gasifiers, liquifiers and gas turbines. Nevertheless, the design engineer needs the data. Consequently, a good case can be made for providing new or properly adapted measuring equipment to determine the much needed values of physical properties, in particular thermal and mechanical characteristics.

Very few commercial instruments have the special capabilities mentioned above. Unfortunately, there is little incentive for the instrumentation industry to develop this kind of equipment because the market is smal1. The modification of existing apparatus or the design and construction of new measuring devices is left up to the ingenuity of the scientist or engineer who needs the data. However, much useful information could be obtained from small groups of workers dedicated to the measurement of the required properties under properly simulated conditions.

In many coal conversion facilities, construction materials are subject to enormous stresses, often as a result of large temperature gradients. To evaluate the effect of these mechanical forces it is common to assess the condition of the component by means of a stress analysis. Such an analysis requires an input of thermal conductivity data, thermal expansion, heat capacity, elastic constants, tensile and compressive stresses, and values for crack propagation and creep.

Thermal conductivity measurements are difficult and tedious. As discussed in Appendix III (Case Study $\mathrm{f}$ ), measurements up to 800 or $1000{ }^{\circ} \mathrm{C}$ are usually performed by means of the static technique, while at higher temperatures the dynamic method is preferred: although both techniques are well-known in principle, there is little agreement about the execution of the experiment, the relative advantages under different conditions, as well as the accuracy and the efficiency of the methods. There is a great need for standardization and commercialization of measuring equipment and testing procedures, for automation by means of microprocessors and data handiing equipment, and for standard reference materials to assist in the comparison of results from different laboratories.

The dynamic technique yields values of the thermal diffusivity rather than conductivity. In order to translate the results into heat conductivity values one needs data on heat capacities. 
Other thermodynamic properties that need attention, especially in the high temperature range $500-1500{ }^{\circ} \mathrm{C}$, are vapor pressures as well as melting points and boiling points. We are thinking here especially of the construction materials. This means data on metals, alloys, ceramics, as well as composites. Information on vaporization of $\mathrm{Cr}$ and $\mathrm{Cr}_{2} \mathrm{O}_{3}$ is important both for some of the super-alloys and for refractory oxides such as $\mathrm{Mg}$ or Ca-chromates. The vapor pressures vary over a wide range depending on the oxygen pressure; the measurements should include the amounts of the dissociation and reaction products.

All these thermal and thermodynamic parameters depend on the environmental conditions. Melting and boiling temperatures will be affected by the pressure of the surrounding gas (both total and partial). New measurement techniques or modifications of DTA and TGA-methods will have to be worked out to obtain reliable data under such conditions.

The situation is rather analogous in the field of mechanical properties. Design of gasifiers, valves*, pressure vessels, preheaters, etc. require data on elastic constants, creep, fracture, strength (tensile-, compressive-, yield-) and hardness not only under ambient conditions, but also as a function of temperature and pressure. That means for metals and alloys, temperature effects up to $1000{ }^{\circ} \mathrm{C}$, and for ceramics up to 1800 or $2000{ }^{\circ} \mathrm{C}$ must be investigated. High and low pressure data are also needed.

In the field of coal conversion designers are particularly interested in data under cyclic conditions. Often sufficiently accurate values of elastic constants at very high temperatures can be obtained by extrapolation, if the temperature dependence is known over an appreciable range above room temperature. However, in order to get these data, measurements must be made at elevated temperatures. Such experiments always involve materials problems. Either the vibrators and transducer are mounted directly on the sample and therefore must be $a b l e$ to withstand the temperature and pressure of the sample itself, or they are indirectly coupled by means of rods or threads in which case these "couplers" should be resistant to the severe conditions. In either case a low-loss glue or interface material has to be found which does not critically affect (or impede) the measurement. This is even more important when the attention is focused on the inelastic properties. Usually, the losses are much more sample and temperature dependent tinan the constants themselves.

*Although valves do not fall in the category of instrumentation in the strictest sense, they do represent one of the most critical groups of control components in coal conversion facilities. As such they do deserve prime attention with respect to material research for improved operation and Tonger lifespan. 
The mechanisms that govern the elastic and inelastic behavior of solids are not well known. It is, therefore, very important that several parameters and characteristics of the material are measured simultaneously, in order to analyze correlations between various properties. Strength and fracture measurements should be accompanied by microstructure studies using x-ray diffraction. Non-destructive evaluation methods ${ }^{38}$ for the detection of voids, cracks and flaws in pressure vessels, valves, reactors, combustors, etc., require further development. One can divide the NDE field in two categories: quality control of the newly fabricated component by the manufacturer or by the plant engineer, and on-line inspection during operation (or intermittently during downtimes). Some of the most widely used methods are based on sonic or ultrasonic absorption. ${ }^{37}$ This approach can be refined by employing multidirectional imaging techniques (tomography). Imperfections and cracks in metals can be detected also by means of fluorescent dyes or eddy current devices. Another way to test materials and components is to load the part under consideration and measure its anelastic behavior. Methods for measuring tensile and compressive strength of ceramics and metal alloys should be extended to higher and lower temperature. One cannot rely on room temperature results only. The fact that material $A$ is stronger than $B$ at ambient temperature does not always mean that the same is true at very high or very low temperature.

of special importance for high temperature applications (heat exchangers, turbine blades) is the group of structural ceramics: silicon nitride, silicon carbide and other silicon based materials. ${ }^{39}$ Both the thermal and the mechanical properties of these compounds are important; unfortunately the measurement of these properties at high temperature is not easy.

\subsection{Testing Procedures and Facilities}

In practically all coal conversion technologies there is a great need for experimental facilities where instruments and materials can be tested under properly simulated conditions. Instrument designers lack the data to build a proper model of a conceptual measuring device. Laboratory workers want to try out a prototype apparatus for their bench-type set-up. Plant operators are skeptical about the usefulness and durability of the instrument that they are urged to use, unless it is tested under "real" conditions. The many groups that are involved in the various stages of coal conversion R\&D agree in principle that well-designed test facilities are very useful. However, there is no consensus how to realize this need. 
Several contradictory arguments are being heard. The laboratory-size test rig is rejected as too small and too much simplified to give answers about the operations in the real plant. On the other hand, in many cases it is awkward to test the instrument in the actual plant. One cannot systematically change the flow rate, the temperatures, the pressures, etc. because such a sequence usually interferes with the operation of the pilot-, demo-, or commercial plant. However, for the testing of the instrument this type of variable, flexible program is essential.

It is clear from the above discussion that choosing the proper test rig from the list of existing facilities is difficult. At the same time, drawing up specifications for the construction of a new test installation is not an easy task either. The main factors are cost, test run duration, proper simulation of operating conditions, and flexibility. A list of desired features nearly always leads to contradictions. Consequently, one has to settle for an intelligent compromise.

The main purpose is to test the critical elements of the instrument or the material under investigation. Does the device or the component operate well under various conditions? What is the variation with temperature? How much? How does it behave as a function of (flow) velocity? Quantitatively! To what extent does the instrument drift, or how much does the material deteriorate over a period of 100 hours?

Cost was mentioned as a major factor. A working estimate for the cost of one hour of testing in a large-laboratory size facility is 20 dollars*. Then a 100 hour test is easily affordable. Few organizations will be able to conduct many 1000 hour tests not only for financial reasons but also because the facility would be tied up for too long a period. Putting the limit at $\$ 20 /$ hour, argues against the use of high pressure. Test facilities running at ambient or lower pressure can be fully automated, but higher pressure installation (even 3 or $5 \mathrm{~atm}$ ) require constant attendance for safety reasons. This adds considerable amounts to the price of operation. Usually high pressure is not a critical test parameter. However, there are instances when higher pressure is important, e.g., the measurement of heat transfer from a flow gas. In this case one can simulate the higher pressure by using a larger flow velocity instead.

*Users fee. (Of course this does not include the capital investment and development cost of the test facility). 
The one parameter that presents major difficulties is flow. ${ }^{40}$ Both the flow measurement and the study of flow patterns may be entirely different in $2 "$ and 10" pipes. In this case test loops must be of sufficient size to yield meaningful answers for pilot- and demo-plants and commercial facilities. That does not mean that smaller test rigs are altogether useless. Certain flow patterns, transitions from laminar to turbulent flow, erosion behavior, etc. can be studied quantitatively in smaller set-ups. But one has to be careful with respect to extrapolation and scale-up.

Having said all this, the fact remains that there is a great need for properly designed test facilities: rigs that permit try-outs of various flow meters - both intrusive and non-intrusive; similarly for temperature and pressure devices; installations that can measure erosion and corrosion rates; set-ups for determination of particles (amount, size, size distributions, etc.) both in flowing gases and liquids; test equipment to determine heat transfer and mechanical rigidity (vibrations), and chambers to determine the thermodynamics and kinetics of various coal reactions.

\subsection{Data Centers}

The main reason for a data center is to learn from experience and to avoid duplication. That is true for nearly every field of endeavor. As long as the field is reasonably limited - let us say "Metallurgy of Aluminum" - one finds that the community of experts is relatively small and homogeneous, the literature is covered by a few journals, and communication between workers in the field is quite good. However, in an area like Fossil Energy, the opposite is true. The community is enormously diverse, one finds mechanical and chemical engineers, chemists, physicists, metallurgists, ceramists, as well as applied mathematicians and electronics experts. Even if one limits the field to those working mainly on materials and instrumentation one still finds representatives of all the groups listed above. How does one find information in a very different discipline, far outside one's own area of expertise? The mechanical engineer will ask: where do I find data on the porosity of coal (Illinois \#6)? The chemist wants to know: How does one measure the temperature of molten slag around $2800^{\circ} \mathrm{F}$ ? Proper answers to these questions may save considerable amounts of time and money. Access to a good library is not enough. One must know where to look and therefore a knowledgeable guide is essential. 
A well-organized Data and Information Center can be that guide. Just as with the topic of Test Facilities one runs into the questions of size and cost. The Center has to be of sufficient size and have an appreciable (as well as appreciative) audience. At the same time, both the cost of the Center and the cost to the customer should be "affordable". There is a certain "hierarchy" in the scope and size of data centers. In increasing order of magnitude one can rank these centers as follows:

1. Compilation of information centers, handbooks, bibliographies, etc.

2. Reference library of archival publications and reports.

3. A well organized file of reference data ("raw" or "evaluated").

4. A complete Handbook of data in the field (comprehensive).

5. A complete guide of data and performance for users and operators.

While the first and second kind of centers can be operated with a very small professional staff and a group of expert volunteers, anything beyond that needs a full-fledged staff, fully computerized including a well-thought out system of gathering, evaluating and dissemination of information.

Fortunately, part of such a Data Center for Fossil Energy materials is already available. This center covers both Material and Failure information on a level equivalent to step 3 ("evaluated"). A first edition of a Handbook entitled "Construction Materials for Coal Conversion Performance and Properties Data", prepared by the NBS, is expected to appear in late 1981.

What is needed is a reference system on measurement and test methods geared to Fossil Energy requirements. That is not an easy task. Not many scientists and engineers present in their publications a detailed description of the equipment and procedures used in the experiments. Methods applicable at very high or low temperatures and pressures are sometimes, but not often, described in individual articles.

Much will depend on the ingenuity and resourcefulness of the staff that will undertake this task. Contacts with a great variety of organizations will be essential: ASTM, ISA, Rev. Scient. Instr., Instrument manufacturers, research organizations of companies specializing in products for extreme conditions, National Laboratories, University Laboratories (with consultation of the National Science Foundation), Professional Societies, Trade organizations and journals, etc. etc.

As with all data systems, the Center staff will have to recruit a number of knowledgeable, responsible contributors. A well-organized data base must be establịshed with efficient input and output. Most important is a we11-developed organization to disseminate the data. Successfut data systems depend on a sizable and satisfied clientele. 
CHAPTER 3. Suggested Program Plan

\subsection{General Considerations}

The program which is detailed below is the result of the deliberations of the working group, many consultations with various experts, a number of site visits, extensive readings of publications and reports, and experience concerning Materials Research and Instrumentation Development within the National Bureau of Standards.

The program plan is not all-encompassing,considering the finite size of the resources available for this kind of R\&D. The focus is on the important areas of highest priority. As progress will be made on some projects, and new materials problems in instrumentation arise elsewhere, the plan will have to be updated.

In the recommendations that follow the main emphasis is on medium-range research. Nevertheless, it should be clear that the suggested projects are selected with the goal of solving major engineering problems in materials and instrumentation in the shortest possible time.

In recommending specific areas for exploration it is apparent that present work in those fields is insufficient. It is also fairly certain that an appreciable amount of research, relevant to Fossil Energy Technologies, is being performed in the nations laboratories. However, much of this work is being done for entirely different purposes; apparently, in many cases, few people in the Fossil Energy field are cognizant of this research.

The program has been divided into 4 major Research Areas:

I. Materials Research for Sensors

II. Properties of Coal

III. Testing and Data

IV. Exploratory Research

The first area is the largest and is subdivided into 3 subfields:

A. Erosion/Hot Corrosion, which addresses the stability of the materials being used, B. Thermal/Mechanical Properties, a major concern in nearly al1 metering devices and construction materials, and $C$. Other Physical and Chemical Properties of prime importance to the design and function of sensors. Area II, the chemistry and physics of coal, has been included because knowledge of the structure and behavior of coal is essential for control of the process reactions, and appropriate instrumentation for these measurements is not readily available. Area III, Testing and Data Centers, are basic requirements for the development of better materials and instrumentation. Finally, a we17rounded program must provide opportunities for creative new ideas of great potential (Exploratory Research-Area IV). 


\subsection{Rationale and Recommendations}

Table 1 presents a listing of the major problems in Instrumentation related to materials. These problems are broadly defined, bringing a number of sub-issues under one common denominator. The second column of this table indicates the recommended materials research needed to solve these problems. The numbers in this column refer to the suggested projects listed at the end of this chapter and in Table 2. Column three summarizes the benefits expected to result from the performance of this research.

often there is not a one-to-one relation between the research and the benefits. This is partly a result of the manner in which the research recommendations and the expected benefits are formulated. Another reason is that the research is generic in nature: solving a materials problem in one field can be helpful in several other areas. Vice versa, realization of a certain benefit requires the results from several material research projects. The actual Recommended Research Program is summarized in Table 2. The program suggests 37 projects in 3 major Research Areas plus "Exploratory Research" (x projects). Each of these major areas has a few sub-areas corresponding to the problems stated in Table 1. Details of the suggested projects are presented at the end of this chapter. (One per page). For each project we have indicated the purpose of the research, the possible applications and the kind of work that should be performed. (Of course, the description of the work is extremely condensed, and will probably have to be modified or reoriented.)

The order in which these Research Areas are presented coincides basically with the priority ranking as perceived by the authors of this report. This does not mean that active projects should be confined exclusively to areas IA and IB, or IA through IC, even if funds would be severely limited. Many other factors play a role: the quality of the project proposals, the competence and expertise of available project leaders, the amount of work already being performed in a particular area, the collaborative aspects of a proposed piece of work, etc. These are arguments and factors that will have to be sorted out by the actual Program Managers.

\subsection{Level of Effort}

As mentioned before, indicating priorities in the presently suggested program is both complicated and hazardous. Many factors have to be taken into account: emphasis on or rejection of certain technologies, political 
decisions, economical conditions, funding levels, etc. In this report most of these considerations have been ignored and an attempt has been made to express an objective opinion.

On this basis we recommend a distribution of effort as indicated in Table 3. The magnitude of the effort is expressed in staff years/year. Three different levels have been indicated: the present level of support, a build-up to a minimum level to be reached in years 2 and 3 , and a further expansion to a steady state level to be maintained from the 4 th year on " for at least 3 years. The total effort over the period of 6 years is in rough agreement with the sum of the recommended staffing for each of the individual projects. 
芩

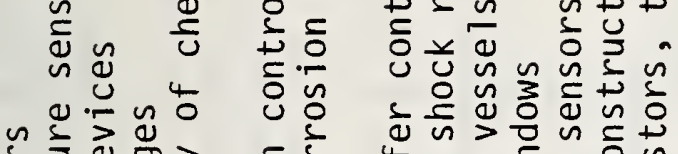

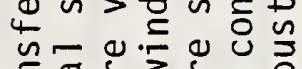

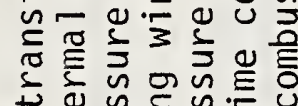
ఎ ब $+\frac{1}{4} \otimes$

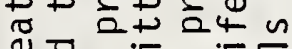

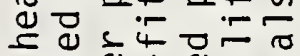
in 1 ป ग

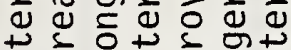

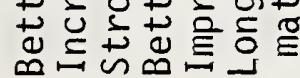

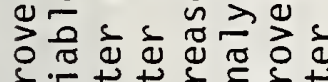

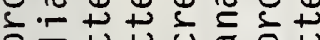

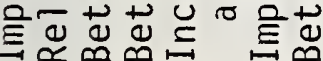

-

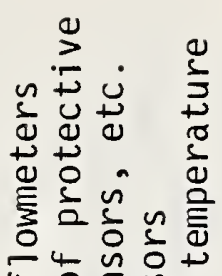
$40 \sum_{0} \cong$ $\infty>\backsim \overline{0}$

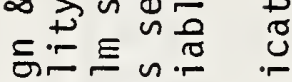

ज可宁可

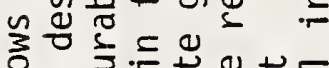
음

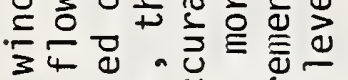

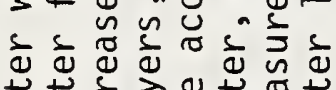
廿⿻

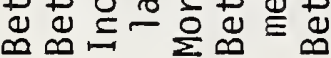

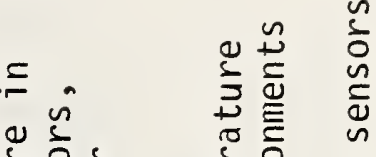

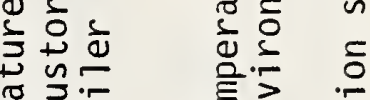

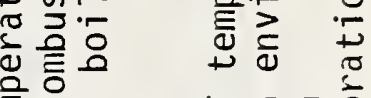
言 ن i

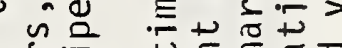

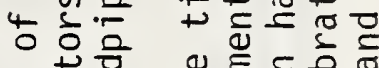
ब U 웡 \&

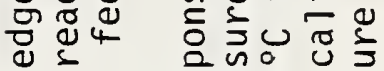
ก

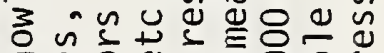

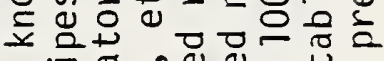

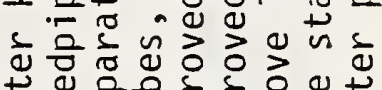
廿 웡윽 는유워

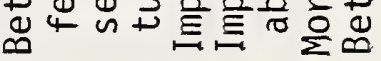
- $\dot{ } \dot{0} \dot{\sigma} \dot{0}$

Nं் $\dot{\sigma}$

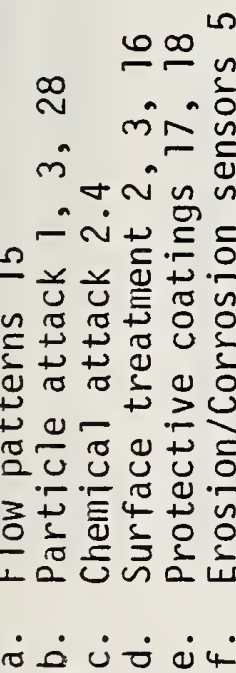

을

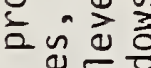

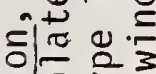

जी

$\div u+$ \&

ธิ宀

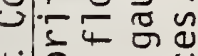

+잉

웅

의 $=\frac{0}{0} \frac{1}{4}$

品

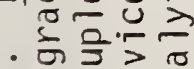

$\leq$ $+\infty$

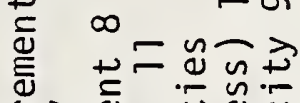

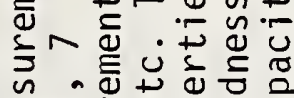

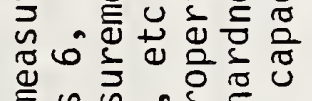

$\infty \stackrel{\mathscr{E}}{=} \backsim$ 的这更

入े

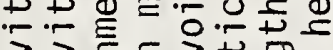

근ㄷำ

는

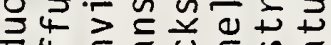

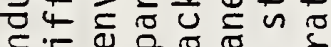

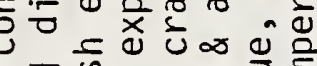

-

б

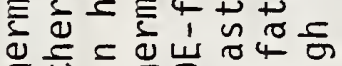

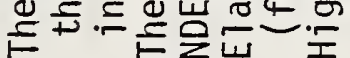

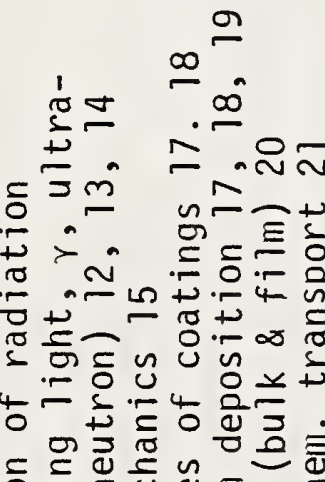

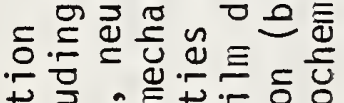

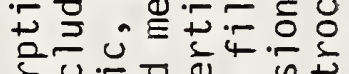

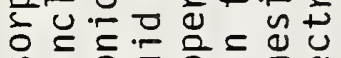

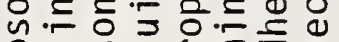

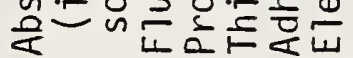

$\dot{\sigma} \quad \dot{0} \dot{0} \dot{0}$

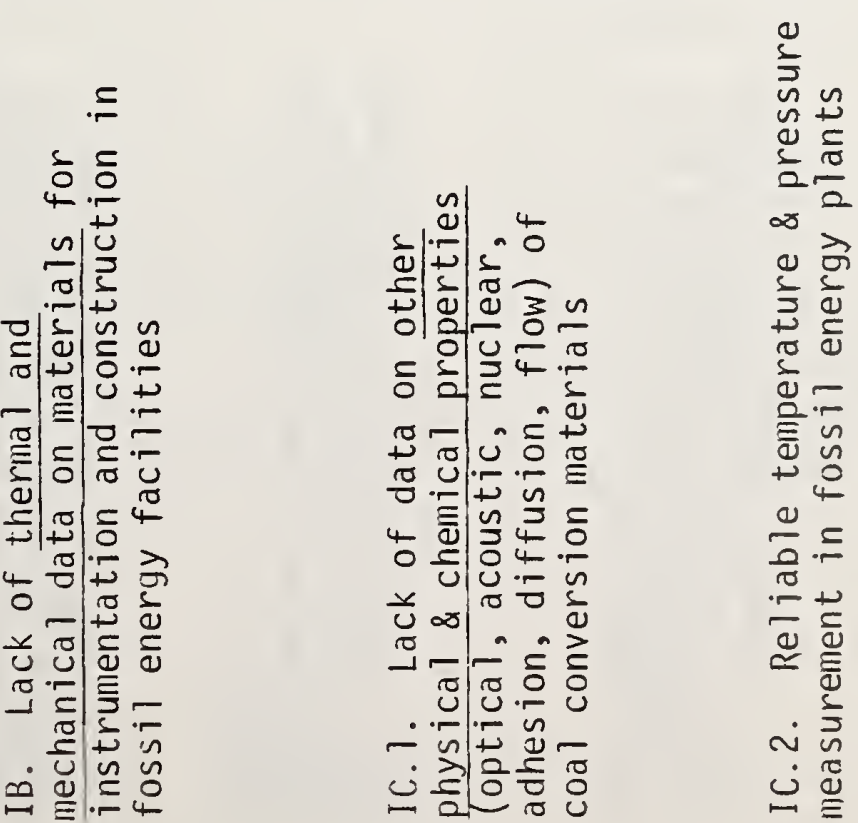




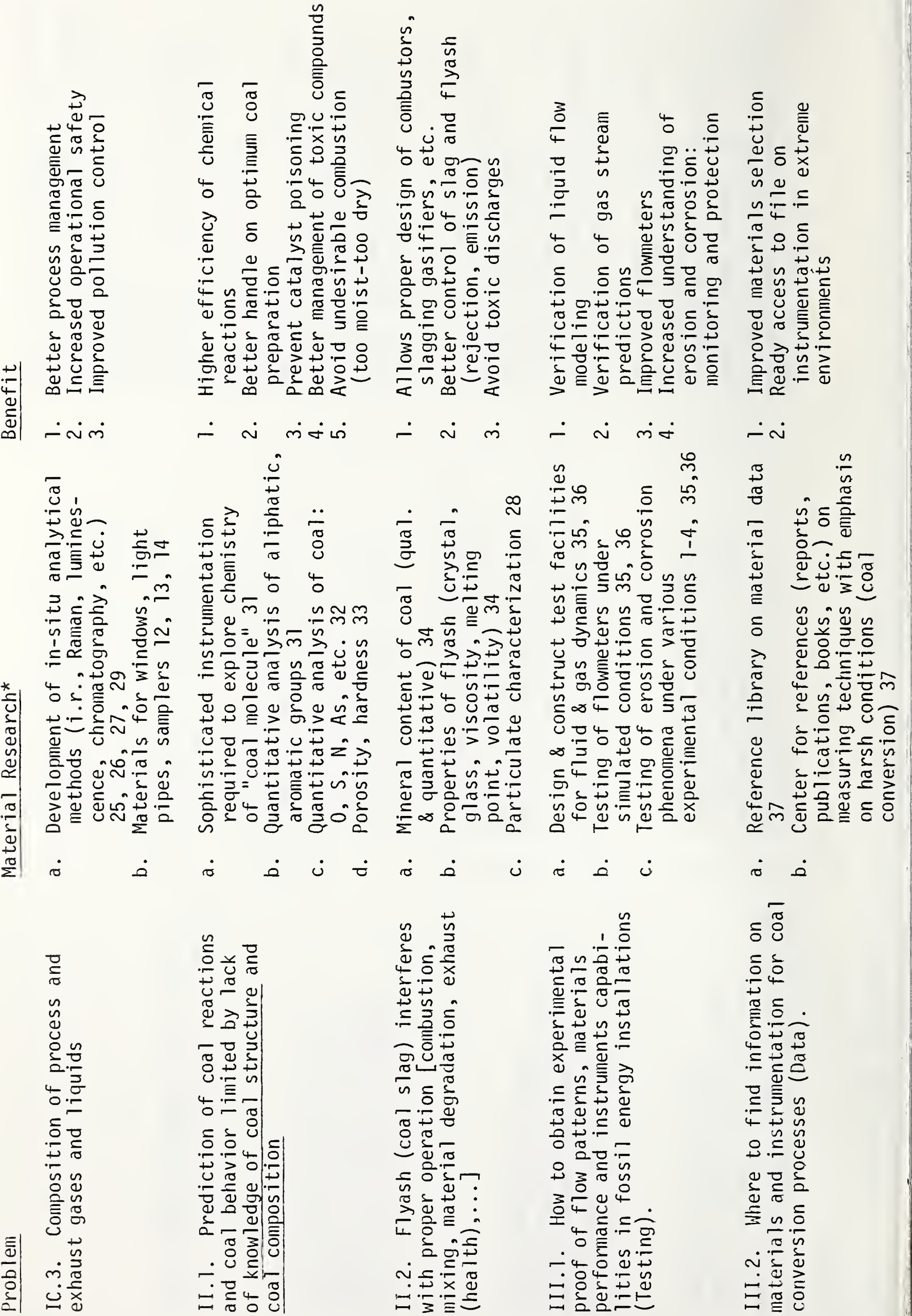


Table 2. Recommended Program (Summary)

Research Area

$\underline{\text { Sub-areas }}$

Project

I. Materials Research for Sensors

A. Erosion/Hot Corrosion

Erosion/Corrosion by Liq/Sol.

1. Erosion by slurries

2. Corrosion by liquids

Erosion/Corrosion by Gas/Sol.

3. Erosion by particles in gas

4. Corrosion in Gas

5. Erosion/Corrosion sensors

B. Thermal/Mechanics
Measurement of Heat Conduction

Thermal Expansion

High Temperature Heat Capacity

Mechanical Properties
6. Static Technique (Heat Conductivity)

7. Dynamic Technique (Heat Diff.)

8. Methods and Data on Thermal Expansion

9. Measurement of Heat Capacity

10. Measurement of Mechanical Strength

11. NDE for detection of cracks, voids,
C. Materials Properties for Measurement of Process Parameters

\author{
Absorption of Radiation \\ (opt., sonic, etc.)
}

Fluid dynamics

Protective Coatings

Adhesion

Electrochemical Cell

Thermometry

Analysis - Chemical

Analys is - Particulates

Analys is - Emissions

Pressure Measurement
12. Windows for acoustic, ultrasonic radiation

13. Windows for $y$-ray, neutrons

14. Optical windows and fibers

15. Two-phase flow (exp. + theor.)

16. Intrusive and non-intrusive flowmeters

17. Plasma sprayed coatings

18. Sputtered or CVD coatings

19. Thin film sensors (temp., strain)

20. Adhesion measurement and theory

21. Ionic conduction $(S, C l, H,-$.

22. Relfability of thermocouples

23. Fluidic thermometers

24. Optical temperature measurement

25. Chromatography

26. I.R. absorption, luminescence, Raman

27. Mass spectrometry

28. Detection \& chracterization of particles

29. Devices for measurement of $\mathrm{NO}_{x}$, $\mathrm{CO}_{\mathrm{X}}, \mathrm{SO}_{\mathrm{X}}$

30. High $T$ piezoelectrics
II. Properties of Coal
Chemistry of Coal
Physics of Coal
Properties of Flyash
III. Testing and Data
Test Facilities for Fluids
Test Facilities for Gas
Data Center

31. Structure of coal - nmr

32. Composition of coal (bonding)

33. Density (porosity) of coal (moisture)

34. Composition \& properties of flyash
High Risk Research
35. Test loop for liquid flow
36. Test chambers for combustion, gas
37. References on materials \& instruments 
Table 3. Level of Effort (in staff years/year)

Research Areas

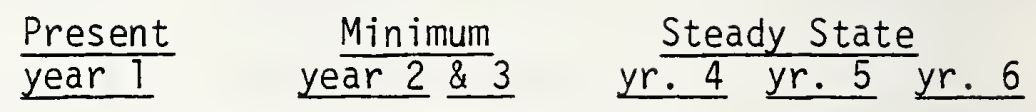

Totals

I. Materials Research for Sensors

(24)

(70)

(70)

(100)

(100)

$(100)$

(464)

A. Erosion/Hot Corrosion

$20 \quad 20$

25

25

25

115

B. Thermal/Mechanical

$20 \quad 20$

25

25

25

115

C. Process Parameters
a) Flow
b) Temperature
c) Composition
d) Level
e) Pressure

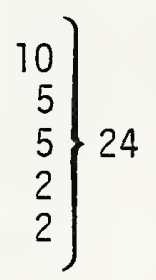

II. Properties of Coal

$\left.\left.\begin{array}{r}10 \\ 8 \\ 8 \\ 2 \\ 2\end{array}\right\} 30 \begin{array}{r}10 \\ 8 \\ 8 \\ 2 \\ 2\end{array}\right\} 30$

50

50

50

234

III. Testing and Data

10

10

14

14

14

62

IV. Exploratory Research

$15 \quad 15$

$16 \quad 16$

16

78

$5 \quad 5$

$10 \quad 10$

10

40

Totals 24

100

100

140

140

140

644

\subsection{Coordination and Implementation}

The implementation of the above program will depend heavily on the major policy decisions with respect to Fossil Energy development, that will be taken in the next 6 to 12 months. It is difficult at this point - May 1981 - to predict the future of the Synfuel program, the MHD effort, the gas turbine technology, etc. However, supposing that some of these programs will go forward, it will then be necessary to pay considerable attention to Materials and Instrumentation. It is inconceivable that the important R\&D needs in this field would be ignored.

A number of general principles should be kept in mind.

- Both the organizers of the program and the participants should constantly realize that these R\&D plans are meant to be medium-range (3-6 years). The facility operators and program managers should restrain themselves, and refrain from pushing the various projects in the direction of quick and shallow "results" or "pay-off". 
- The program is meant to be interdisciplinary. It covers in most cases such disciplines as metallurgy, ceramics, chemical engineering, physics, mechanics, optics (sometimes), etc. There should be close collaboration between groups of instrumentation experts and groups of materials scientists or engineers. Preferably groups of the first and of the second kind should be at the same institution or even in the same laboratory. Collaborative proposals from two or more research teams should be encouraged.

- It is essential that every research project (both experimental and theoretical) maintains close contact with operators of Fossil Energy Test Installations and Pilot Plants. It should be a contractual requirement that the instrumentation and materials developers visit one or more pertinent plants and test facilities several times a year. At the same time visits of plant operators to the R\&D laboratories should be encouraged!

- A most important aspect is close contact between the research teams and instrument manufacturers. Project managers and monitors should realize constantly that one of the major goals of their research is to develop an accurate, durable device that can be used to measure an essential parameter in gasifiers, liquefiers, combustors, turbines, etc. Consequently, it is important to seek and maintain contact with representatives of instrument companies and/or plant operators and encourage them to take interest and, if possible, participate in the design and manufacturing of the particular apparatus under development.

- Coordination and Dissemination

A key element of the suggested program must be a well organized network of contacts between all interested parties. Scientists and engineers have to be keenly aware of the efforts that are being mounted to solve the instrumentation problems of this industry. Conferences, technical workshops, and an up-to-date newsletter are essential for the success of this program.

It seems to us that the return on the R\&D investment in the Fossil Energy field could be vastly improved by a better dialogue between the various groups involved in the research. Better links should be established between the Fossil Energy Program in the Department of Energy and such organizations as the Office of Energy Research (DOE), the Materials and Chemistry Branches of NSF, as well as relevant sectors of NASA and the Defense Department. Close ties with leading groups in industrial, academic and government laboratories are extremely important. And last but not least 
cooperation with working groups like SCIEP (Society for Control and Instrumentation of Energy Processes) and professional Societies like the Instr. Soc. of America, the American Physical Society, Am. Chem. Soc., Am. Ceramic Society, Am. Soc. for Metals, IEEE, etc. should be broadened.

In order to carry out these functions it is recommended that the Department of Energy specifically charges one or more persons with the responsibility for coordination of the various program elements and contact between all the participants. 


\subsection{Recommended Projects}

\section{Materials Research For Sensors}

A. Erosion/Hot Corrosion

Project 1. Erosion by STurries

Purpose: To improve performance of (intrusive) flowmeters, thermocouples, thin film sensors, radiation windows, etc.

Application: Slurry pipes, reactors, preheaters, pumps, valves. Effects on windows, light pipes, transducers, etc.

Approach:

- study erosive effects of slurries under controlled conditions of solids concentration, particle size and shape, velocity, temperature, etc. on a variety of materials (inconel, stainless steels, ceramics, etc.)

- investigate surface damage using optical and $x$-ray radiation, electron beams, and other appropriate means.

- develop theoretical models to describe erosive effects.

- coordinate with projects 2, 15, 16 and 35.

Staffing: $3-5$ staff years for a minimum of 4 years. 
Project 2. Corrosion by Coal Slurries and Other Coal Liquids

Purpose: To improve performance and service life of (intrusive) flowmeters, thermocouples, thin film sensors, pressure devices, valves, pumps, etc.

Application: Separators, slurry pipes, heaters, reactors, etc.

\section{Approach:}

- explore chemical and physical attack on solid surfaces by liquids containing sulfur, oxygen, halides and other chemical species (as well as, fast moving particles) at high temperature, as a function of pressure, concentration, $\mathrm{p}_{\mathrm{H}}$, etc.

- characterize the surface by means of a broad range of microscopic and spectroscopic techniques.

- describe corrosive attack theoretically.

- study the behavior of protective films (intrinsic and applied).

- coordinate with projects 1, 15, 16 and 35.

Staffing: $3-5$ staff years for minimum of 4 years. 
Project 3. Erosion by Particles in Gas

Purpose: To improve performance of gas flowmeters; gas analyzers; temperature-, pressure-, level devices; transducers; surface sensors, etc.

Application: cyclones, gas turbines, gasifiers, fluid bed combustors, stack exhaust, boiler tubes, access windows and pipe sections.

Approach:

- investigate erosive effects of particle laden gas streams under various conditions of velocity, angle of incidence, temperature, pressure, chemical environment, particle. size and shape. Study erosion on metals, alloys, ceramics, glasses.

- analyze surfaces on a scale from nms to ums (thickness) employing a broad range of techniques.

- develop theoretical models for erosive wear.

- coordinate with projects 4, 16, 28 and 36 .

Staffing: 3-5 staff years for a minimum of 5 years. 
Project 4. Corrosion in Gaseous Environment

Purpose: To improve the quality and durability of thermometers, pressure meters, level indicators, detectors, transducers, flowmeters, analyzers, etc. Application: gasifiers, preheaters, burners, boiler tubes, gas pipes, fluidized bed combustors, reactors, gas turbines.

Approach:

- study corrosive attack of solids by oxygen, sulfur, alkalis, moisture, etc. Determine the rate determining steps, and explore the surface and surface coatings by means of ESCA, ISS, Auger spectroscopy, etc.

- explore hot corrosion and localized corrosion.

- study the formation and durability of protective coatings (intrinsic and applied).

- coordinate with projects 3,20 and 36 .

Staffing: $3-5$ staff years for a minimum of 5 years. 
Project 5. Erosion and Corrosion Sensors

Purpose: To produce sensor(s) that can monitor the erosive and/or corrosive wear of instruments and components in F. E. facilities.

Application: Boiler tubes, gas turbine blades, reactor walls, slurry pipes, liners, combustors, cyclones, etc.

Approach:

- design thin film sensors that can record corrosive and/or erosive wear using electrical, dielectric, electromagnetic, (ultra) sonic, optical, thermal or magnetic principles.

- try to determine or estimate the lifetime of such sensors.

- if the film simulates the surface-to-be-measured prove the validity of this simulation.

- develop and operate a meaningful program for testing of sensors in coal conversion atmospheres.

- coordinate with projects $1-4,19,20,35$ and 36 .

Staffing: 2-4 staff years for 4 years. 
B. Thermal/Mechanical Properties

Project 6. Develop Standard Techniques and Reference Materials for Heat Conductivity Measurements between R. T. and $1000{ }^{\circ} \mathrm{C}$ (static measurements).

Purpose: To provide much needed data on heat transfer through construction and instrumentation materials, as well as process liquids and solids.

Application: Heat exchangers, combustor walls, reactor liners, transport tubes, pressure vessels, boiler pipes, catalysts (and substrates), coal, ' coal slurries and coal slags.

\section{Approach:}

- review, compare and analyze methods reported in the literature for the measurement of thermal conductivity of (fossil energy) materials over the range $20-1000^{\circ} \mathrm{C}$.

- develop (in coordination with ASTM) an appropriate static measurement method for thermal conductivity (and related parameters if necessary) and select suitable standards for temperatures between 20 and $1000{ }^{\circ} \mathrm{C}$.

- concentrate efforts on steels, special alloys, selected ceramics, composites and glasses. Study effects of density (porosity) and grain size.

- coordinate with Projects 7 and 8.

Staffing: 4-5 staff years for 3-5 years. 
Project 7. Develop standard methods and reference samples for thermal diffusivity measurements between 25 and $1800^{\circ} \mathrm{C}$ (dynamic measurements).

Purpose: To provide much needed data on heat transfer through construction and instrumentation materials, as well as process liquids and solids.

Application: heat exchangers, preheaters, combustors, fluidized bed systems, gas turbines, reactors, liners; coal, char and coal slags.

Approach:

- examine and assess techniques to measure the thermal diffusivity of (fossil energy) materials using a pulse or periodic method (dynamic) between 25 and $1800{ }^{\circ} \mathrm{C}$.

- develop (in coordination with ASTM) an appropriate dynamic measurement method for thermal diffusivity and choose appropriate standard specimens for the above indicated temperature range.

- concentrate experimental work on steels, alloys, composites, and selected ceramics.

- study effects of density (porosity), grain size and defects.

- coordinate with projects 6,8 and 9.

Staffing: 4-5 staff years for 3-4 years. 
Project 8. Thermal Expansion Methods and Data

Purpose: To assist in the selection of better matched materials for instrumentation and construction (especially at high temperature).

Application: Ceramic liners, (surface) sensors, thermocouples, etc. in gasifiers and liquefiers; pressure devices in fluidized beds; access windows and pipe sections.

Approach:

- Study and further develop accurate methods for measuring thermal expansion of metals and non-metals over an extended temperature range.

- investigate what affects the thermal expansion, and how one can "tailor" the magnitude of the T. E. coefficients (density, grain size, etc.).

- coordinate with projects 6,7 and 10 .

Staffing: 2-3 staff years for 3 years. 
Project 9. Measurement of Heat Capacity of Solid Construction Materials, Process Gases and Liquids

Purpose: To determine the thermal efficiency of coal conversion products.

Application: Gasifiers, liquefiers, pressurized bed combustors, heat exchangers, preheaters, reactors, liners, boiler tubes, catalyst (substrates). Approach:

- explore appropriate and convenient techniques for measuring heat capacity at (very) high temperatures.

- provide data on selected process materials.

- coordinate with projects 7 and 25-27.

Staffing: $2-3$ staff years for 3 years. 
Project 10. Measurement and Values of Mechanical Properties in extreme environments.

Purpose: To increase the durability of measuring equipment and construction materials in F. E. installations.

Application: Valves, pressure vessels, reactor liners, light pipes, cyclones, separators, boiler tubes, turbine blades, etc.

Approach:

- develop appropriate methods for the measurement of elastic and inelastic properties at high temperatures for both metals $\left(1000^{\circ} \mathrm{C}\right)$ and ceramics $\left(1800^{\circ} \mathrm{C}\right)$.

- design similar techniques for the determination of tensile strength, yield strength, fracture strength, creep and hardness in the upper temperature range (800-1800 ${ }^{\circ} \mathrm{C}$ depending on the material).

- construct theoretical models to explain the decrease or increase of strength.

Staffing: 2-3 staff years for 5-6 years. 
Project 11. NDE inspection methods for detection of cracks, voids, etc.

Purpose: To evaluate the strength (or lack thereof) and the (im)perfection of metaliic and ceramic bodies at ambient and at high temperatures.

Application: pressure vessels, preheaters, reactors, gasifiers, liners, boiler tubes, turbine blades, etc.

\section{Approach:}

- design or modify NDE methods to detect microcracks, flaws, and voids in metallic and non-metallic materials. This will involve systematic exploration of acoustic, ultrasonic, electromagnetic and other loss techniques.

- coordinate with projects $10,12,35$ and 36 .

Staffing: 3-4 staff years for 5-6 years. 


\section{Measuring Process Parameters}

Project 12. Acoustic and UItrasonic Transmission through various solids, Tiquids and gases.

Purpose: To aid the design and construction of sonic "windows" needed for in-situ flow metering, chemical analysis, temperature measurement, etc.

Application: Determination of process parameters and chemical composition of process gases and liquids in gasifiers, liquefiers, combustors, gas turbines.

Approach:

- provide data on absorption of sonic and ultrasonic radiation in various materials used for access windows, guides, spool pieces, etc.

- determine also the absorption of sound and ultrasound by flowing liquids and gases (whth and without particulates); measure this absorption as a function of various relevant parameters: temperature, pressure, sound frequency, etc.

- coordinate with projects 15,35 and 36 .

Staffing: 3 staff years for 2-4 years. 
Project 13. Transmission of y-rays and neutrons through solids and liquids.

Purpose: To aid the design and construction of "windows" for ionizing radiation needed for in-situ flowmetering, chemical analysis, etc.

Application: Determination of process parameters (e.g., flow velocity) and chemical composition in liquefiers, gasifiers, combustors, etc.

Approach:

- provide data on absorption of neutrons, $\gamma$-rays, $x$-rays in various materials used for access windows, spool pieces, etc.

- determine the absorption of neutrons, $\gamma$-rays and $x$-rays by (flowing) liquids (with and without particulates). Measure this absorption as a function of several relevant parameters: temperature, pressure, energy of the particles or radiation.

- perform analysis of radiation from activated atoms and molecules (NAA, fluorescence).

- coordinate with projects 15 and 35.

Staffing: 3 staff years for 2-4 years. 
Project 14. Optical windows and fibers

Purpose: To aid the design and construction of windows for optical radiations (i.r., visible, u.v.) needed for flow metering, chemical analyses, temperature recording, etc.

Application: Determination of process parameters (e.g., temperature) and chemical composition in combustors, heaters, gasifier- and liquefiers tubing, etc.

\section{Approach:}

- provide data on optical constants and absorption in various materials used for windows, guides, fibers, etc. (under extreme conditions of $T, P$ and chemical reactivity).

- furnish similar information on absorption, refraction, and scattering of light by (flowing) liquids and gases (with and without solid particulates).

- coordinate with projects 24, 26, 28 and 36.

Staffing: 4 or 5 staff years for 4-5 years. 
Project 15. Fluid dynamics of multicomponent flow.

Purpose: To improve the efficiency of slurry transport and slurry flow metering.

Application: coal/water mixing and feeding, slurry tanks, heaters, reactors and pipes containing partly dissolved coal.

\section{Approach:}

- study two-phase (and three-phase) flow as a function of the pertinent physical-chemical variables: particulate concentrations; shape, size, and size distribution of particles in fluid; temperature; pressure; velocity; pipe size; surface conditions; etc. Analyze the laminar and turbulent flow regimes and the boundary layer behavior. Particle-particle and fluidparticle interactions in flowing systems should be a focus of activity.

- mount a significant effort in flow modeling (both 2- and 3-phase). Assess effects of protrusions and constrictions, variable cross sections, bends, etc. in the pipes.

- coordinate with projects 1,16 and 35.

Staffing: 8-9 staff years for 3-4 years (e.g., 3 or 4 different groups). 
Project 16. Intrusive- and Non-intrusive flowmeters

Purpose: To develop improved flow measuring capability.

Application: slurry transport pipes, slurry tanks, inlet-and outlet of heaters and reactors.

\section{Approach:}

- improve intrusive flow metering technology, e.g., orifices or nozzles, by applying flow analyses and selecting suitable materials. Make a systematic study of the erosion (and corrosion) caused by the flow. Decrease erosive effects by designing wall profiles for minimum turbulence.

- apply flow principles and materials expertise to the design of a non-intrusive flowmeter (e.g., ultrasonic Doppler, or thermal pulse, or etc.).

- Coordinate with projects 1, 15 and 35.

Staffing: 4-5 staff years for 3-5 years. (at least 2 groups). 


\section{Project 17: Plasma sprayed coatings}

Purpose: To develop protective layers for thermocouples, fluidic thermometers, optical light pipes, thin film sensors, sampling devices, transducers, detectors, etc. in aggressive fossil energy environments.

Application: All components and instruments in coal conversion facilities.

Approach:

- investigate the deposition of arc plasma sprayed and flame sprayed coatings 0.1-100 $\mu \mathrm{m}$ : voltage, geometry, time (periodicity), powder size and composition, powder feed; substrate temperature, etc.

- explore grading by changing feed rate.

- study the durability, as well as the structure, density and homogeneity of these layers; also determine the diffusion and internal stresses. Use appropriate surface and thin film analysis techniques.

- coordinate with projects 5, 19, 20, 22, 23 and 36.

Staffing: $2-3$ staff years for 4 years. 
Project 18. Sputtered and CVD coatings.

Purpose: To develop protective layers for thermocouples, optical

light pipes, thin film sensors, transducers, detectors, etc.

Application: All components and instruments in coal conversion facilities.

Approach:

- study the deposition of sputtered and/or CVD coatings $(1-100 \mu \mathrm{m})$ :

quality of film as a function of substrate temperature and rate of deposition.

- investigate grading.

- study the lifetime as well as the structure density and homogeneity of the above layers.

- coordinate with projects $5,19,20,22,23$ and 36 .

Staffing: 2-3 staff years for 4 years. 
Project 19. Thin film sensors (erosion/corrosion, temperature, etc.)

Purpose: To develop the thin film sensor technology for a number of physical and chemical measurements especially at high temperatures.

Application: Monitoring of erosion/corrosion, temperature, strain, vibration, etc. in various components of gasifiers, liquefiers, combustors, gas turbines, etc.

\section{Approach:}

- design thin film sensors for the measurement of erosion/corrosion, temperature, strain, and/or flow(?) up to at least $1000^{\circ} \mathrm{C}$.

- assess the preference for plasma sprayed, CVD or sputtered films

- determine the quality and durability of these sensors.

- coordinate with projects $5,17,18,20$ and 36

Staffing: 2-3 staff years for 4 years. 
Project 20. Adhesion: measurement and theory

Purpose: Improve the adhesion of thin films, protective layers, etc. to flat and curved surfaces of tubes, reactors, etc.

Application: Sensors, transducers, detectors, thin film thermometers, Tevel-and pressure devices in gasifiers, liquefiers, gas turbines, etc.

Approach:

- develop methods to define and measure the adhesion of material A to material $B$.

- study the parameters determining (good) adhesion.

- investigate the theoretical aspects of the physics and chemistry governing the interface (bonding, diffusion, geometry, etc.).

- coordinate with projects 17,18 and 19.

Staffing: 4-5 staff years for 4 years (at least 2 groups). 
Project 21. Ionic Conduction ( $\mathrm{S}, \mathrm{Cl}, \mathrm{N}, \mathrm{O})$

Purpose: To develop sensors for partial gas pressures of sulfur, halides, and other chemical species.

Application: Gas turbines, gasifiers, combustors, fractionators.

Approach:

- study the mechanisms of ionic conduction in a variety of sulfides, oxides, halides, organics for use in electrochemical cells.

- investigate the ac- and dc-conductivity and the polarization effects of ionic conductors where the moving species are $0, S, N$, and halide ions.

- explore a variety of materials for electrodes and indicate the advantages and disadvantages of each.

- study the durability of the ionic conductors under various conditions.

Staffing: $3-4$ staff years for 4 years. 
Project 22. Reliability of Thermocouples

Purpose: To develop fast and reliable temperature measurement in harsh, high temperature environments.

Application: Preheaters, reactors, separators, fluidized bed combustors, Tiquefiers, etc.

Approach:

- improve reliability of thermocouples, both from the durability (Materials) and operational point of view (emphasis $400-1800^{\circ} \mathrm{C}$ ).

- find long-life sheathing materials resistant to chemical attack, especially by oxygen, sulfur and hydrogen.

- study the accuracy, precision and response time.

- coordinate with project 36.

Staffing: 3 staff years for 5 years. 
Project 23. Fluidic Thermometers

Purpose: To develop reliable temperature measurement devices for harsh, high temperature atmospheres.

Application: Combustors, gasifiers, reactors, fluidized beds, preheaters, etc.

Approach:

- expand the applicability of fluidic thermometers by proper materials research.

- improve accuracy, precision and response time. Explore different geometries (smaller) and iighter construction.

- coordinate with projects 17, 18, 20 and 36.

Staffing: 3 staff years for 4 years. 
Project 24. Optical Temperature Measurement in Gases and Plasmas

Purpose: To develop dependable non-intrusive thermometers.

Application: Combustors, (slagging) gasifiers, gas turbines, etc.

Approach:

- explore Raman, fluorescence, radiometric, and/or line reversal methods for temperature measurement.

- investigate methods and design equipment to introduce light into high temperature environments and study also high temperature detectors as well as means to extract the signal from the high-T environment (windows, light pipes, etc.).

- determine emissivities of appropriate materials in the required temperature range.

- assess durability, accuracy/precision and response time.

- look into the possibilities of intermittent measurements (e.g., insert and retract some kind of periscope into the high temperature chamber, or reactor for short periods of time).

- coordinate with projects 14 and 36.

Staffing: $3-4$ staff years for 4-5 years. 
Project 25. Chromatography

Purpose: To provide convenient, analytical methods for the determination of chemical composition under difficult conditions of high temperature, high pressure and strong corrosion.

Application: Process liquids and gases at several critical points in the flow train of gasifiers, liquefiers, fluidized bed combustors, etc.

\section{Approach:}

- study gas- and liquid chromatography for use in fossil energy processes.

- increase processing speed and reliability.

- investigate several materials for optimum choice: e.g., samplers.

- coordinate with projects 35 and 36.

Staffing: 3 staff years for 2-3 years. 
Project 26. Chemical analysis by optical means

Purpose: To provide convenient, reliable, analytical methods for the determination of chemical composition.

Application: Process liquids and gases at several critical points in the flow train of gasifiers, liquefiers, fluidized bed combustors, etc.

Approach:

- explore the use of i.r. absorption, Raman scattering, and/or luminescence for in-situ chemical analysis.

- review and select best tunable lasers, detectors, windows and light guides (fibers?) for the above methods.

- design, build and operate at least one experimental set-up for determining 2 or more species.

- coordinate with projects 14,35 and 36.

Staffing: $4-5$ staff years for 3-4 years (at least two groups). 


\section{Project 27. Mass Spectroscopy}

Purpose: To provide convenient, reliable, not overly costly, analytical methods for the determination of chemical composition of gases.

Application: Process liquids and gases at several critical points in the flow train of gasifiers, liquefiers, fluidized bed combustors, etc.

Approach:

- adapt mass spectrometry technique for real-time monitoring of reaction products in severe environments (including high temperature, pressure, etc.).

- investigate appropriate materials and suitable geometry for m.s. probes.

- coordinate with projects 25, 26 and 36 .

Staffing: 3 staff years for 2-3 years. 
Project 28. Measurement of particulates

Purpose: To detect and analyze particles in gas streams to prevent erosion, and avoid health hazards (exhaust).

Application: Gasifiers, gas turbines, stack gases from coal combustion and coal conversion facilities.

Approach:

- adapt optical techniques (microscopy, holography, absorption, light scattering) designed to measure particle concentration, size and size distribution, for use in high temperature, high pressure, chemically active environments.

- compare optical techniques with other methods for particle analysis; SEM, STEM, sedimentation, Coulter counter, etc.

- develop uniform powders to be used as standards for the above methods.

- coordinate with projects 3, 14, 24 and 36.

Staffing: 3-4 staff years for 4-5 years (at least 2 groups). 
Project 29. Measurement of $\mathrm{NO}_{x}, \mathrm{CO}_{x}, \mathrm{SO}_{x}$, etc.

Purpose: To monitor emissions and avoid (illegal) pollution.

Application: A11 Fossil Energy Facilities.

\section{Approach:}

- modify devices, designed to detect $\mathrm{NO}_{\mathrm{x}}, \mathrm{CO}_{\mathrm{x}}$ and $\mathrm{SO}_{x}$, for use as analyzers of exhaust gases from gasification and $X_{i q u e f a c t i o n}$ plants, gas turbines, fluidized bed combustors, etc.

- investigate and develop proper materials for i.r. and u.v. windows and for detectors of radiation in specific spectral ranges.

- coordinate with projects 14,26 and 36.

Staffing: 3-4 staff years for 3 years. 
Project 30. Materials for pressure and for acoustic flow measurement (High-T piezoelectrics)

Purpose: To record elevated pressures and sonic responses conveniently and reliably.

Application: Fluidized bed installations (PFBC), gasifiers, heaters, reactors, feedback lines.

Approach:

- investigate piezoelectric materials for use as transducers, detectors and pressure gauges under conditions of high temperature and pressure.

- study material durability, signal stability and response time.

- coordinate with projects 16, 35 and 36 .

Staffing: 3 staff years for 3 years. 
II. Properties of Coal

\section{Project 31 . Chemical Structure of Coal}

Purpose: To provide advanced instrumentation leading to data on and knowledge of chemical bonding in coal as a basis for predicting chemical reactions, reaction rates, dissolution, etc.

Application: Gasification and liquefaction reactions; reactions in heaters, combustors, separators; catalytic reactions.

\section{Approach:}

- determine bonding of $\mathrm{C}$ and $\mathrm{H}$ throughout the "coal molecule", using such techniques as high resolution NMR and IR-spectroscopy.

- review possible other methods for probing molecular structure of coal.

- attempt to construct "coal-molecule" models.

- coordinate with project 32.

Staffing: at least 5 staff years for 5 years (2 or more groups). 
Project 32: Chemical Composition of Coal

Purpose: To provide advanced instrumentation for the chemical analysis of coal especially with respect to organically bonded $S, N$, 0 , etc.

Application: Gasification and liquefaction reactions: desulfurization, $\mathrm{NO}_{\mathrm{x}}$ production, catalyst poisoning, etc.

Approach:

- Develop methods for the quantitative analysis of $0, \mathrm{~S}, \mathrm{~N}, \mathrm{Fe}$, alkal is, halides, As, Ni, P, etc. in coal and determine their position and bonding, using besides MMR such techniques as Raman and Mössbauer spectroscopies, ESCA, Auger, $X$-ray diffraction, EPR, etc.

- emphasize organically-bonded species.

- coordinate with project 31.

Staffing: 2-3 staff years for 4 years. 
Project 33. Physical-Chemical Properties of Coal

Purpose: Measurement of coal properties essential for handling, pulverizing, dissolving and reacting of coal.

Application: Coal feeders, coal dryers, coal mixers, coal crushers.

\section{Approach:}

- measure the density of coal; determine open and closed porosity and pore size of various coals and coal forms.

- define and determine hardness, agglomeration and volatility of coal.

- develop in-situ method for moisture analysis; kinetics of coal drying.

- measure acoustic and dielectric properties of coal.

- determine BTU-value of various coals.

- coordinate with projects 31 and 32.

Staffing: 3-4 staff years for 5 years. 
Project 34. Flyash (coal Slag)

Purpose: To develop measurement techniques and provide data on physical and chemical properties of coal slag (flyash) that seriously affect coal conversion processes.

Application: Flow and reactions of process fluids and vapors in liquefiers, gasifiers, cyclones, gas turbines, combustors, stacks, etc. (operation, durability, safety, health).

\section{Approach:}

- determine chemical composition and phases (including amorphous) of flyash particles and of condensed coal slag (at various temperatures, pressures, and flow velocities).

- measure the viscosity and volatility of molten slag; develop predictive models as a function of composition.

- coordinate with projects 3,28 and 36.

Staffing: $3-4$ staff years for 4 years. 
III. Testing and Data

Project 35. Test facilities and procedures for liquid/solid flow*.

Purpose: To provide capabilities for testing dynamic behavior of fluids and slurries of flowmeters and of other instrumentation operating in moving fluids.

Application: Heaters, reactors, separators, transport tubes (for fluids and slurries), and other components of coal conversion facilities containing process fluids.

Approach:

- develop appropriate procedures for (long time) testing of liquid flow patterns, operation and durability of various measuring devices, and the properties of specific materials under well-defined conditions of moving liquids.

- design and build one or more loops for testing liquid and slurry flow of sufficient size to simulate turbulent and laminar flow over an appreciable range of velocities, temperatures, etc.; the installation must be well instrumented and be able to accommodate a variety of flowmeters. Besides it must contain measuring devices to record erosion and corrosion.

- coordinate with projects $1-5,15,16$ and 22.

Staffing: at least 8-10 staff years for 6 years.

Initial capital cost: at least $\$ 750,000$.

*It is assumed that the facility operators will be intimately involved in research using these facilities. 
Project 36. Test chambers and procedures for gas streams and combustion*. Purpose: To be able to test (particle-laden) gas flow patterns and durability of instrumentation and materials in severe, high-temperature environment.

Application: Fluidized bed combustors, gasifiers, gas turbines, gas analyzers, sensors in reactors, cyclones, tubing, etc.

\section{Approach:}

- create facilities for testing the behavior of gas streams with and without particles or droplets; such facilities must be extensively instrumented for determination of flow patterns, boundary layer behavior, measurement of particle size and distribution, and be able to operate at high temperatures and pressures and various chemical environments.

- construct one or more combustion chambers designed for testing of several types of metering devices including thermometers, pressure and strain gauges, erosion and corrosion sensors; the test chamber must provide means to investigate the behavior of flyash and condensed slag at very high temperatures.

- develop testing procedures for (long time) testing of gas flow patterns.

- coordinate with projects $3,5,22,24,28$ and 34 .

Staffing: at least 5 staff years for 6 years (2 or more groups). Initial Capital Cost: Approximately $\$ 250,000$ per chamber.

*It is assumed that the facility operators will be intimately involyed in research using these facilities. 
Project 37. Data and information on materials for instrumentation.

Purpose: To provide a convenient and efficient data file on materials properties and measurement techniques.

Application: A11 fossil energy research and development, testing facilities and plant construction.

Approach:

- develop an information center containing physical and performance data on pertinent materials (under severe conditions) and create at the same time a reference library and clearinghouse on instrumentation and measurement methods relevant to fossil energy technologies.

- Optimize contacts with the entire fossil energy community. Create effective means for input from this community and dissemination of the Center's data and reference.

Staffing: 2-4 staff years for 8 years. 


\section{Exploratory Research}

Project 38. Promising New Ideas (High Risk)

Purpose: Reserve funds to be able to support promising new ideas.

Application: Novel materials for new measurement techniques applicable in Fossit Energy Processes.

Staffing: 50 staff years total.

\section{Possible Examples: Sintering}

Combustion catalysts

Adhesion (theory and experiment)

NDE for "green shapes"

Erosion- and corrosion protection 


\section{References}

1a. C. H. Samans and W. R. Hulsizer, J. Eng. Mater. Technol. 99, 372 (1977).

1b. S. M. Wiederhorn et al., J. Eng. Mater. Technol. 99, 143 (1977).

2. R. T. King and R. R. Judkins, "Fossil Energy Materials Needs As sessment", ORNL/TM-7232, JuTy 1980.

3. Energy Materials Coordinating Committee (EMaCC). Report FY 1980 (DOE/ER-0102).

4. Fossil Energy I\&C Briefs (Prepared for the DoE by JPL), Vol 2, \#1, January 1981.

5. Proceedings of the Symposia on Instrumentation and Control for Fossil Energy Processes, 1977, 1978, 1979, 1980 (Prepared for DoE by Argonne National Laboratory).

6. "Overview of Coal Conversion Process Instrumentation, Argonne National Laboratory, Tech. Memorandum \#1, May 1980 (ANL-FE-49628).

7. Technical Memoranda No. 1-10, Components Technology Division, Argonne National Lab., 1977-1981 (ANL-FE-TM 01, 02, etc).

8. K. G. Porges, et al., in Proceedings of the 1978 Symposium on Instr. and Control for Fossil Energy Processes, ANL-78-62, pp. 438-475.

9. P. A. Kinzie, "Thermocouple Temperature Measurements", John Wiley and Sons, New York, 1973.

10. T. Negas, et al., Proc. of the 20th Anniversay of Fluidics Symposium (AS), pp. 37-43 (1980).

11. See for example, Measurement of Thermal Radiation Properties of Solids, J. C. Richmond ed. Office of Scientific and Technical Information, NASA (1963), and Symposium on Thermal Radiation of Solids, S. Katzoff ed. Scientific and Technical Information Division, NASA (1965).

12. Sidney A. Self, Review of Soviet Plasma Diagnostics on the U-25B MHD Facility for Joint US-USSR Generator Studies, HTGL Report No. 116, Stanford University, January 1980.

13. J. Bradshaw, et al., "Application of the Two Line Atomic Fluorescence Technique to the Temporal Measurement of Smal1 Volume Flame Temperatures" in Characterization of High Temperature Vapors and Gases, J. W. Hastie ed., NBS Special Publication 561, Vol 2, p. 1079 (1979).

14. M. Lapp and C. M. Penney, Laser Raman Gas Diagnostics, Plenum Press, New York (1974).

15. A. C. Eckbreth, "CARS Thermometry in Practical Combustor", Combustion and Flame 39, 133 (1980).

16. J. W. Hastie, ed., Characterization of High Temperature Vapors and Gases, NBS Special Publication 567/2 (2 Vols), (1979). 
17. A. C. Eckbreth, et al., "Combustion Diagnostics by Laser Raman and Fluorescence Techniques", Prog. Energy Combustion Sci. $\underline{5} 253$ (1979).

18. S. A. Self, R. H. Paul and R. Keating, A Fiber Optic Probe for Temperature Measurements in Combustion MHD Plasmas, HTGL Report No. 120, Stanford University, September 1980.

19. Bernard R. Cooper, Physics Today 31, p. 32, 1978.

20. Caroline L. Herzenberg, IEEE Trans. Nucl. Science, NS-26, 1568 (1979).

21. W. T. Smith, American Laboratory 12, 95 (Nov. 1980).

22. Sidney A. Self, High Temperature Gas Dynamics Lab., Mech. Eng. Dept., Stanford Univ., Memorandum Report \#18, Nov. 1980. (Report on an NSF Workshop at Mississippi State University, September 1980).

23. S. A. Self and R. L. Keating, In-Situ Sampling Filter for High Temperature High Velocity Flows, HTGL Report No. 117, Stanford Univ., May 1980.

24. Frederick P. Schwartz and Hideo Okabe, Anal. Chem. 47, 703 (1975).

25. A. W. Ruff and S. M. Wiederhorn, "Erosion by Solid Particle Impact", NBSIR 78-1575, January 1979.

26. George F. Schmitt, "Liquid and Solid Particle Impact Erosion" in Wear Control Handbook, ASME, 1980.

27. K. Natesan, Corrosion and Mechanical Behavior of Materials for Coal Gasification Application, Argonne National Laboratory (ANL-80-S).

28. V. L. Hill and E. J. Veseley in "Properties and Performance of Materials in the Coal Gasification Environment", GRI/MPC/ASM/DoE Conference, Pittsburgh, September 1980.

29. W. A. Ellingson, Materials Technology for Coal-Conversion Processes, Progress Reports, Argonne National Laboratory, 1980 and previous years.

30. R. R. Dils and P. S. Follansbee, "Superalloy Sensors", Superalloys: Metallurgy and Manufacture, Kear, B. H., Muzyka, D. R., Tien, J. K., and WTodek, S. T., Eds., Claitors, Baton Rouge, LA, 1976, pp. 37-44.

31. N. Berkovitz, "An Introduction to Coal Technology", Acad. Press, New York (1979), pp. 21-157.

32. M. L. Gorbaty et a1. Science 206, 1029 (Nov. 1979).

33. E, V. Beaupre, American Laboratory 12, 89 (Nov. 1980).

34. Proc. of the Conference on Chemistry and Physics of Coal Utilization W. Virginia University, June 1980.

35. C. L. Herzenberg, et a7., ANL-CEN-FE-80-12 (1981). 
36. N. Berkovitz, "An Introduction to Coal Technology", Academic Press, New York (1979), pp. 45-53, 324.

37. S. J. Schneider, et a1., Chapter 3 in "Current Topics of Materials Science", Vol. 4, Ed. by E. Kaldis, North Holland Publishing Co., Amsterdam, 1980 , p. 89.

38. Wolfgang Sachse and Nelson N. Hsu, Chapter 4 in Physical Acoustics Vol. XIV, p. 277 (1979). Academic Press, NY.

39. R. N. Katz, Science 208, 841 (1980).

40. Instrumentation and Process Control for Fossil Energy Demo Plants Ann. Techn. Progress Report, Argonne National Laboratory, FE-49622-12, October 1977. 
, 


\section{APPENDIX I - Review of Major Processes}

\section{a. Coal Gasification}

Gasification of coal is a technology aimed at producing gases of various heat content by hydrogenation of coal. The basic chemistry is simple. ${ }^{\text {* }}$ * Pulverized coal is combined with steam and reacted at high temperature and pressure to form $\mathrm{CH}_{4}, \mathrm{CO}, \mathrm{CO}_{2}, \mathrm{H}_{2}$, and various hydrocarbons. The three fundamental chemical reactions are:

the carbon-steam reaction $\mathrm{C}+\mathrm{H}_{2} \mathrm{O} \rightarrow \mathrm{CO}+\mathrm{H}_{2}$ the shift reaction $\quad \mathrm{CO}+\mathrm{H}_{2} \mathrm{O} \rightarrow \mathrm{CO}_{2}+\mathrm{H}_{2}$

the methanation reaction $\mathrm{CO}+3 \mathrm{H}_{2} \rightarrow \mathrm{CH}_{4}+\mathrm{H}_{2} \mathrm{O}$ (catalytic)

At the same time a number of other reactions are involved such as $\mathrm{C}+\mathrm{O}_{2} \rightarrow \mathrm{CO}_{2}$ (combustion), $\mathrm{C}+\mathrm{CO}_{2} \rightarrow 2 \mathrm{CO}$ (Boudouard reaction), $\mathrm{C}+\mathrm{O}_{2} \rightarrow \mathrm{CO}+\mathrm{O}$, $\mathrm{C}+2 \mathrm{H}_{2} \rightarrow \mathrm{CH}_{4}$, etc. The extent to which all these reactions will play a minor or major role depends very much on the temperature and pressures being applied and the presence or absence of catalysts. In general the caloric value of the gaseous product, but also the complexity of the gasification facility, increases with temperature and pressure. The various gasification techniques are usually classified on the basis of the quality (heat content) of the end product: low BTU (100-200 BTU/scf), medium BTU (300-400 BTU/sCf), and high BTU (800-900 BTU/sCf). The oldest technology, which reached commercial scale in Germany in the 1930's, is the Lurgi method which produces a "syngas" of about 170 BTU/scf at temperatures around $1000{ }^{\circ} \mathrm{C}$ and pressures of about 20-30 atm, or lower. The Lurgi process has enjoyed progressive improvements which have increased the size and reliability of the operation. Similar evolution has been true of the Wellman process, which yields a 170 to 200 BTU/scf product. These oxygen-and-steam-blown reactors produce gas having typical compositions of $50 \%$ hydrogen, 35\% carbon monoxide, and $15 \%$ methane.

The Koppers-Totzek and Winkler gasifiers operate at atmospheric pressure, generate no tars, and produce a methane-free product of approximately $30-35 \%$ hydrogen, 45-55\% carbon monoxide, and 12-16\% carbon dioxide. The Winkler process operates at relatively low temperature $\left(900^{\circ} \mathrm{C}\right)$ and can only react lignites and subbituminous coals. The Koppers-Totzek process operates at much higher temperatures $\left(1815-1925^{\circ} \mathrm{C}\right)$, and can accept a wide variety of coals of the higher rank.

*References for Appendix I at the end of the Appendix (p. 10). 
The generation of gasifier technology currently under development in the U. S. is suitable to produce synthetic natural gas and is intended for consumption rates of 5 to 10 thousand tons of coal per day. These processes rely upon the various methanation reactions to produce high quality "pipeline" gas. Three general categories of processes may be used to describe these gasification methods.

Category I - initial gas produced in the gasifier must proceed through a shift reaction before it becomes "high-BTU gas". Fluidized bed or entrained coal reactors are used.

Category II - hydrogasification processes using steam and hydrogen to produce methane-rich gas which needs little further shifting to reach sufficient quality. Fluidized bed or entrained coal reactors are used.

Category III - much the same production results as Category I but these processes use a liquid medium in the gasification process. These may involve some level of catalysis.

A few years ago four Category I processes were under development: these were known by the names Bi-Gas, Synthane, Acceptor, and UCC. The latter three have been discontinued; only the Bi-Gas pilot plant is operating at this time.

In Category II the HYGAS process has reached the pilot plant stage. Category III includes the molten salt process and the ATGAS (molten iron) process. Commercialization of these technologies remains to be seen. Considerable R\&D efforts are underway with several processes. Modification of the Koppers-Totzek and Lurgi gasifiers is directed at greater flexibility and higher pressure operation. Adaptation of the Texaco Partial Oxidation process, developed for oil gasification, to coal gasification is proceeding; a pilot plant using this approach is being operated. The gas from the Texaco gasifier is being used to generate electricity by means of gas turbines. This requires that the particulate content of the gas be kept low by removing the molten slag at the reaction stage.

The materials and instrumentation problems in all these gasifiers are serious. Thermocouples do not have sufficient lifetime to measure reactor temperatures [see Case Study c (Appendix III)]. Slag causes many difficulties: slag temperature, slag viscosity, slag thickness all are hard to measure. Determination of particulate concentration and sulfur content $\left(\mathrm{SO}_{2}\right)$ is not an easy task. 
Pulverized coal is fed into combustors, gasifiers or reactors in several ways: siurry pumping, lock hopper transfer, pneumaticaliy, or by steam injection. Char (partialiy combusted coal) is often injected into a gasifier through a steam eductor, as in the BI-GAS pilot plant. For process control and safety it is vitaliy important to know the char flow. Recently some new equipment has been designed to measure the char flow [see Case Study b (Appendix III)].

b. Liquefaction ${ }^{2}$

Most techniques for coal 1iquefaction are based on the Bergius process. Pulverized coal is mixed with a hydrocarbon liquid (which has been produced by the process itself) and reacted with hydrogen (obtained by the gasification of coal). The products from the reactor are separated into a light, middle and bottom (heavy) fraction. These fractions are used for different purposes and yield several products. Originaliy the operating pressures were $175 \mathrm{~atm}$ and higher (at reactor temperatures of $400-500{ }^{\circ} \mathrm{C}$ ) but lately the pressures have been reduced to about 100-120 atm. During the last 10-15 years a number of specific processes have been under development and many have reached the pilot plant stage 4 to 6 years ago. Some of the we11-known processes are:

a) the Solvent Refined Coal Process [SRC-I (solid product) and SRC-II (1 iquid product)]

b) the H-Coa 7 Process (catalytic)

c) the Exxon Donor Solvent Process (catalytic).

A simplified schematic of the SRC-II Process is shown in Figure 1.

Proper instrumentation is a major problem in these processes; (an overview of the multitude of measuring methods that can be used for determining process parameters was published by Argonne National Laboratory in 1980). ${ }^{3}$ Measurement of mass flowrate is a crucial parameters in the slurry streams which occur throughout gasification and liquefaction processes. Not only are solid-liquid flows encountered but solid-liquid-gas systems are prevalent in liquefaction reactions. Attainment of mass flowrate vaiues requires measurement of the phase fractions of the components of these systems is necessary in addition to the velocity of the system. To obtain effective control of the mass balances throughout these synthesis reactions require mass flowrate values.

Other parameters that have to be measured at many different locations of the total system are temperature and pressure. One also wants to record the level of slurries and liquids in the heater and in the reactor. 


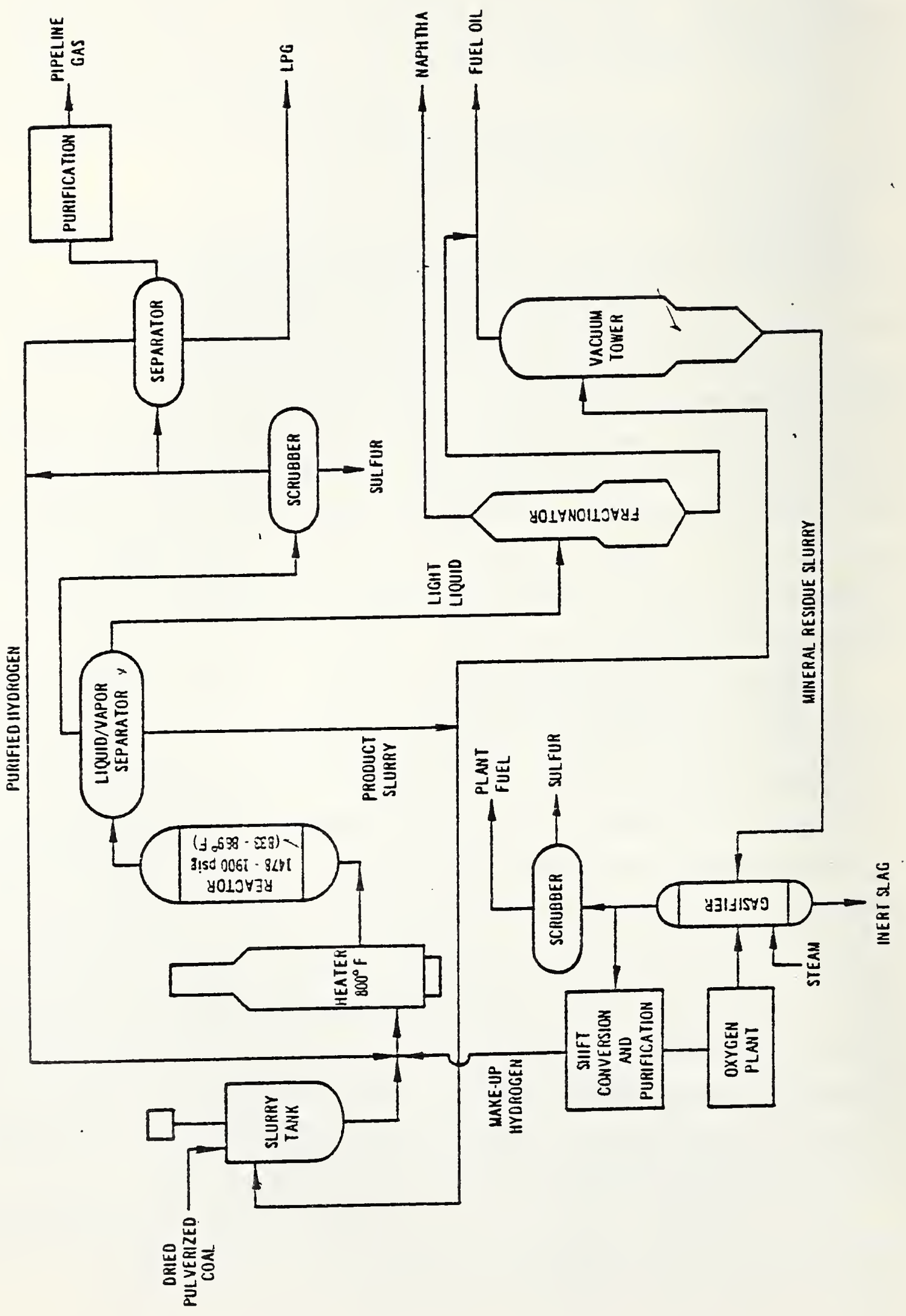

䓪 
Finally, a number of quantities like slurry viscosity, partial pressure of hydrogen, and sulfur content have to be known to guarantee efficient, safe, and clean operation.

c. Direct Combustion

Fluidized bed combustion ${ }^{1}$ is strongly promoted for a number of reasons. The name "fluidized bed" stems from the fact that small coal particles are being agitated by an air stream and hence the bed of particles benaves more or less like a fluid. Consequently, the heat and mass transfer becomes much more efficient. Furthermore, the $\mathrm{NO}_{x}$ formation is reduced considerably due to the lower operating temperature (750-950 $\left.{ }^{\circ} \mathrm{C}\right)$. Another advantage is that $\mathrm{SO}_{x}$ emissions can be decreased by means of limestone addition. The two principal approaches are atmospheric and pressurized fluidized bed combustion ( $A F B C$ and $P F B C$ ). The latter operates at somewhat higher temperature and takes considerably less space than conventional thermal plants. Fluidized bed combustors can be employed to generate steam (see Fig. 2) or to heat air. In addition, in PFBC, one can ciean the fiue gas (remove particulates) and use it to drive a gas turbine.

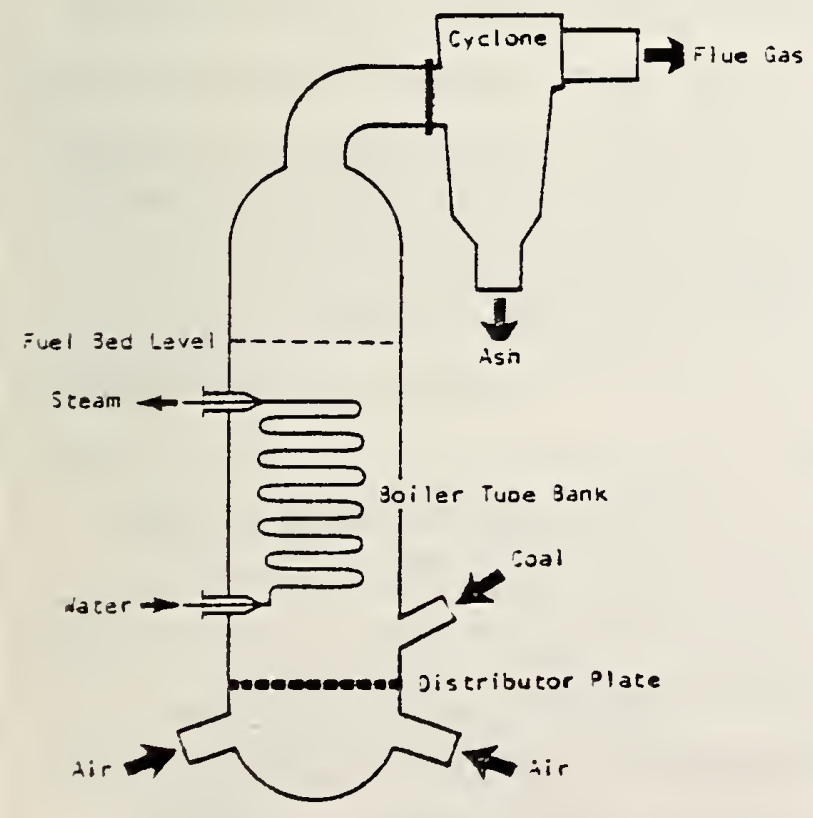

Figure 2. Schematic illustrating the principles of fluidized bed combustion (from Ref. 1, p. 207).

This technology appears to be promising because there do not seem to be major barriers to commercialization (with the exception of fireside corrosion); besides, meeting environmentai standards is quite possible.

There are a number of rather obvious instrumentation and materials needs. As far as the feed system is considered a reascnably accurate measurement of the coal (and limestone) solid-mass flow is required. It is highly desirable to determine the concentration and size distritution of the particles in the 
flue gas, as well as its chemical composition, particularly with respect to alkali content. Another very important parameter is a reliable indication of the bed level. One uses for the latter purpose differential pressure devices which, unfortunately, tend to plug up. An essential measurement is that of temperature, at several heights in the bed. Thermocouples have two problems: short life due to the corroding atmosphere and very slow response time. d. Gas Turbines 5

Instrumentation in gas turbines will be of particular interest in the 1980 's. The interest arises both from the cost and limited supplies of conventional fuels. The high cost of the fuels requires an accurate description of the temperature and heat fluxes within the turbine in order to optimize the operating temperature, and thereby the efficiency, while still maintaining reasonable durability. At the present fuel cost, design changes which effect only a $0.2 \%$ increase in the engine efficiency are being implemented. In the aircraft gas turbine industry, cost of turbine degradation due to the use of the higher temperatures is now approaching $\$ 10^{9} /$ year. Therefore, the potential benefits resulting from improved instrumentation are enormous.

Gas turbines are often fueled by synthetic gas from a gasifier or from a pressurized fluidized bed combustor. The hot gases exiting from the turbine can be used to drive a steam generator (see Fig. 3). It is especially important that the particulate loading of the gas entering the turbine will be maintained at an extremely low level to avoid erosion and corrosion.

The importance of understanding the dynamic as well as the average conditions in the gas turbine introduces the need for diagnostic measurements of gas temperatures, gas composition (particulates, alkali, etc.), velocities, heat fluxes and corrosion and erosion rates in the combustor and downstream turbine. Fast response instrumentation implies unique materials problems, for the sensor dimensions must be extremely small and stable to be useful. Subtle metallurgical solutions are required to isolate signal generating elements on compressor or turbine airfoils. A high temperature thin film technology must be developed to enable measurements which measure the variable of interest without perturbing the aerodynamics or heat transfer near the turbine component or diagnostic control element. An example of design requirements for erosion/corrosion sensors is presented in Appendix III (Case Study d). 


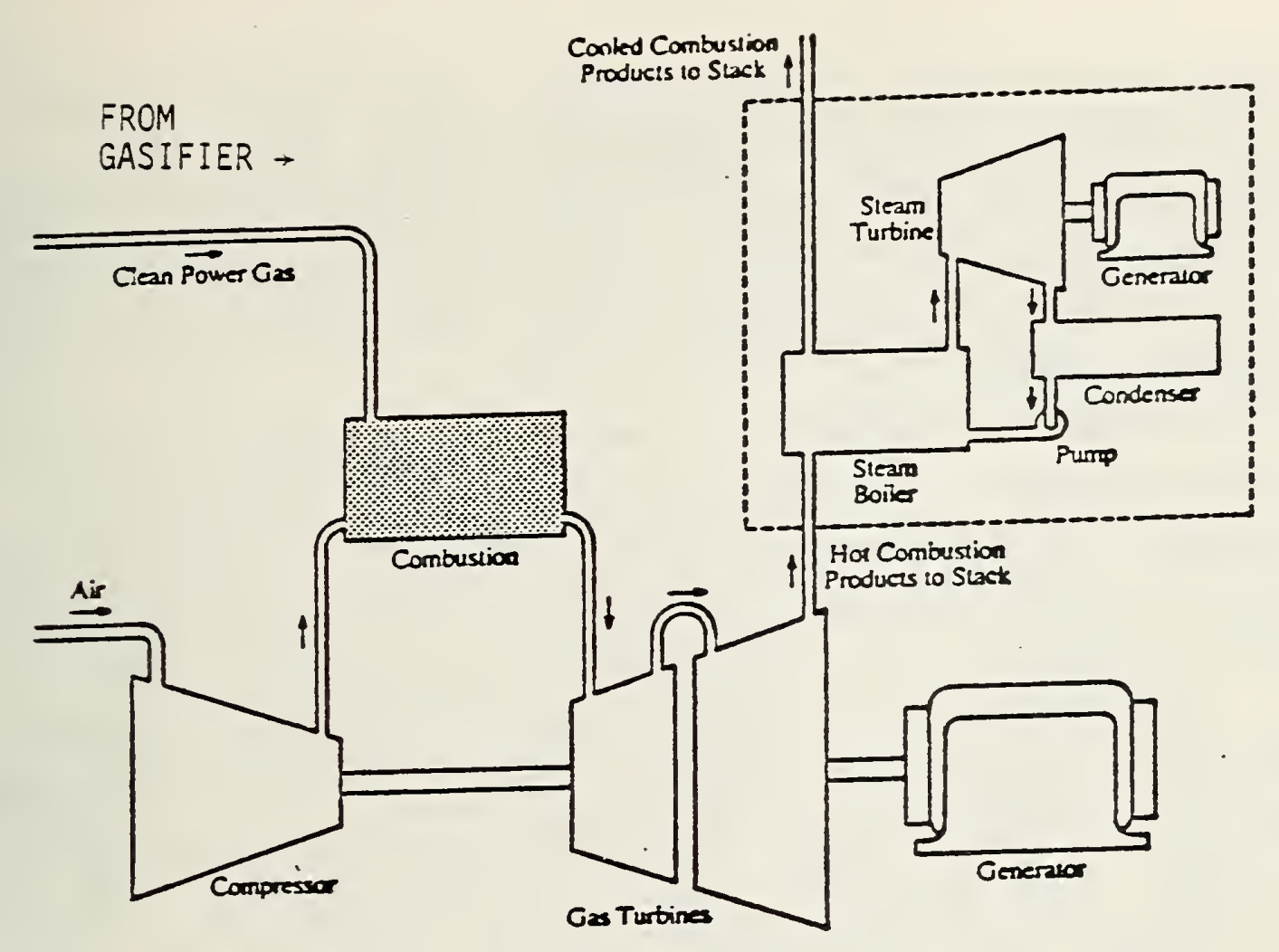

Figure 3. Combined-cycle gas and stream turbines fueled by power gas. Air from the compressor is mixed with the gas from the gasifier and burned in the combustion chamber. Heat in the gases leaving the gas turbine is captured in a stream boiler to produce additional power with the result of nigh overall efficiency. [From "Clean Power from Fossil Fuels", by Arthur M. Squires, from Ref. 5].

e. Magnetohydrodynamics (MHD) ${ }^{6}$

The basic principle of open cycle MHD is the direct conversion into electricity of the energy released by the burning of fossil fuel (coal, oil or natural gas). Because the process takes place at high temperature the efficiency is high. A stream of high-speed, very hot gases, produced in a combustor and made electrically conductive by seeding with alkaii, is passed through a transverse-oriented magnetic field. The resulting current, perpendicular to the gas stream and to the magnetic field, flows into electrodes, which permit the passage of $D C$ current to the load. The gases exiting from the generator are still hot and can be used to drive 
a conventional steam plant. Such a combined cycle plant should have an overa 11 efficiency of $50 \%$ or more compared with about $37 \%$ for large conventional coal or $0 i l$ buring installations. Besides the high efficiency, the fact that most of the sulfur will react with the alkali-seed and therefore be eliminated from the exhaust makes the MHD process attractive from the environmental point-of-view.

Realization of this promise is, however, not an easy task. The very severe operational conditions put heavy strains on the materials requirements. The temperature of the gas in the burner is $2600-2800{ }^{\circ} \mathrm{C}$, which demands intense cooling of the combustor walls. If the fuel is coal, slag will condense on the wall and contribute to the heat insulation. In many cases the metal is lined with a layer of refractories to produce an additional thermal barrier. However, little is known about the thermal conductivities of these ceramics and of solid and molten slag at these temperatures. Such lack of data leads to large uncertainties in the combustor design and in the parameters of the gas, seed and slag in the burner.

Somewhat similar conditions exist in the MHD channel. The wall temperature can vary from a few hundred ${ }^{\circ} \mathrm{C}$ in the case of metal electrodes (e.g., copper) to values between 1500 and $1900{ }^{\circ} \mathrm{C}$ when the electrode material is a refractory ceramic. The thermal flux through the electrodes and insulators can be as high 100-300 $\mathrm{W} \mathrm{cm}^{-2}$. Because of their large heat conductivity metal electrodes can be as thick as $1-10 \mathrm{~cm}$, but ceramic electrodes and insulators, being very poor heat conductors, must be $5 \mathrm{~mm}$ or thinner. Hence, the thermal gradients are very high and thermal shock resistance is an important consideration.

Furthermore the electrodes must be able to sustain considerable electrical current densities of the order of 1-2 $\mathrm{A} \mathrm{cm}^{-2}$. Such large currents can produce significant electrochemical effects, drawing $\mathrm{K}^{+}$- and $\mathrm{Fe}^{2+}$ or $\mathrm{Fe}^{3+}$ ions deep into the cathode (and $\mathrm{O}^{2-}$ towards the anode). The large electrical currents also produce arcing through the gas boundary layers and breakdown in the solid slag and in the electrodes. The latter effects are major sources of electrode degradation. 
Finally, one has to deal with chemical interactions between seed, slag or vapor species and the wall materials. Not the least of these chemical problems is the absorption of water on cooling and the resulting swelling of ceramic insulators and/or electrodes. The oxygen partial pressure next to the wall is about $10^{-3}$ atm which constitutes a slightly oxidizing atmosphere, and thus gives rise to considerable metal corrosion at these high temperatures.

Further down the flow train there are still other difficulties: air preheater materials and boiler tubes that must be resistant to alkali corrosion and slag particle erosion, seed recovery (which has to be better than 95\%) and finally the usual environmental requirements of $10 \mathrm{~W} \mathrm{NO}_{\mathrm{x}}$ emissions.

Although the problems seem to be immense, systematic materials research and testing, as well as careful measurement of all the process parameters should be able to provide most, if not all of the solutions. During the last 7 or 8 years a considerable amount of materials science and engineering, both in the Soviet Union and in the U.S. (as well as collaborative studies by the two countries), 7 have greatly contributed to a better understanding of the various physical and chemical processes taking place along the flow train. Many tests conducted in small test rigs as well as in large MHD-installations have shown that generator and diffuser materials can survive for periods of at least 200 to 500 hours. During these tests the importance of frequent recording of several parameters became abundantly clear. Thermocouples embedded in the generator walls gave continuous information about the temperature of the channel surface (inside), the temperature of the cooling water and the temperature gradient. These data presented an excellent check on the operation of the main channel. Yet the thermocouples are bulky and tend to degrade (with the electrodes). Smaller and more durable thermocouples and protection are needed.

Much more difficult is the measurement of the surface temperature of flowing slag. Pyrometers could be used if the emmisivity of the slag (at approximately $1800^{\circ} \mathrm{C}$ ) were known more accurately.

Other quantities that are being recorded in MHD installations and test rigs are the cross channel voltages and currents, Hall angle, interelectrode voltages and magnet current. Slag concentration and particle sizes have been measured in one experimental MHD facility. One would like to extend such techniques for (both slag and seed) to all MHD facilities, small and large. 


\section{References}

1. N. Berkovitz, "An Introduction to Coal Technology", Academic Press, New York, 1979, p. 250.

2. Ref. 1, p. 302 .

3. "Overview of Coal Conversion Process Instrumentation", Argonne, Nat1. Lab., Tech. Memorandum \#1, May 1980 (ANL-FE-49628).

4. C. L. Herzenberg, et a1., "A Study of Instrumentation Needs for Process Control and Safety in Coal Fluidized Bed Combustion Systems", Argonne National Laboratory, Report ANL/CEN/FE-80-12, (1981).

5. A. M. Squires, Scientific American 227, 26 (1972).

6. S. J. Schneider, et al., Chapter 3 in Current Topics of Materials Science, Vol. 4, Ed. by E. Kaldis, North Holland Publ. Co., Amsterdam, 1980, p. 89.

7. "Open Cycle Magnetohydrodynamic Electrical Power Generation", General Editors, M. Petrick (USA) and B. Ya Shumyatsky (USSR), Argonne National Laboratory, Argonne, IL 1978. 
APPENDIX II.

a. A Sample of Organizations Involved in Research for Instrumentation and/or Materials in Fossil Energy

Argonne Nat1. Laboratory

(slurry) flow, erosion/corrosion, temperature, chemical analysis

Oak Ridge Nat1. Lab.

Sandia Labs., Livermore

on-line sampling, heat exchangers, pressure vessels, coal properties

particulates, laser diagnostics

coatings, erosion (in fluids)

Nat1. Bureau of Standards

properties of slag/flyash, corrosion/erosion, fracture, thermodynamics, $\mathrm{SO}_{x}$, $\mathrm{NO}_{x}$,

Materials Data Center

Exxon Res. \& Eng. Labs.

IITRI-Metals Properties Council

coal properties, catalysis, valves, etc.

Stanford University

W. Virginia University.

Pittsburg \& Midway Mining Co. (Gulf)

Grand Forks ETC

Bartlesville ETC

Pittsburg ETC

Westinghouse

corrosion of metals and alloys in F.E.

plasma diagnostics, particulates (MHD)

properties and analysis of coal

coal properties, viscosity

coal analysis

thermodynamics (coal \& coal derivatives)

combustion, catalysts

properties of materials for gasifiers, test facility for MHD materials

Mississippi State University

corrosion/erosion, seed recovery (MHD), temperature (optical)

Univ. of CA-Berkeley

erosion/corrosion, solubility of coal

Penn State University

Montana State University

coal characteristics, structural ceramics

transducers, electrodes (MHD)

General Electric

Pratt and Whitney

Battelle

Southern Res. Institute

NASA (Lewis)

U.S. Geological Survey

Illinois Geological Survey

claddings for high temperature turbines

erosion/corrosion (turbines)

modeling of heat flows, erosion/corrosion

particulates, metal properties

new alloys for gas turbines

coal analys is

coal characterization

Purdue University

thermodyn. \& kinetics of coal liquids

Fluidyne Co.

Avco-Everett Research Lab.

refractories (testing-MHD)

gas flow, heat transfer (MHD)

Babcock and Wilcox

stress analysis of refractories, metal corrosion

Massachusetts Inst. of Technology

material properties at high temperature

University of Minnesota

corrosion 
b. SCIEP (Society for Control and Instrumentation of Energy Processes) President: Herb Kaplan, Crest Energy Systems, Inc., (Norwalk, CT)

Subcommittees:
a) Advanced Technical Requirements
b) Control Systems Development
c) Environmental Control
d) Flow Measurements
e) High Temperature

f) Level and Pressure

g) On-stream Analysis-Gas

h) On-stream Analysis-Solids

i) Particles

j) STurry letdown valves

k) Viscometry
Principal Organizers: Nancy O'Fallon, Argonne Natl. Lab. Harold Horowitz, IBM/FDS John Walsh, Jet Propulsion Lab. Peter Alexander, TRW Energy Systems Herb Kaplan, Crest Energy Systems and Fred Zweibaum, Barnes Eng. (Radiometry)

Mike Barroody, Catalytic Inc.

Frank Finch, Los Alamos Sci. Lab.

Carol Herzenberg, Argonne Nat1. Lab. Jim Wang, Sandia Labs (Livermore)

Armand Bosso, Stearns-Roger Joe McDonald, Haake Inc. 
APPENDIX III.

Case Study a. Flow Measurement Research for Coal Slurry Flows

Realization of technologies for the liquefaction or gasification of coal on a commercial scale will require measurement capabilities for many process parameters, flow measurement being one of the foremost. Achievement of automatic process control capabilities will of course require on-line measurement methods. In many processes the input to the system involves the pulverization of coal which is then slurried with either water or with oils recycled from the process. The Solvent Refined Coal process is an example of this type of process fluid feedback. Automatic control of the formation of these slurries will require a flow measurement of the slurry stream to control the material balance in the reactor. At this point in the process the flow regime is solid-liquid in nature. Addition of hydrogen to the slurry changes the system to a gas-liquid-solid system. The fluid dynamic characteristics of two and three phase systems are not well understood or elucidated. This is particularly true for flow measurement technologies which are not in as mature a state of development as are those for single-phase fluids.

The conditions imposed upon future flow measurement technologies useful for liquefication and gasification process are typical of an extremely harsh environment. The environments of liquefaction processes are those of high density coal slurries (two or three phase) at varying levels of temperatures and pressure. Recirculation of the slurry is done in many processes which requires mass flow measurement of near reactor operating temperatures of approximately $850^{\circ} \mathrm{C}$. Obviously this is a highly erosive and corrosive environment. Additionally, the properties of the fluid further complicate the situation since the viscosity of the recycled solvent is high approaching 2000 centistokes.

Two generic approaches to flow measurement in two and three phase streams may be considered, the first case is the intrusive one and requires direct contact of the flow sensing elements with the flowing environment, that is, modification of the streams fluid dynamic behavior for the metering purposes. Non-intrusive devices are mounted externally to the flow and depend upon modification of an impressed field of some type with subsequent detection of that modification by the flow. These impressed fields, usually optical, acoustic, electromagnetic or nuclear, must penetrate the piping containing the flow. Therefore, spool pieces or 
windows are necessary which are either transparent or translucent to the applied radiation field. In the case of electromagnetic and nuclear radiation, non-ferrous materials which will withstand the erosive, corrosive high temperature and pressure environment are necessary. Various types of coatings may be useful where only relatively thin layers of erosion resistant materials may be laid down upon the material of the spool piece wa11. Nuclear radiations require a low absorption cross-section to achieve penetration to the flow field. In the case of neutron activation methods the spool piece must be reasonably transparent to both excitation neutrons and the delayed gamma rays used for the measurement.

Intrusive methods have been developed extensively for single-phase flow measurements. Adaptation of these techniques to solid-liquid or solid-liquid-gas systems poses a considerable materials problem. These methods are based upon the changes in the pressure field of the flow by partial obstruction of the cross-sectional area of the pipe, thereby producing a differential pressure.

Nozzles and orifice plates are the most widely used geometries for this purpose. This type of metering technique even for single-phase fluids requires considerable research to be useful for accurate flow measurement purposes. Empirically determined coefficients are necessary to completely characterize metering performance. Adaptation of these techniques to two and three phase solid-liquid flows must be expected to require similar empirical methods given the current state of physical understanding for systems of this type. Therefore, values of discharge coefficients, i.e., the ratio of observed to theoretical flow rate, will be necessary to evaluate these systems. In the case of orifice plates the discharge coefficient adjusts for an approximate $40 \%$ difference between actual and theoretical flow rate.

Successful adaptation of these differential pressure producing flow measurement devices is attractive because the response of the devices is reasonably simple, well developed commercially and reliable in operation.

A materials problem has been solved in this case. Use of a superalloy, stellite, has been successful in maintaining a response that provides process measurement information [Source: Canfield-SRC-II Pilot Plant, Ft. Lewis, WA], although the pressure taps necessary for the differential pressure response measurement must be opened and cleaned several times daily. Such a high level of maintenance is not acceptable for demonstration or commercial scale plants. Investigation of fluid dynamic phenomena around pressure taps 
including methods or shapes which inhibit fouling of the tap coal particles will provide a crucial step to the use of these types of flow measurement devices for liquefaction and gasification processes.

Utilization of intrusive devices for flow measurement will require some level of testing under conditions similar to those of plant environments. Therefore, the need for flow loops for testing and research and development are a necessary step in this direction. A wide range of instrumentation would be provided with a test bed by such a facility. Additionaliy, the experimental facility would be available to perform fluid dynamic research directed toward a broadened understanding of dense phase flow phenomena. The greatest impact on flow measurement technology would probably be to intrusive types of devices. Certainly such a facility would allow the determination of discharge coefficients for differential pressure producing devices of various geometries. Testing of phase concentration measurement techniques would be possible in flows of known concentration.

Such a flow loop would provide the means to investigate the effect of impingement angle upon the erosion rate of surfaces exposed to the flow. Some theoretical and experimental efforts exist in this area although it is not extensive $[1,2,3]$. Such information would provide the means to design geometries for a wide range of uses in these highly erosive environments which have minimum erosive and ablative characteristics. For flow metering purposes a geometry may exist which has low erosion characteristics because the range of impingement angles occur over a particular range. Given this information nozzle geometries for flow measurement could be designed which combined erosion resistant materials with minimum erosion conditions to produce a long-lived and reliable flow measurement device. Of course, the emphasis here is the combination of research in the areas of fluid dynamics. of both dense-phase and particulate laden streams and materials science to produce useful and reliable flow metering techniques.

\section{References}

[1]. Carter, G., Nobes, M. J. and Arshak, K. I., WEAR, 53 (1979) 245-261.

[2]. Yeung, W., WEAR, 55 (1979) 91-106.

[3]. Tabakoff, W., Kotwal, R. and Hamed, A., WEAR, 52 (1979) 161-173. 
Case Study b. Acoustic Char-Flow Monitors for the BI-GAS Pilot Plant*

Background/Requirements

At the request of the BI-GAS pilot-plant personnel, the ANL Fossil Energy I\&C group proposed methods of instrumenting the process to obtain an indication of a stoppage of char flow in each of three char-flow lines. The technique selected for development relied upon the use of a hightemperature sodium-immersible, acoustic-monitoring microphone developed in the DOE LMFBR program. The basis for this technique was a result of conclusions reached from an ANL test on the HYGAS pilot plant, which indicated that the presence of fine solids in a flowing stream attenuated sound. The microphone was selected because it could withstand the $850^{\circ} \mathrm{F}$ and 2000-psi steam environment within the BI-GAS char-flow Iines.

Sensor Location/Construction

A steam eductor, used to entrain the char in the steam flow, is the broadband noise source of the sound which was expected to be attenuated by the fine solid char particles. A microphone was installed in the BI-GAS reactor in the char-flow line at the position shown in Fig. 1. The construction details of the microphone are shown in Fig. 2. The details of the microphone installation are shown in Fig. 3 , where the microphone is placed in a holder supported by the Grayloc blind flange and then mounted in the Tee section. Figure 4 is a photograph of the mounted microphone with the leads penetrating the Grayloc blind flange. The microphone is positioned in the char-flow line in a wide slot in the pipe wall, such that its outer edge is placed even with the inside surface. The microphone is placed in this position so that it will not be subjected to direct impingement abrasion or erosion of the particles in the flowing stream, but will still have a direct acoustic path from the flow stream.

Basis of Operation

Acoustic measurements were made via the arrangement shown in Fig. 5. The measurements indicated that, within a limited frequency band, the presence of char did attenuate the normal acoustic spectrum present during steam flow, and hence, a signal could be derived that would indicate, in a quantitive manner, the presence of char flow. The spectral analysis of the microphone signal is shown in Fig. 6 for various rates of char flow. In each

\footnotetext{
*This article is a summary of the information in Technical Memorandum ANL-FE-49622-TMO8, "An Acoustic Char Flow Monitor for the BI-GAS Pilot Plant", by P. D. Roach and A. C. Raptis, July 1979.
} 
part of the figure, the upper trace is the spectrum of the signal when only steam is flowing in the line. The lower trace is the spectrum taken when char is also flowing. The exact amount of char was not known, but the relative flow rate was inferred from valve openings and readings of differential pressure instruments. Figures $6 \mathrm{a}, 6 \mathrm{~b}$ and $6 \mathrm{c}$ correspond to low, moderate, and high relative flow rates, respectively. The lower trace in Fig. 6d shows the spectrum with no char and no steam flowing.

\section{Electronics}

An instrument to process the microphone signal and provide both the flow/no-flow indication and the char-density indication was designed. The block diagram for this instrument is shown in Fig. 7. The microphone signal is first amplified in an external charg amplifier and then is sent to the flow monitor, where it is analyzed into three different frequency bands by bandpass filters. The RMS detectors and LOG RATIO converters generate a $D C$ voltage proportional to the log of the ratios of the amplitudes in the frequency bands. The A signal is the lowestfrequency component and is least attenuated by the char, so this signal is taken as the amplitude reference. The other two signals are then normalized to this reference, the result being fed to a voltmeter for the intermediate band and to a voltage comparator for the high-frequency band. The high frequencies are most sensitive to the presence of char, and this signal (signal $C$ ) is used for the flow/no-flow indication. Whenever the high-frequency signal drops below a certain level relative to the lowfrequency band, the CHAR FLOW light turns on.

The intermediate-frequency band (signal $B$ ) is less sensitive to the presence of char, but gives a usable signal over a wider range of char density. This band is used to give a continuous indication of char density. It is expected that the signal derived from this intermediate-frequency band can be calibrated in terms of actual mass density of char in the pipe. Then, if flow velocity can be determined, the mass flow rate of char would be obtained.

Qther features that have been incorporated into the flow monitor permit external use of its signals and provide indications of proper operation. Both voltage and current outputs are provided for driving a recorder or a process-control system with the char-density signal. These outputs have adjustable gain and time constant. The flow/no-flow signal is used to provide a contact closure for an external alarm system. But 
the contacts will close only if the unit has power and the input signal is within specified bounds. This guards against misleading CHAR FLOW indications that might be based on signals outside the range of accuracy of the circuit.

Front-panel indicators show if the input signal is too large or small, and the panel meter may be used to check various circuit voltages. But for comprehensive testing of circuit function, it is necessary to inject known test signals. For this purpose, a separate test module has been constructed. This module provides four different signals designed to confirm proper operation of all the flow-monitor circuits. In this way, each flow monitor can be quickly checked out, either as part of a routine maintenance procedure or when the operator suspects a malfunction. The finished flow monitor is shown in Fig. 8. Three identical modules are shown, one for each of the three char-feed legs. Also shown is the module used for testing the flow monitor.

Other Applications and Needed Research

This acoustic-attenuation technique is generally applicable to the measurement of solids-density flow and, when used in conjunction with cross-correlation techniques to get flow velocity, mass flow can be obtained. In the case of BI-GAS, a source of broadband noise was already present in the flow stream; for other flow streams, an acoustic source may have to be introduced. Development of such sound sources may be useful for other applications involving this technique.

The ANL high-temperature microphone can be used as a transmitter but it is not very efficient, particularly in a gaseous environment. The microphone does not lend itself for use at high-power, high-frequencies and, new bonding construction techniques would be needed to use it for an effective transmitter.

To make the acoustic attenuation technique useful for highertemperature fossil-fuel combustion/conversion applications (above the 650-750 ${ }^{\circ} \mathrm{C} 1$ imit of the microphone), new sensors/sensor construction, or new techniques of measurement using existing sensors must be developed. Two basic deficiencies limit the use of the microphone sensor at high temperature.

1. Despite the fact that the lithium niobate piezoelectric element in the microphone has a Curie point of about $1200{ }^{\circ} \mathrm{C}$, the apparent resistance of the microphone decreases to a point where the signai conditioning equipment fails to operate as temperatures approach $700{ }^{\circ} \mathrm{C}$. This is due to the low source impedance of the lithium niobate. To correct this, either new piezoelectric materials or new methods of amplification are necessary. 
2. At temperature above about $500{ }^{\circ} \mathrm{C}$, the oxygen comsumption in the microphone becomes excessive to the point where, after an interval of a few months at $650{ }^{\circ} \mathrm{C}$, the sensor can indicate a short and fail to operate. Upon replenishment of the oxygen supply in the sensor, the faulty operation is corrected. For applications where the sensors cannot be accessed, an oxygen reservoir is provided to extend the time interval between regenerations. Selection of materials to slow down the absorption of oxygen from the surface of the lithium niobate or incorporation of materials to provide sufficient oxygen is needed. 


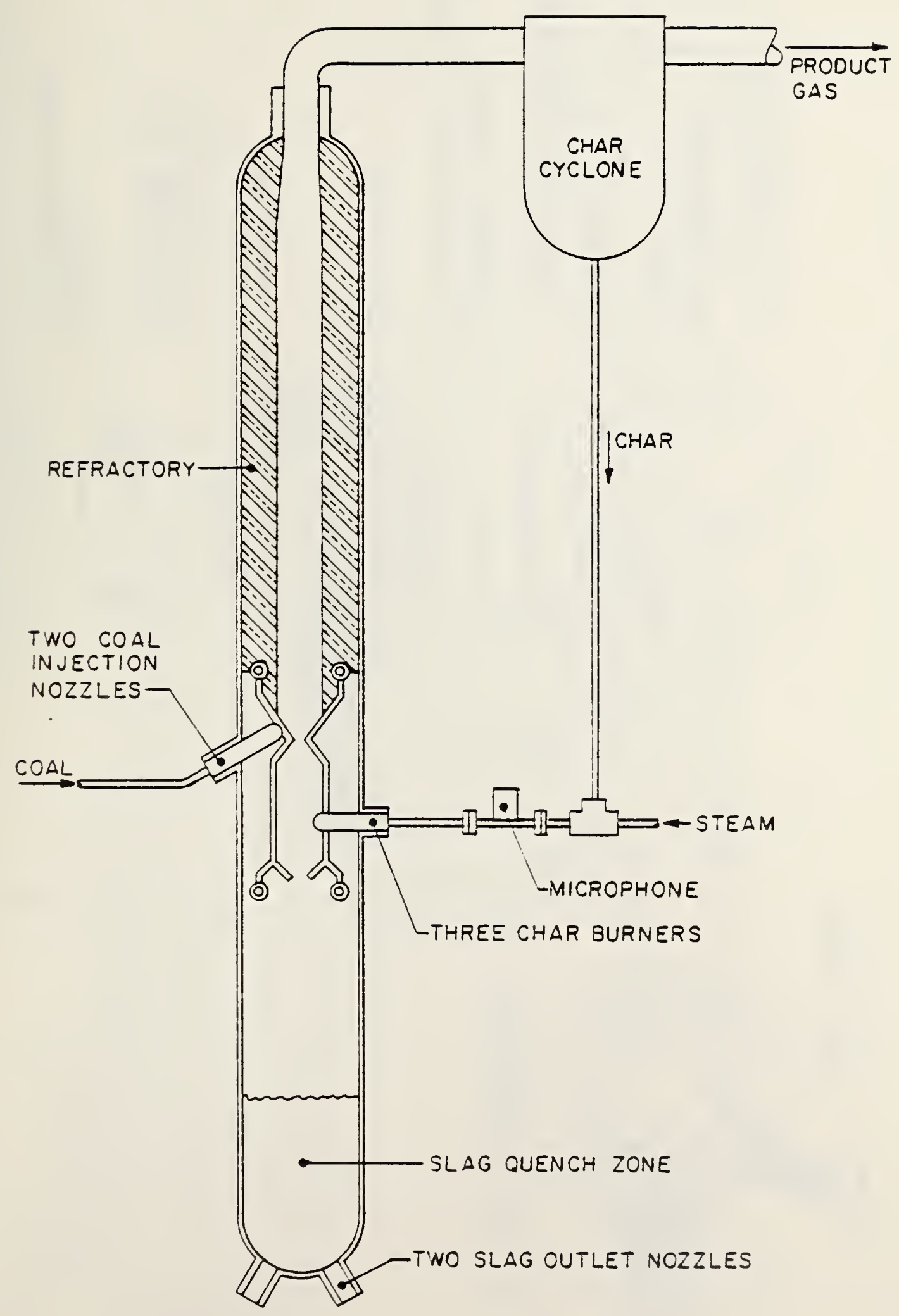

Fig. I Schematic Diagram of SI-GAS Reactor 


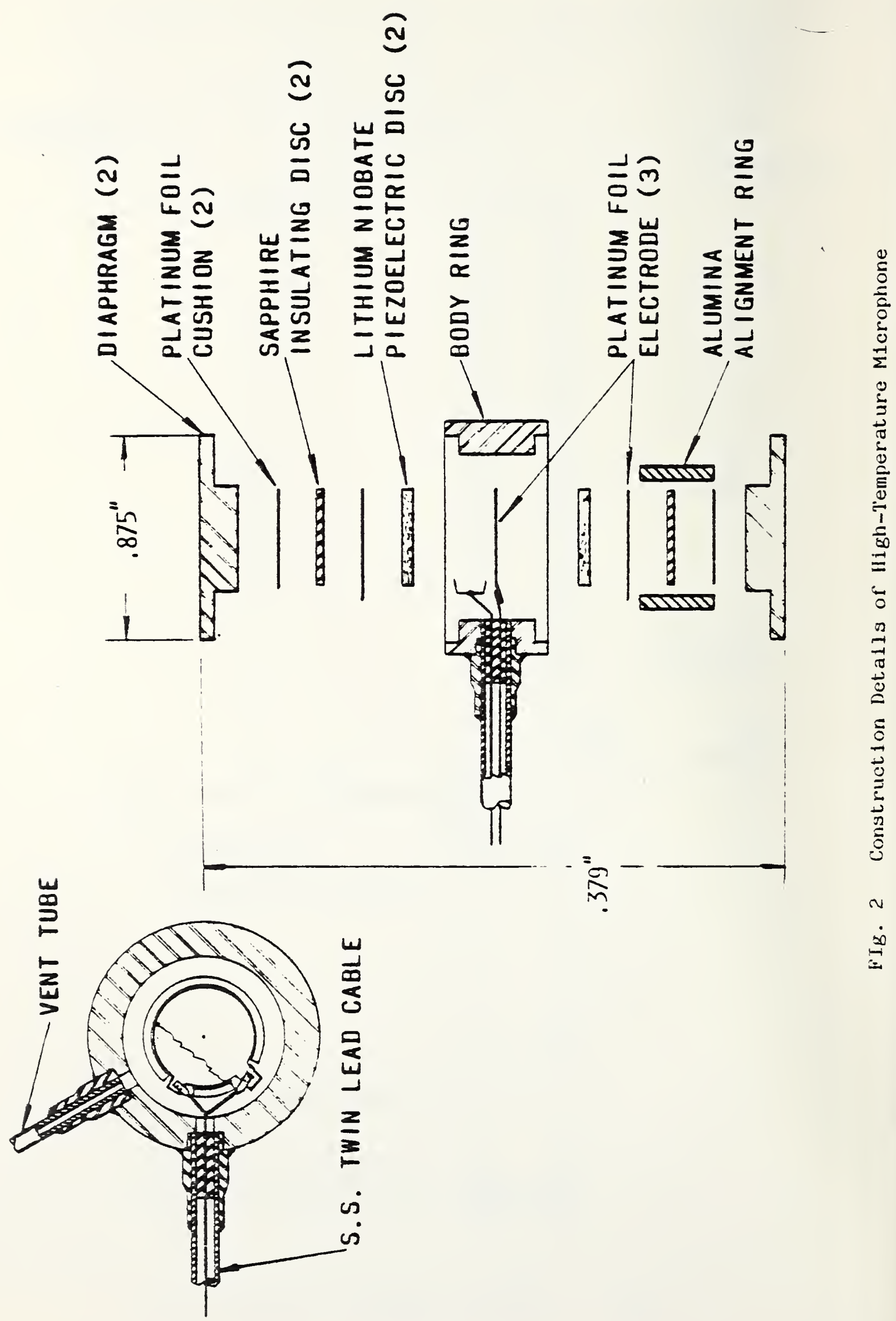




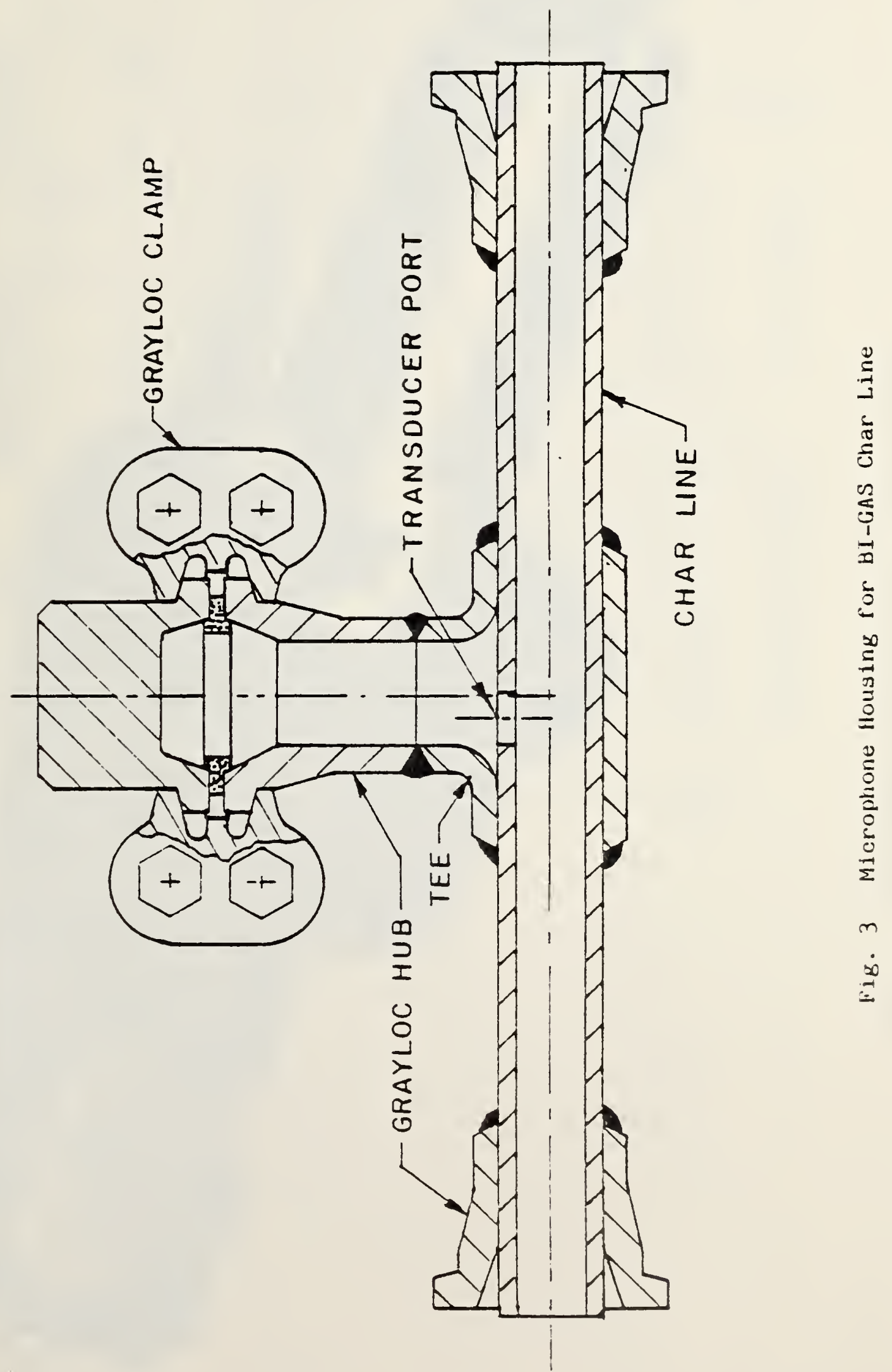




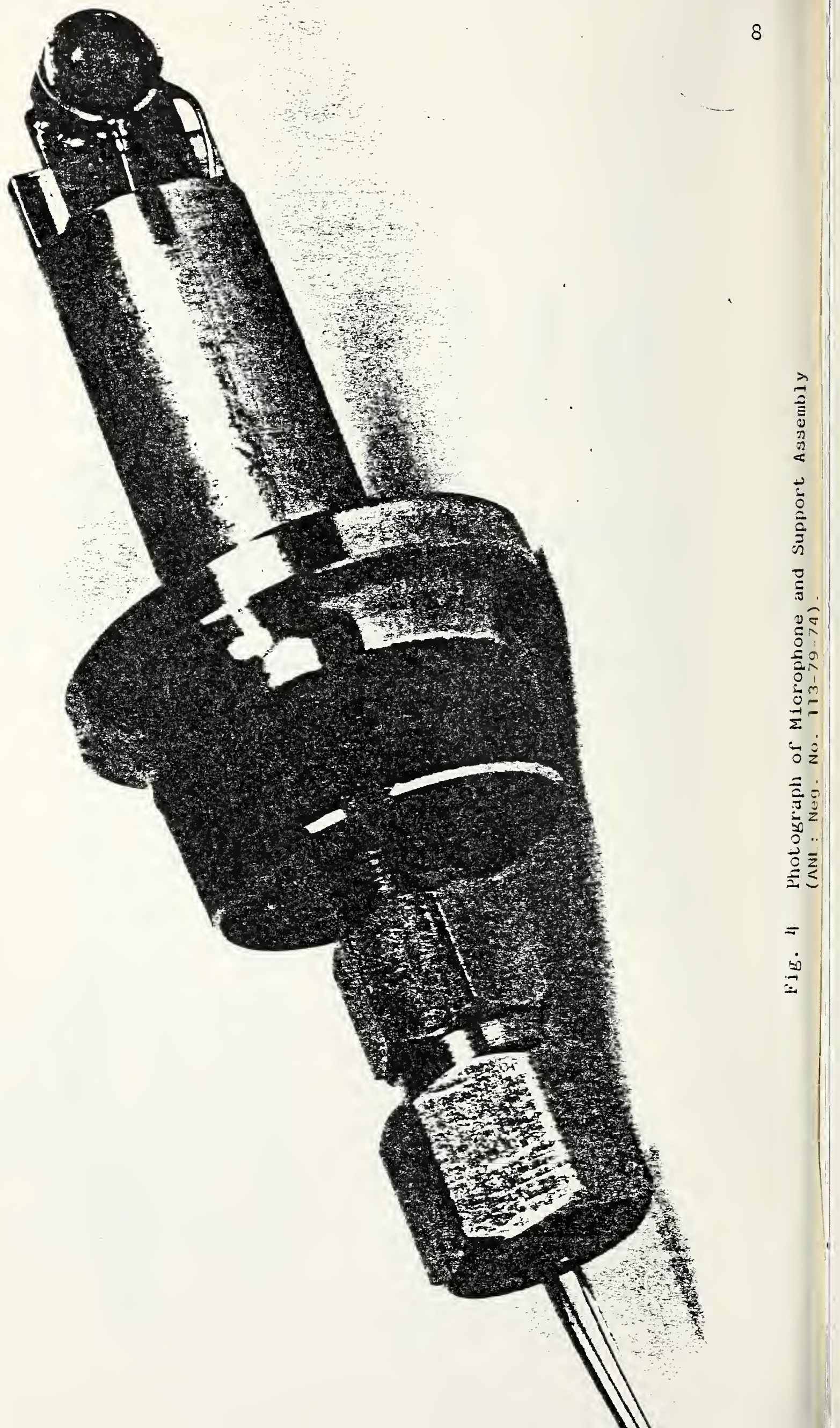




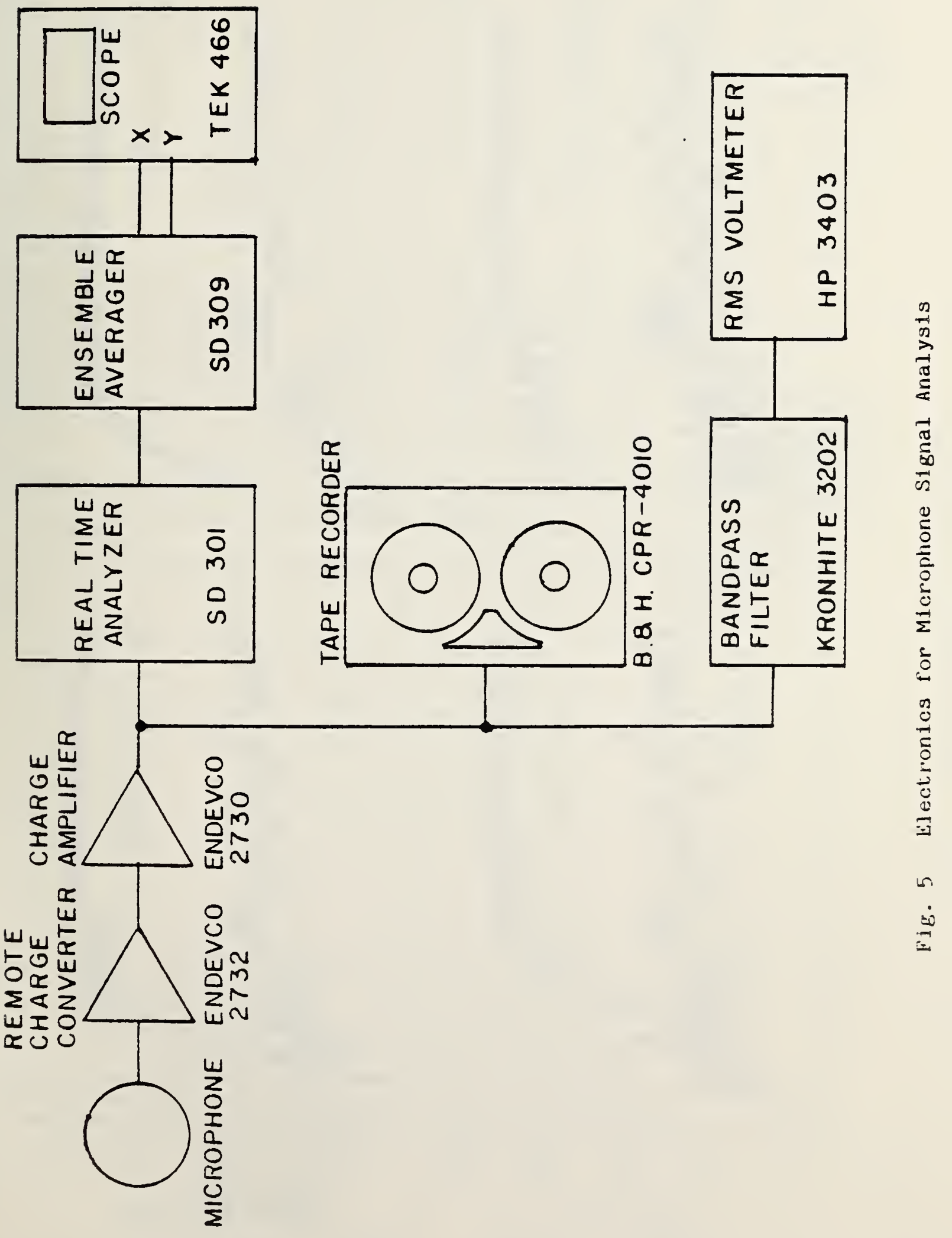



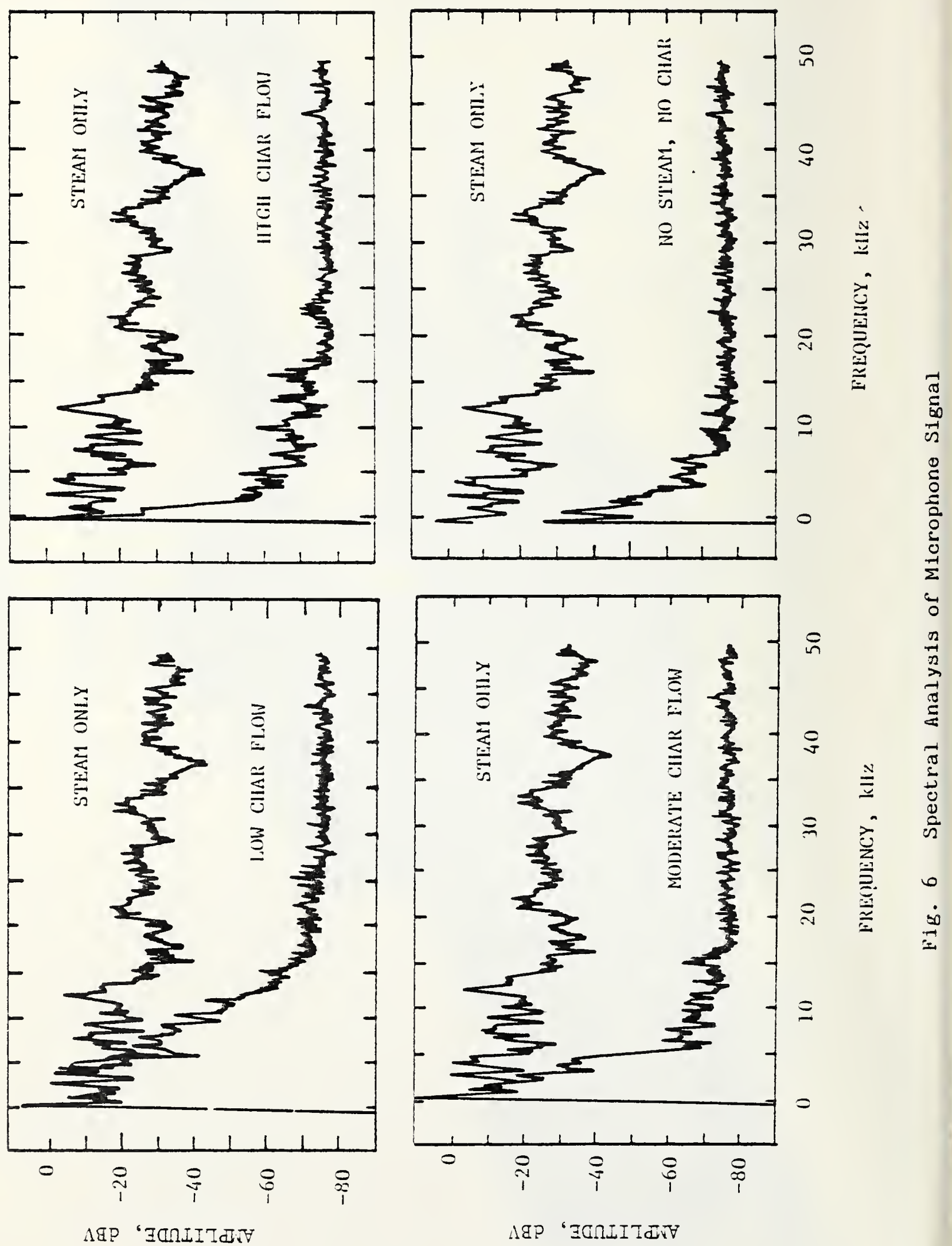


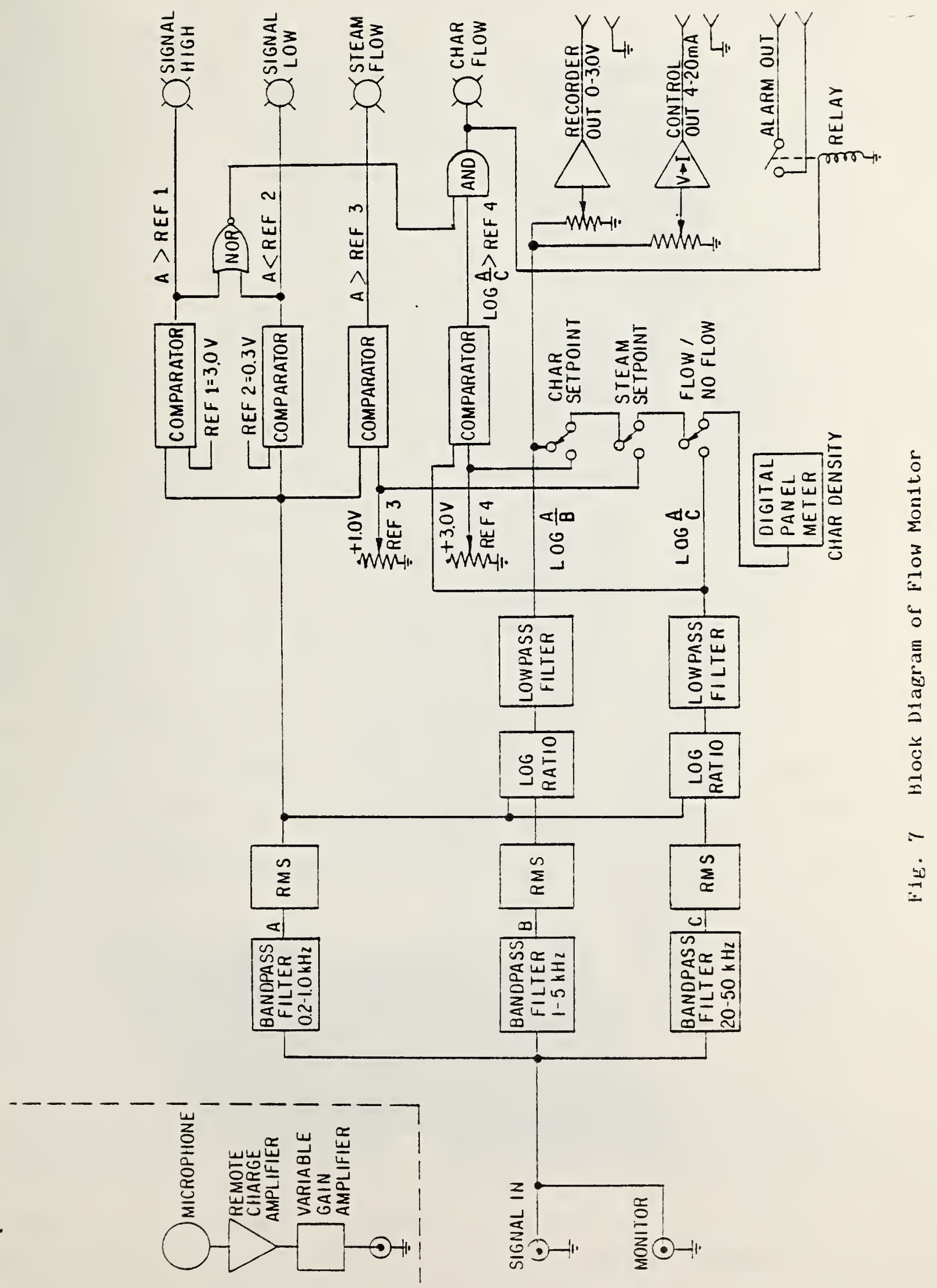




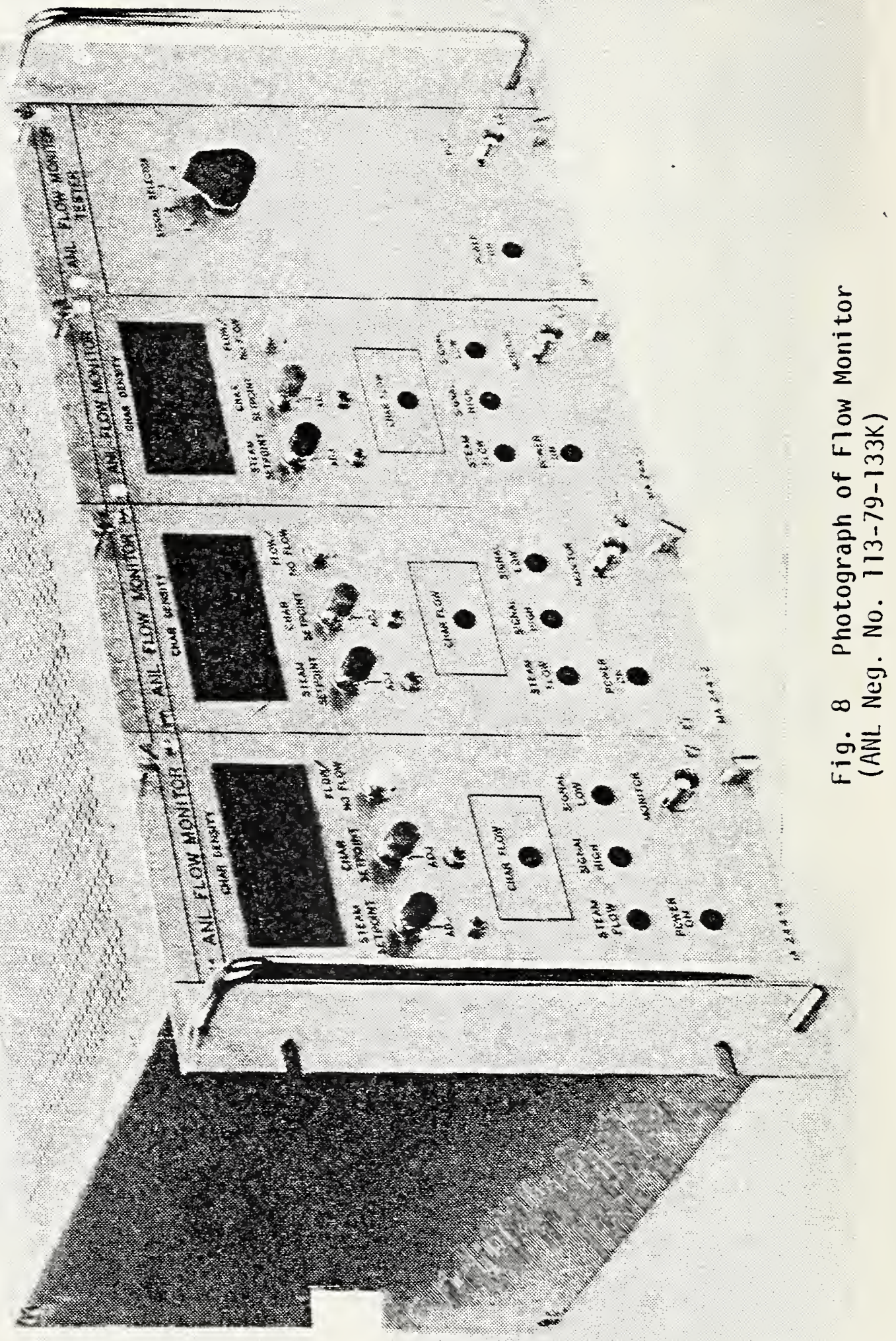


Case Study c. Temperature Measurement in Coal Gasifiers (G. W. Burns - NBS)

Second generation coal gasification technologies, such as the BiGas and Hygas processes, under evaluation for producing pipeline quality high BTU gas, place severe operating conditions on materials and components. The most severe conditions occur within the gasification zone of the reactors where a high temperature, high pressure, erosive and corrosive environment exists which can quickly destroy conventional materials and components. Of the new gasification technologies, some of the most stringent material requirements are associated with the BiGas process, owing partly to its higher operating temperatures.

According to Pitcher [1], one of the most critical components needed for controlling and monitoring the BiGas gasification process is the high temperature instream temperature sensor. The sensor should record the gas-particle stream temperature with an accuracy of $0.5 \%$ or better, should have a life of 8000 hours or more, and should have a time response of less than 0.5 seconds.

The BiGas pilot plant, which was put into operation in 1976, has a 2-stage, entrained-bed, high pressure, oxygen-blown, ash-slagging gasifier. In stage 1 of the gasifier a mixture of hot char, oxygen, steam, and fue 1 gas is injected by way of three char burners. Finely ground, pulverized coal is introduced into the gasifier, along with steam, by two coal injectors located just above stage 1. (See Fig. I of Case Study b). In most runs the gasifier is operated with the containment vessel pressurized to $750 \mathrm{psig}$. Temperatures in stage 1 are typically 1450 to $1650{ }^{\circ} \mathrm{C}$ while the temperatures in stage 2 (entrained-bed section) range from about 750 to $1000{ }^{\circ} \mathrm{C}$.

In the approximately 2-meter high stage 1 zone, there are three pressure taps located near the top, middle and bottom of the zone for installing temperature sensors. The pressure taps are water-cooled and wi11 accept a device having a diameter of up to $17 \mathrm{~mm}$. Four similar taps are also spaced through the stage 2 zone which is about 8 meters high and has a 0.7 meter inner diameter.

It is interesting to note that when the BiGas plant was put into operation, thermocoupie assemblies consisting of tungsten-rhenium thermocouples protected by a molybdenum disilicide coated molybdenum sheath inserted in a silicon carbide thermowell were installed in stage 1 and 2 . Many failures of these thermocouple assemblies occurred in both stages after operating times of less than 50 hours, due both to mechanical breakage and to what appeared to be chemical attack or solution of the silicon carbide thermowel1 [2]. 
These failures prompted plant personnel to experiment with various materials for thermowells. They found that assemblies consisting of stainless steel thermowells and stainless steel sheathed, compacted MgO-insulated, Type $K$ thermocouples provided much improved performance in stage 2 . As far as stage 1 is concerned, various materials, including alumina, mullite, zirconia, beryllia, molybdenum, and a molybdenum-zirconia cermet were tried but they offered little improvement. Of all the materials evaluated to date, chromic oxide coated molybdenum thermowells have provided the longest service (50 to 200 hours) in stage 1 . The plant is currently operating using such thermowel1s in stage 1, along with tungsten-rhenium thermocouples of the type described previously.

Post-test studies of thermocouple assemblies removed from stages 1 and 2 of the BiGas gasifier have been carried out at NBS [3]. Examinations of stage 2 assemblies that had about 200 hours of service revealed little corrosion or erosion of the stainless steel thermowells or of the stainless steel thermocouple sheath. However, the thermoelectric output of the Type $K$ thermocouples was found to be low by the equivalent of $25{ }^{\circ} \mathrm{C}$ at $1000{ }^{\circ} \mathrm{C}$, due to the preferential oxidation of chromium in the $\mathrm{Ni}-9.5 \% \mathrm{Cr}$ positive thermoelement.

Examination of several of the chromic oxide coated molybdenum thermowells, that had about 15 hours of gasifier service during a run in which the char feed rate was believed to have been about $24 \%$ higher than that normally used, showed that the chromic oxide coating had been completely removed and that the wall thickness of the thermowell had been reduced by as much as $0.8 \mathrm{~mm}$. The molybdenum thermowells were also very weak due to the formation of a grain boundary phase.

Thermocouple assemblies using the new highly stable, nickel-base thermocouple called Nicrosil/Nisil [4] have also recently been evaluated in stage 2 of the BiGas gasifier. Thermocouple assemblies, constructed by NBS, consisting of a stainless steel sheathed, compacted MgO-insulated, Nicrosil/ Nisil thermocouple protected by an aluminized type 310 stainless steel thermowe 11 have been operated for up to 600 hours in the gasifier. Post-test examinations have revealed calibration changes of less than $10^{\circ} \mathrm{C}$ in the thermocouples and no evidence of any appreciable compositional changes in the thermoelements. In addition, virtually no corrosion or erosion of the a) umininzed stainless steel thermowelis was detected. 
It seems likely that the necessary lifetime requirements can be met with such assemblies, but their response times are much too slow (minutes). However, the possibilies of using smaller devices fabricated from the same materials to gain a faster response appear promising in stage 2 .

It is highly unlikely, however, that the necessary lifetime and response time requirements can be met with contact type thermometers in stage 1 . Hence, development of non-contact thermometry techniques for such measurements is considered essential. Even so, work should continue to develop better materials for protecting contact type thermometers and to perfect more functional types and designs of such thermometers, since they will be needed to assess the accuracy of non-contact thermometry measurements.

Some investigations using an integrated radiometric system for determining temperatures in stage 1 of the BiGas gasifier have already been reported by Zweibaum et a1. [5,6]. They encountered problems with interpretation of the spectral test data owing to difficulties with keeping the instrument aligned and with keeping the fields of view of the two sensing heads superimposed. The alignment problem was aggravated by the small available diameter of the pressure tap in the gasifier wall. Nevertheless, their preliminary measurements showed that the two-color ratio technique is an appropriate technique to use for such temperature measurements.

\section{References}

[1] Pitcher, N. D., BiGas High Temperature Thermocouples - Design

Considerations and Operating Experience, Proceedings of the 1977

Symposium on Instrumentation and Process Control for Fossil Demonstration Plants, Chicago, I1linois, July 13-15, 1977, p. 367, (ANL-78-62).

[2] Walker, K. E., Status of the BiGas Pilot Plant Program, presented at Ninth Synthetic Pipeline Gas Symposium, Chicago, Illinois, October 31 November 3, 1977.

[3] Burns, G.W. and Scroger, M. G., Development of High Temperature Instrumentation for Coal Conversion Plants, DOE/NBS Interagency Agreement No. EA-77-01-6010, Technical Status Reports for June 1978 and October 1978.

[4] Burley, N. A., Powell, R. L., Burns, G. W., and Scroger, M. G., The Nicrosil versus Nisil Thermocouple: Properties and Thermoelectric Reference Data, Nat. Bur. Stand. (U.S.) Monogr. 161, 167 pages (Apri1 1978).

[5] Zweibaum, F. M., Kozlowski, A. T., and Surette, W. E., Integrated Radiometric System for Gasifier Temperature Measurements - Part 2, Proceedings of the 1979 Symposium on Instrumentation and Control for Fossil Energy Processes, Denver, CO, August 20-22, 1979, p. 442 (ANL-79-62/CONF-79055).

[6] Zweibaum, F. M., Kozlowski, A. T., Lamontague, J. J., and Surette, W. E., Integrated Radiometric System for Gasifier Temperature Measurements - Part 3, Proceedings of the 1980 Symposium on Instrumentation and Control for Fossil Energy Processes, Virginia Beach, Virginia, June 9-11, 1980, p. 300 (ANL-30-62/CONF-300602). 

Case Study d. High Temperature Gas Turbine Erosion/Corrosion Thin Film Sensors and Related Devices (R. R. Dils - NBS)

There is a wide range of applications for durable thin film devices for harsh, high temperature environments. Measurements of fundamental properties such as temperature, pressure, velocity and heat flux in such environments require unusual effort and even the simplest of thin film devices will have an immediate impact. For example, thin film devices recently developed for the gas turbine industry are deposited directly on turbine airfoils where they provide the surface temperatures and strains in the complex air cooled turbine components - for the first time. Furthermore, in combination with wide bandwidth gas temperature measurements, the surface temperature measurements have provided the first measurement of the local heat transfer coefficients on the airfoils; the data provided a new understanding of the heat transfer to and within the airfoils and lead to new and more efficient airfoil cooling designs.

In this Case Study, the application of thin film airfoil and control devices is examined with regard to the engine operation and materials design of the thin film devices.

Introduction

Conventional surface measurement techniques on turbine airfoils perturb the boundary layer on the surface of an airfoil or the heat flows within the airfoil to the extent that detailed analyses of the data are quite difficult. This problem is particularly acute in cooled turbine airfoils, where increases in the turbine inlet temperatures have been accompanied by complex air and water cooling designs and attendant reductions of the component cross sections. To meet this need, a new technology for constructing arrays of thin, insulated, sensing films directly on turbine airfoil surfaces must be developed.

While the use of thin film sensors for low temperature surface measurements has been common for some time $[1,2,3]$, practical thin film devices for use in harsh environments must satisfy several design constraints which preclude the use of conventional methods and materials of construction and severely limit the choice of alternate materials and techniques of construction.

There is a new method of construction of high temperature thin films $[4,5]$ which has provided the first thin film turbine airfoii devices in large scale aircraft gas turbine and a brief review of this technology serves to introduce the potential and problems of high temperature thin film devices in gas turbines. 
State of the Art of High Temperature Thin Film Turbine Airfoil Sensors

The existing method of high temperature thin film construction uses a thermally grown metal oxide to electrically insulate the sensing element from the substrate. In this technique, a turbine component is coated with an alloy capable of growing an adherent, high dielectric strength metal oxide. The coated component is then oxidized and arrays of sensors and leads are sputtered on the oxidized surfaces. Wire leads are attached to the sensors and the assembly is reoxidized. The development of practical surface sensors for use in harsh environments is primarily dependent on the development of a coating which is compatible with the substrate material and capable of growing useful insulating surface oxide layers. For turbine alloys, the iron base alloy, $\mathrm{Fe} 25 \mathrm{Cr}$ $5 \mathrm{AT} 0.1 \mathrm{Y}$, has been selected from the group of MCrATY high temperature alloys which form adherent oxides during oxidation. An extensive investigation of the electrical properties of the oxides grown on these alloys led to the initial selection of FeCrAly. The dielectric strengths of oxides grown on this alloy $\left(5 \times 10^{4} \mathrm{~V} / \mathrm{cm}\right.$ at $\left.1093{ }^{\circ} \mathrm{C}\right)$ are high and the conductivities of the oxides $\left(10^{-8} \mathrm{ohm}^{-1} \mathrm{~cm}^{-1}\right.$ at $\left.1093^{\circ} \mathrm{C}\right)$ are low [6]. In addition, the alloy has desirable mechanical properties throughout the operating range of the sensors and devices using this alloy are usually durable.

Each element of the sensors is chosen for its specific electric, chemical, or mechanical properties and, as a result, it is necessary to combine materials with widely varying types of chemical bonding. The metal oxide is an insulator with strong ionic bonds, the coating is a high temperature metal alloy and the sensing element is usually a noble metal alloy 1-2 um thick. Therefore, when the temperature of the assembly is changed, thermal mechanical strains develop within the assembly. In a gas turbine, the assembly experiences unusual thermal mechanical strains during normal operation $[7,8]$. When the engine is decelerated from takeoff to idle, a compressive strain of $1.7 \%\left(5,860 \mathrm{MN} / \mathrm{m}^{2}\right.$ stress $)$ is developed in the uniform oxide layer. At imperfections in the oxide, shear tractions are applied to the metal/metal oxide interface and cause a concentration of inplane stresses at the interface. In addition, the combustor exhaust gases induce small, high frequency temperature oscillations at the metal surface; in a typical gas turbine [9], the oxide and metal coating near the surface oscillate $\pm 5{ }^{\circ} \mathrm{C}$ several times a second (6-8). These temperature 
oscillations induce only a $\pm 60 \mu \mathrm{m} / \mathrm{m}$ strain ( $\pm 21 \mathrm{MN} / \mathrm{m}^{2}$ stress) in the oxide and $a \pm 120 \mu \mathrm{m} / \mathrm{m}$ strain $\left( \pm 12 \mathrm{MN} / \mathrm{m}^{2}\right.$ stress) in the coating but the latter strain is adequate to cause plastic deformation of coatings which are sufficiently weak and ductile to accommodate the strains associated with the large infrequent temperature cycles. The deformation of the substrate displaces the surface material into the boundary layer where the oxide and metal are apparently subjected to additional large heat flows.

The resultant thermo-mechanical strains within the assembly can be accommodated by a limited number of techniques. A scanning electron micrograph study of devices after extensive use in laboratory combustor exhaust gases shows that, in general, the thermal strain in useful ( $1-2 \mu \mathrm{m})$ thin oxides is stored as elastic strain energy in the oxide, while strain relief in usable thick $(2-5 \mu \mathrm{m})$ oxides occurs by buckling and attendent plastic deformation of the substrate. It is concluded that, in order for the sensor assembly to remain intact, it is necessary to select a system in which: 1) the compressive shear stress of the oxide is greater than the buckling stress of the oxide when it is attached to the coating, 2) the metal oxide/metal interface yield and shear strengths are greater than the coating yield strength, 3) the coating yield strength is small and 4) the coating is ductile over the entire operating range of the sensors. In successful devices, the oxide buckles and cracks when the assembly is thermally cycled, but the strain relief within the coating is sufficiently uniform that the oxide layer remains attached to the coating and continues to insulate the sensing film from the coatings. FeCrAlY satisfies these requirments; the oxide is adherent and the material is sufficiently weak and ductile throughout the operating range that thermal strain relief occurs primarily by oxide buckling and deformation of the FecrATY.

The thermomechanical strains across the noble metal/oxide interface are much smaller since the thermal expansion coefficients of both materials are similar and the yield stress of the noble metal is low. However, it was found that high velocity combustor exhaust gas flow over the sensors does cause delamination of the sensing elements deposited on smooth oxide surfaces. There is no significant bonding between aluminum oxide and useful noble metal alloys, and therefore, the films must be mechanically attached to the oxide. The coating is abraded before oxidation in order to cause the growth of an irregular oxide. The films are then sputtered into the irregular surface and interlocked with the oxide. This technique is quite successful. At present, the sensors fail after 20 hours in $1093{ }^{\circ} \mathrm{C}$ combustor exhaust gases due to gradual carbon particle erosion of the films or changes in the electrical properties of the films. 
The thin film sensors represent quite a change in turbine airfoil instrumentation. The oxide layer and coating are common to high temperature turbine components and the only alteration in the component configuration is due to the thin, $2.5 \mu \mathrm{m}$, sensing films. These films are over two orders of magnitude thinner than the conventional strain and temperature sensors which are externally applied to the airfoil surfaces or placed in slots in the airfoil surface. The sensor height is five to ten times smaller than the critical height which will cause a disturbance of the boundary layer on a turbine airfoil. The thermal impedance of the sensor elements is over one thousand times smaller than the thermal impedance of the boundary layer on the turbine airfoils or the airfoil wal1. Therefore, the sensors do not perturb the airflow near the component, the heat flow from the gas stream to the component, or the heat flow within the component. The sensor metallurgy is based on the superalloy and coating technology developed for gas turbines so that the sensors can be applied to a number of common gas turbine component alloys.

A primary use of the sputtered sensor technology is the measurement of steady state and wide bandwidth surface temperatures of stationary and rotating turbine components. In general, useful information is received within a $0-1000 \mathrm{hz}$ bandwidth with an accuracy equal to standard grade platinum-platinum/rhodium thermocouples. In principle, any array can be sputtered on an airfoil using available, high resolution, microcircuitry masking techniques. The rugged nature of the sensors and ability of the FeCrAlY coating and adherent aluminum oxide to endure most superalloy forming and heat treating cylces suggests that the sensors can also be sputtered on subassembly surfaces which can then become internal surfaces in a final assembly. The heat transfer to a component and heat fluxes within the component can be described in some detail from the steady state temperatures measured with arrays of sensors on the component surface or combinations of internal and external sensor arrays.

The local heat transfer to an airfoil in combustor exhaust gases can also be obtained from an analysis of the surface temperature waves induced by the combustor exhaust gas temperature fluctuations. Surface temperature Fourier components within the 2-200 hz bandwidth have been found useful for this purpose ${ }^{10}$; these Fourier components are rapidly attenuated near the surface of the component and the ratios of their 
amplitudes to the amplitudes of corresponding gas temperature Fourier components are a simple function of the local heat transfer coefficient. Both turbine airfoi] temperature and heat transfer coefficient measurements have been measured in large scale aircraft gas turbines using these sensors.

The sputtered temperature sensors have been used in dynamic oxidation experiments where they have provided the first direct measurement of surface temperature waves which can damage the protective metal oxide and significantly increase the rate of oxidation of a material. The thermal/mechanica strains induced near the surface of aluminized superalloys in gas turbine main burner exhaust gases do cause fragmentation and separation of the protective aluminum oxide and it is suspected that the gas dynamics of some high temperature gas streams found in power generating units may also significantly affect the oxidation and corrosion processes in these units.

It is apparent that a wide range of sensing elements can be applied to the surface of a component once an adherent, high dielectric strength oxide layer is developed on the component. For example, a temperature compensated strain gauge would consist of a strain sensing Pt-W element and a Pt/Pt-10\% Rh thermocouple. Any number of arrays can be contemplated to provide temperature compensation because the temperature and strain sensing elements can be sputtered in such intimate arrangements that the temperature compensation is quite accurate. In these devices, a thin protective aluminum oxide layer would be sputtered on the assembly to reduce the rate of oxidation of the strain sensing element.

Erosion and salt deposition monitoring devices can also be constructed on the surface of turbine components. In laboratory combustor exhaust gases, it has been found that the life of the thermocouple elements on small cylinders is a sensitive function of the hard carbon particle density and the position and thickness of the sputtered noble metal films. The rate of erosion of an airfoil in an engine can be observed while the engine is operating by monitoring the resistance of platinum or other films sputtered on the airfoil or by inspection of the films after an engine test.

Pronounced hot corrosion is caused by ash deposition on the surface of the turbine component. However, the rate of ash deposition is a complex function of the chemistry of the ingested gases, combustion dynamics, and the air flow and temperature along the turbine airfoil. Therefore, it is difficult to predict the rate of ash deposition in an engine. The problem can be avoided by sputtering thin films of reactive nickel-base 
alloys on an airfoil and monitoring the degradation of the films through changes in their resistivity or thickness. In this manner, it should be possible to isolate those engine conditions which cause extensive ash deposition and to monitor the total amount of ash deposition in an operating engine. Alternatively, electrodes could be sputtered on the airfoil and the deposit characterized by the electrochemical potential developed between the electrodes.

The Elements of a Thin Film Sensor Program

The goal of a program on high temperature thin film sensors is to supply generic background information on methods of construction and signal generation for practical thin film devices. The information falls into 2 categories: accommodation of the thermal mechanical strain with the sensor and signal generation.

A systematic study of methods of accommodating thermal mechanical strains has both an analytical and experimental component. The analytical effort would concentrate on analyses of potential films from the literature data and the application of large scale finite element computor codes to model the thermal mechanical strains within the sensors. The experimental effort would evaluate several alternate means of storing or relieving the thermal mechanical strains, i.e., stored elastic strain, controlled buckling and plastic deformation, control of the relative values of the compressive shear and buckling stresses of the films, control of the relative values of the interface tensile and shear strengths at several interfaces within the assembly, and control of the relative yield strengths of the films. Experimental films and devices would be constructed and evaluated in a variety of static and dynamic environments, including a controlled hot gas stream apparatus. Evaluations of the film and sensor composites would be conducted using state of the art optical, SEM, TEM, EPMA etc. techniques.

The objective of this part of the effort will be a set of specific device compcnents to meet specific needs. Pursuit of these objectives will lead to the generic understanding of the thin film behavior in harsh environments, and the general rules and design concepts for the construction of such thin film devices. The work will break new ground and establish new rules since parallel efforts are not underway in other laboratories. 
Thin film signal generation at high temperatures is an equally fascinating subject. Stable films can generate a signal, such as a thermoelectric emf or a change in resistivity due to changes in temperature or strain. Alternatively, the film can intensionally interact with the environment as in the case of new corrosion and erosion films now being developed for corrosion control in gas turbines. In this case, the chemistry of the film is altered to respond to specific deleterious chemicals in the environment and reaction with the chemicals changes the properties of the film. The films can also consist of grating arrays which are passive and simply scatter or absorb signals from external sonic or optical excitors. These devices can be used to measure surface displacements or to investigate optical processes in the gas stream between the light source and the thin film. Passive or active high temperature optical mirrors are a simple example application of this type of technology.

Therefore, the second part of the effort would examine signal generation in high temperature thin films. Understanding and developing methods of signal generation at high temperature requires advanced solid state studies of the films, with specific focus on the film transport properties. In stable films such as strain gauges, it will be necessary only to study the impurity transport and stability of the film. In other instances, more involved descriptions of ionic and electronic transport across high temperature semiconductors which require collective and localized electron models to describe the behavior of the outershell bonding and nonbonding electrons will be necessary. Alternate forms of signal generation would be investigated. 'The initial studies would concentrate on devices to measure, temperature, heat flux, and corrosive conditions to $4500^{\circ} \mathrm{F}$. The theoretical and experimental effort would concentrate on the description of thin films generated in the laboratory. The goal of this part of the effort would be a specific set of devices and a general background to develop design concepts for high temperature thin film devices.

\section{References}

1. Burger, H. C. and Van Citter, P. H., "Preparation of Bismuth-Antimony Vacuum Thermal Elements by Vaporization", Z. Phys. Vol. 66, 210 (1930).

2. Harris, L. and Johnson, E. A., "Technique of Sputtering Sensitive Thermocouples", Rev. Sci. Inst. 5 , 153 (1934).

3. See, for example, Chopra, K. L., Thin Film Phenomena, McGraw Hill, New York, 1969. 
4. Dils, R. R., "Process of Coating a Gas Turbine Engine Alloy Substrate", U. S. Patent 3,890,456, 17 June 1975.

5. Dils, R. R. and Follansbee, P. E., "Superalloy Sensors", SUPERALLOYS: METAlluRgy AND MANUfACTURE, Kear, B. H., Muzyka, D. R., Tien, J. K., and Wlodek, S. T., Eds., Claitors, Baton Rouge, La., 1976, pp. 37-44.

6. Dils, R. R. and Follansbee, P. S., "Electronic and Ionic Conduction in Aluminum Oxides Grown on High Temperature Metal Alloys", presented at Symposium on High Temperature Electron and Ion Transport in Solids, Electrochemical Society Meeting, San Francisco, May 12-17, 1974.

7. Wells, C. H., Follansbee, P. S., and Dils, R. R., "Mechanisms of Dynamic Degradation of Surface Oxides", STRESS EFFECTS AND THE OXIDATION OF METALS, J. V. Cathcart, Ed., AIME, New York, 1975, pp. 220-244.

8. Dils, R. R. and Follansbee, P. S., "Dynamic Oxidation and Corrosion in Power Generating Units", CORROSION, 33, No. 11, p. 385, 1977.

9. Dils. R. R., "Dynamic Gas Temperature Measurements in a Gas Turbine Transition Duct Exit", J. OF ENGINEERING FOR POWER, TRANS. ASME, VOT. 95, Series A, No. 3, July 1973, p. 265.

10. Dils, R. R. and Follansbee, P. S., "Heat Transfer Coefficients Around Cyl inders in Crossflow in Combustor Exhaust Gases, J. OF ENGINEERING FOR POWER, TRANS. ASME 99 , No. 4, p. 497 (1977). 
Case Study e. Analysis by High Pressure Sampling Mass Spectroscopy

(P. K. Schenck - NBS)

Analytical measurements in the process stream of coal conversion plants will inevitably involve the use of sampling probes for either "off-line" or on-line" chemical analysis. All of the sampling-based diagnostic tools of potential application in monitoring the coal conversion processes are presently limited by materials durability problems associated with the sampler. In order to economize on instrumentation, devices with multispecie capability are favored over species-specific devices. A multispecie analytical capability can readily offset the cost or complexity disadvantages of more sophisticated instrumentation.

The high pressure sampling mass spectrometer is a multispecie device potentially applicable to real-time monitoring of reaction intermediate concentrations in coal conversion processes (including laboratory, pilot and fuli-scale plants). A typical mass spectrometer system consists of a sampler, high capacity vacuum system, ion source and mass analyzer. Materials durability problems are primarily associated with the sampler. The mass spectrometer sampler, as with samplers for other possible instruments, must not only survive the coal conversion environment, but must reliably and accurately sample the process stream. This latter aspect has been particularly problematical in the use of microprobes for $\mathrm{NO}_{\mathrm{X}}$ determinations where secondary reactions occur on the internal walls of the probe (depends on wall material and geometry. Molecular beam probes, on the other hand, minimize the chance for such wall reactions.

The sampler design and material selection thus becomes the critical element in the application of mass spectrometers to "on-line" in situ analysis. In the molecular beam sampling approach, the probe usually consists of a sampling cone (which is usually water cooled) backed up by second cone or skimmer. The purpose of the skimmer is to sample only the center of the gas jet formed by the supersonic expansion of the sampled gas into the mass spectrometer. Probe theory exists for relating probe geometry, skimmer geometry and probe-skimmer spacing to gas pressure and thermodynamic characteristics. In practice, compromises in design are made because of materials durability problems. Probe theory for pressure much above one atmosphere, such as those encountered in coal gasifiers and turbines, may require some extension.

Adaptation of the high pressure sampling mass spectrometer to the problem of monitoring reaction intermediates in the coal conversion process will require a systematic study of probe design and materials under the 
aggressive conditions of high temperature, pressure and reactive gas. Only a few preliminary studies have been carried out even for laboratory systems. Typical high pressure sampling mass spectrometer systems have been used in the laboratory to sample atmospheric flames at temperatures as high as $2500{ }^{\circ} \mathrm{C}$. The one atmospheric pressure at the sampling orifice is reduced in stages to $210^{-11} \mathrm{~atm}$ at the mass analyzer. Species concentration of $>10^{-6} \mathrm{~atm}$ in the original sample gas can be analyzed with 20-50 percent accuracy. Corrosion problems particularly of the sampling cone and skimmer were severe in the. flame environment. Alkali metals, $\mathrm{NaCl}, \mathrm{NaOH}, \mathrm{NaSO}_{4}$ (and $\mathrm{K}$ analogues) as well as acid oxides such as $\mathrm{SO}_{2}$ are particularly corrosive. These species are present in many combustion systems and certainly will be present in coal gasifiers. Hastie (1973) at the National Bureau of Standards carried out some preliminary work which lead to the development of ceramic probes suitable for highly reducing (fuel rich) flames. Four materials were studied: silica, alumina, Ca-stabilized zirconia, and lava - a commercially available aluminum silicate with the latter material selected for routine use. The choice of lava as a probe material was based on its ready machinability in the raw form and its resistance to thermal shock and corrosion. Alkali metals and acid oxides are highly corrosive at high temperatures and will quickly destroy the integrity of metallic sampling cones. Further work in characterizing lava and similar possible sampler materials is needed.

Other species of interest in coal conversion processes such as $\mathrm{N}_{2}$, $\mathrm{NO}_{x}$, $\mathrm{C}_{2}, \mathrm{H}_{2} \mathrm{O}, \mathrm{H}_{2}, \mathrm{CH}_{4}$ and other simple hydrocarbons (product gas) are no problem for the mass spectrometer. Many other species, too numerous to list, have been studied by mass spectrometers attached to combustion systems ${ }^{9}$.

More recently, probe measurements have been reported in combustor systems and jet engines. Greene et $a 7^{2}$ (1978) of the Midwest Research Institute have used mass spectroscopy to study coal dust/air flames. Workers at Aerodyne Research ${ }^{3}$ have used mass spectroscopic determinations of ion concentrations in simulations of MHD plasmas. In this work, a coal burner (coal dust/air) heavily seeded with $\mathrm{K}_{2} \mathrm{CO}_{3}$ was used to simulate a coal-fired MHD generator. The predominant positive ions observed with the mass spectrometer were potassium and the other alkalis $\left(\mathrm{Na}^{+}, \mathrm{Rb}^{+}\right.$, $\mathrm{Cs}^{+}$). In addition, several negative molecular ions, $\mathrm{OH}^{-} \mathrm{PO}_{2}{ }^{-}$, etc., were observed. Other trace species, including heavy metals, were detected as neutrals. This application used a cooled stainless steel sampler. 
In order to prevent plugging by condensing slag or seed particles, a nozzle plug cleaner was incorporated in the design. The design of a nozzle with a material capable of surviving the $2000{ }^{\circ} \mathrm{C}$ plus temperatures and alkali environment would have allowed continuous sampling without the periodic mechanical plug cleaning which would be necessary in practical plant applications. Large temperature gradients between the probe and sample gas also have undesirable effects in perturbing the gas composition. Miller ${ }^{4}$ (1978) at Aerochem Research has carried out similar studies in flames to study ion-molecule thermochemistry. Miller was particularly concerned that his sampling procedure would freeze out any chemistry to assure that his measurements accurately reflected the presampling environment in his burner. A simple gas dynamic model of his sampling cone indicated that only reactions involving the major constituents of the sampled gases would proceed at rates fast enough to affect the accuracy of the sample. Miller concentrated on the negative ion chemistry of species such as $\mathrm{OH}^{-}, \mathrm{Cl}^{-}$, and several metallic oxide ions. The choice of specific probe design and types was also a topic at the 1976 AIAA 14th Aerospace Sciences Meeting. Several papers in the published proceedings ${ }^{5}$ will provide the reader with a tutorial on probe design and selection.

A major stumbling block is still the effect of the probe on the measurement to be made. Will the probe walls act as a catalyst, or can they successfully freeze out the reaction intermediates? Only a few simultaneous in situ versus probe concentration measurements have been made in combustion environments. McGregor ${ }^{6}$ (1976) reported that the in situ concentrations of $\mathrm{NO}_{x}$ were much higher than probe-sampled measurements in a jet engine exhaust. The order of magnitude discrepancy points out the problem of accurate probe sampling, even if the probe can survive the environment. McGregor's work used optical absorption techniques for both the in situ and probe measurements. More recently Cattolica et a ${ }^{7}$ (1980) at Sandia reported on the comparison of in situ laser absorption spectroscopy for $\mathrm{OH}$ concentration measurements versus mass spectrometric probe measurements in a methane-air flame. While there was reasonably good agreement in the two techniques, the probe measurements were shifted downstream relative to the in situ absorption measurements. This work also points out the need for careful probe design to reduce composition changes during sampling. 
Systematic studies at the laboratory and pilot plant level are needed to develop high pressure sampling mass spectrometer probes capabie of surviving coal conversion atmospheres. These studies should include:

1. Thermodynamic calculations should be made of the phase fields formed between candidate metal and/or ceramic probe materials and coal conversion atmospheres. From these calculations, the most promising materials would be selected and probes of various geometries designed. Some materials may be excluded on thermal stress grounds (e.g., high purity alumina).

2. These probes would then be tested for their durability and sampling fidelity in laboratory atmospheres at temperatures, pressures and gas compositions representative of coal combusion/gasification.

3. Probes could then be tested for their accuracy by simultaneously using in situ optical techniques such as laser absorption and tomographic analys is in conjunction with the mass spectrometer to map out species concentration in a simulated coal conversion environment.

4. Successful probes would then be tested in pilot plants for their durability and accuracy.

5. Once demonstrated, a program could be developed where an HPMS system would be installed at a selected pilot plant for systematic in situ analysis of process gas compositions.

\section{$\underline{\text { References }}$}

1. J. W. Hastie, Combustion and Flame, 21, pp. 49-54 (1973).

2. Frank T. Greene, Jacob E. Beachey, and Thomas Milne, in 10th Materials Research Symposium, NBS Special Publication 561, p. 431 (1979).

3. J. C. Wormhoudt and C. E. Kolb, ibid., p. 457.

4. W. J. Miller, ibid., p. 443.

5. Experimental Diagnostics in Phase Combustion Systems, edited by B. T. Zinn, (Vol. 53 in progress in Astronautics and Aeronautics), particularly the contributions by Bowman, Miller and Cernansky in Chapter 1 (1977).

6. W. K. McGregor, in Combustion Measurements, edited by R. Goulard, p. $325(1976)$.

7. R. J. Cattolica, S. Yoon, and E. L. Knuth, Sandia Report \#SAND80-8804 (1980).

8. Tomographic analysis is a reconstruction of point-by-point information from the "line-of-sight" data typical of optical absorption experiments.

9. See C. Stearns and F. Kohl in ref. 2 . 
Case Study f. Measurement of Heat Conductivity (H. P. R. Frederikse - NBS)

Every form of coal conversion, be it production of gas or liquid fuel or electricity, involves a host of thermal processes. Heat is produced, absorbed, transported or converted into another form of energy. In all these processes, heat transport or heat flow plays a very important role. The heat is transported through a wall material or through the fuel itself: solid, liquid or gas. Consequently, knowledge of the thermal conductivity of these materials is essential for the design and operation of most components of coal conversion facilities. It is hardly necessary to emphasize the importance of this parameter in heat exchangers and boiler tubes, both with respect to the metal wall and the ceramic liners. The same holds for the construction materials of combustors, as well as (pre)heaters and reaction vessels for gasification or liquefaction. Particularly important are heat conductivity data for the selection of MHD-electrodes and for direct or indirect air preheaters. The temperature and hence the operation of catalysts and catalyst beds depends on the thermal transport of the catalytic materials and their substrates.

In many cases usefur data can be found in the literature especially when the material is a well-known commercial metal, alloy or ceramic, and the temperature range in question does not exceed $800-900{ }^{\circ} \mathrm{C}$. To find reliable values for the thermal conductivity of newly developed materials or specially treated materials appears to be more difficult especially at temperatures above $1000{ }^{\circ} \mathrm{C}$. One should not forget the importance of the heat conductivity of the fuel and its various components. Little is known about the transport of heat through coal, coal slurries, coal slag (both in the solid and molten state), and through the product fluids. In many instances the heat flow is determined more by the heat resistance of the surface or interface than by that of the bulk materials. In general, it is difficult to determine the appropriate heat conductivity of non-homogeneous materials (which are abundantly used in coal conversion technology)! What is the heat conductivity of a cermet (ceramic-metal) composite? How does the heat conduction of a ceramic brick depend on its porosity and on the material in the pores (1iquid or gas)? How does one analyze the heat flow through a powder or through a phase-separated alloy or ceramic? 
Yet two other material aspects require good thermal conductivity data: modeling of heat flow through multicomponent walls, and the calculation of stress patterns in solid components (often produced by large temperature gradients). An example of the first one is the work of J. R. Schorr at Battelle who has designed a conductivity model for the transport of heat through a multilayered refractory-lined wa11. With this computer model one can explore the effects of voids, cracks, gas composition, temperature and pressure for a variety of materials.

The second aspect is illustrated by various stress analyses, (using a finite-element approach), aimed especially at the design of ceramic components for turbines, combustors and heat exchangers. Both thermally and mechanically induced stresses are being calculated and mapped.

The question arises: What is the reason that heat conductivities of materials are infrequently investigated, measured and analyzed? Is the feeling prevalent that there are enough reliable heat conductivity data and that better or more accurate values are not needed? What is the reaction of the designer who finds two sets of data on identical (?) alumina differing by factors of 2 or more? Or is the reason of this neglect that the study and measurement of heat conduction is not "exciting" enough? Or perhaps that the measurement methods are complex and tedious and the equipment expensive?

A11 these arguements do not carry much weight. The fact is that there is a need for good heat conductivity data, that the science of heat flow is interesting (especially when one takes a broad spectrum of material and environmental conditions into account), and that the measurement methodology requires a lot of attention!

It might be worthwhile to review the scientific situation with respect to thermal conductivity as it appears at this moment. This can best be done by discussing 4 aspects of the problem. Although it is always dangerous to mention only a few names, it seems appropriate to indicate some of the leaders in these 3 areas:

1. General Phenomenology (metals, semiconductors, insulators, magnetic materials, etc.).

iwo textbooks have appeared in the last 5 years: one by J. E. Parrott and D. Stuckes ("Thermal Conductivity of Solids", 1975) and the other by R. Berman ("Thermal Conduction in Solids", 1976). 
2. Theory of thermal conduction in solids

The Dean of the field is P. G. Klemens, both with respect to low temperature processes, and more recently also concerning high temperature mechanisms. (see Chapter 1: "Theory of the Therma 1 Conductivity of Solids" in "Thermal Conductivity", Vol. 1, Ed. by R. P. Tye, Acad. Press, New York, 1969).

3. Measurement methods

Many static and dynamic techniques are described in detail in the 2-volume book by R. P. Tye cited above.

4. Data Collection and Dissemination

Much data can be found in the files of the Thermophysical Properties Research Center at Purdue University, until recently headed by $Y$. S. Touloukian. 1. General Phenomenology

Because $\lambda$ (=thermal conductivity) is a function of $T$, the gradient in $Q=\lambda A \frac{\Delta T}{d x}$ should be small; this way one can determine $\lambda$ at a particular temperature, rather than over a range of temperature. Thermal conductivities cover a range of some 5 to 6 orders of magnitude. Copper is thought to be the best conductor, but in the temperature range around $20 \mathrm{~K}$ sapphire has a larger conductivity (of the order of $100 \mathrm{~W} \mathrm{~cm}^{-1} \mathrm{~K}^{-1}$ ). On the other hand, fibrous materials have the lowest heat conductivity amounting to about $2 \times 10^{-4} \mathrm{~W} \mathrm{~cm}^{-1} \mathrm{deg}^{-1}$ at room temperature, with large contributions from the trapped air, from convection and from radiation. It is often difficult to find a material with a desired heat conductivity in a particular temperature range. The reason, of course, is that the right conductivity is not the only condition that has to be satisfied. Often the material has to be a conductor, corrosion resistant, able to withstand alkali and/or sulfur attack, and mechanically strong. Consequently, the choice is narrowed considerably and often such a material does not exist. In those cases one would like to know how the heat conductivity can be increased or decreased by changing the physical and/or chemical properties of the material. Very little is known except qualitatively how the heat conductivity varies with alloying, phase distribution, impurity content, density, grain size, crystallinity, etc. The other approach to modification of the heat conductivity is to cover the material with a (thin) coating, e.g., a metal layer on a ceramic, or a glassy film on a (porous) ceramic.

\section{Theory}

Understanding the fundamentals of heat conduction in solids is difficult because the variety of heat transport mechanisms is great and most of these mechanisms are complex. The following listing gives some idea of this complexity. 
In a crystalline solid heat can be transported by electrons, by lattice vibrations (phonons), by magnetic excitations (magnons) and by photons (radiation). However, none of these "particles" or modes have infinite mean free path. The thermal conductivity is limited by a host of scattering processes:

1) phonon-phonon (mainly 3 phonon, but also higher order). Without going into detailed explanation, it is interesting to enumerate the variety of P-P processes: Normal and Umklapp processes, processes involving acoustic and/or optical phonons, longitudinal and/or transverse phonons, each having their own $\omega$ - and T-dependence.

2) Electron-phonon (and phonon-electron)

3) Phonon-paramagnetic ions or phonon-magnon Scattering of phonons, electrons, or magnons by:

4) Point defects (impurities, isotopes, vacancies)

5) Grain boundaries, dislocations, strain fields

6) Mixed composition (solid solution, alloys)

7) Multiphase composition (phase separation, ceramic and metal, crystalline and amorphous, solid and liquid, solid and gas)

8) Voids (effect of density)

9) Anisotropy

Often one has to consider non-crystalline materials; glasses, polymers, liquids. Theoretical treatments of these materials are still in their infancy.

While it is often possible to separate some of the mechanisms (or reduce them to a negligible contribution) at (very) low temperature, at high temperature a large portion of the above list comes into play and therefore analysis and understanding becomes a very tough task.

3. Measurement Techniques

The various methods can be classified as follows:

1) Static (thermal conductivity)
a) linear flow: ba $\dot{r}$, disc, composite (standards)
b) radial flow
c) Joule heating (for conductors)

2) Dynamic (thermal diffusivity)

a) periodic heating: bar, disc

b) pulse and flash heating

Although this is not the place to elaborate about these techniques, a few remarks are in order. The static measurements are reasonably straightforward; they work well especially at very low temperatures. At temperatures above 50 or $100 \mathrm{~K}$ and up to 1000 or $1200 \mathrm{~K}$ the static methods are quite 
useful if one pays sufficient attention to proper (heated) guards and thermal insulation. The purpose is to establish a precise, well-controlled, linear heat flow pattern. As a result, the static methods are time consuming. The accuracy of these techniques usually is of the order of $25 \%$. To attain this accuracy it is recommended to use a comparative method employing one or more sets of standards. Also, to facilitate the establishment of a true linear heat flow and increase the precision, it is recommended to use a microprocessor for the sensing of the temperature indicators, the control of the heaters and the feedback between these systems.

At high temperatures, above 600-1200K (depending on the material) the static methods do not give reliable results because of the rapidly increasing heat losses (especially radiative). The effect of high temperature radiation losses can be minimized in the periodic technique using frequencies of $0.02-200 \mathrm{~Hz}$, and in the flash method limiting the pulse to milliseconds. The dynamic technique requires proper temperature sensors with sufficient sensitivity and fast response time (i.r. detectors and photomultipliers). A second detector or pyrometer can be used to measure the mean temperature. The major feature of the dynamic method (thermal diffusivity) is that it requires knowledge of the specific heat in order to translate the results into heat conductivity data. In many cases at high temperature one can use the $3 R$ approximation for $C_{v}$. If experimental values are required, the measurement of heat capacity may present problems in some cases.

In general, dynamic methods give not as high a precision as static methods. However, they are much faster. Static measurements often take several hours for one point at one temperature. On the other hand, the results can be more precise and the technique lends itself to simultaneous measurement of other parameters (e.g., electrical conductivity as well as Hall and Seebeck effects for electrical conductors).

4. Data and Standards

Parrott and Stuckes state that "thermal conductivity data (published by the TPRC at Purdue University) show a disparity in data probably greater than that of any other physical property". The discrepancies are always several or many percent, and may be as high as an order of magnitude. Much of this diversity stems from poor measurements, although some of it is due to the variation in materials. Two rules should be kept in mind when providing thermal conductivity data: 1) The apparatus should be checked by measuring one or more "standard" samples. Unfortunately, no set of standard reference materials exist which cover the range of heat conductivities.

2) The material 
should be well-characterized by providing such information as source of the sample, chemical analysis, fabrication treatment, density, grain size, crystal structure, orientation of sample with respect to heat flow, as well as shape, size and density.

\section{Recommendations}

The above discussion leads logically to a suggested research program:

1. Systematic investigation of the thermal conductivity especially at high temperature up to at least $2000{ }^{\circ} \mathrm{C}$. Study of transport and scattering mechanisms one by one and comparison of anticipated results with those expected for pure, high quality, strain free single crystals: analysis of the effects of imperfections, many phases, voids, etc. (see listing on p. 4 of this Case Study).

2. Development of a reliable, reasonably inexpensive apparatus using the static comparative technique and a microprocessor for temperature, heat flow and feedback control.

3. Refine the dynamic method, improving laser heating, sensitivity of the temperature sensor, optical signal transmission and develop a convenient recording and data acquisition system.

4. Develop sets of standard reference samples both for the static and for the dynamic technique. Compare results of the best of both techniques.

5. Maintain and strengthen a high quality data base system connected with many reliable measurement laboratories and providing good and fast information to all interested customers. 


\section{APPENDIX IV: MiniWorkshop}

On request of the sponsors of this project a one-day workshop was held at the National Bureau of Standards to discuss the report and to provide the Department of Energy (Fossil Energy Program) with additional comments on the suggested program plan.

The participants in this exercise were:

T. K. Lau

S. J. Dapkunas

R. Skaggs

J. Carr

R. Gottschalk

S. Wolfe

N. O'Fation

R. L. Anderson

J. V. Walsh

R. V. Shanklin

C. Semler

H. Frederikse

R. R. Dils

G. Burns

J. Whetstone

J. Hastie

S. J. Schneider

$T$. Negas
DoE (FE)

DOE (FE)

DoE (FE), gues tworker from LASL

DoE (FE)

DoE (Energy Res. Office)

DoE (Energy Res. Office)

Argonne National Laboratory

Oak Ridge National lab.

Jet Propulsion Laboratory

TRW (Energy Office)

Ohio State University (Dept. of Ceramics)

NBS

NBS

NBS

NBS

NBS

NBS

NBS 
Distribution List

Department of Energy (20)

National Bureau of Standards (20)

Nancy O'Fallon

A. C. Raptis

T. P. Mulcahey

W. A. Ellingson

R. L. Anderson

J. R. Hightower

J. V. Walsh

Peter Alexander

R. V. Shanklin

R. Eustis

Sidney Self

W. M. Roquemore

R. Jaffee

D. Canfield

S. Petty

B. R. Rossing

D. Murphee

J. Honig

R. Braunstein

A. V. Levy

J. C. F. Wang

Herb Kaplan

F. M. Zweibaum

M. J. Baroody

B. R. Cooper

A. J. Forney

F. T. Finch

G. J. Lapeyre

Martin L. Gorbaty

Roland L. Schmitt

Delbert E. Day

Robert J. Stokes

C. E. Semler

R. Essenhigh

Roger Staehle

$H$. Kent Bowen

J. Lambert Bates

D. Eastman
Argonne National Lab. Argonne National Lab. Argonne National Lab. Argonne National Lab.

Oak Ridge National Lab.

Oak Ridge National Lab.

Jet Propulsion Lab. (Pasadena, CA)

TRW Energy Systems (Lakewood, CO)

TRW (McLean, VA)

Stanford Univ (Dept. of Mechanical Engineering)

Stanford Univ (Dept. of Mechanical Engineering)

Air Force Aero Propulsion Lab (Dayton, OH)

EPRI (Palo Alto, CA)

Pittsburgh \& Midway Mining CO (Ft. Lewis, WA)

AVCO (Everett, MA)

Westinghouse Res. Lab. (Pittsburgh, PA)

Mississippi State Univ. (MHD Energy Center)

Purdue Univ. (Dept. of Chem)

UCLA (Dept. of Physics)

Lawrence Berkeley Lab.

Sandia-Livermore Labs.

SCIEP (Norwalk, CT)

Barnes Engineering (Stamford, CT)

Catalytic, Inc. (Wilsonville, AL)

$U$. of West Virginia (Dept. of Physics)

Forney Engineering CO (Colorado)

Los Alamos Scientific Lab.

Montana State Univ. (Dept. of Physics)

Exxon Corp. Research Science Lab (Linden, $\mathrm{NJ}$ )

General Electric Research \& Dev. Center (Schenectady, NY)

Univ. of Missouri-Rolla (School of Mines and Met.)

Honeywel1 Corp. Materials Science Center

Ohio State Univ. (Dept. of Ceramics)

Ohio State Univ. (Coal Research

Univ. of Minnesota (Metallurgy Dept.)

MIT (Ceramics Dept.)

Battelle (Pacific Northwest Lab.)

IBM (Yorktown Heights, NY) 
4. TITLE AND SUBTITLE

MATERIALS FOR INSTRUMENTATION FOR FOSSIL ENERGY TECHNOLOGIES

5. AUTHOR(S)

H. Frederikse, P. Schenck, G. Burns, R. Dils, J. Whetstone 6. PERFORMING ORGANIZATION (If joint or other than NBS, see instructions)

NATIOMAL BUREAU OF STANDARDS

DEPARTHENT OF COMMERCE

WASHINGTOR, D.C. 20234

9. SPONSORING ORGANIZATION NAME AND COMPLETE ADDRESS (Street. City, Stote, ZIP)

Department of Energy

Fossil Energy

Washington, DC 20545

10. SUPPLEMENTARY NOTES

Document describes a computer program; SF-185, FIPS Software Summary, is atrached.

1. ABSTRACT (A 200-word or less factual summary of most significant information. If tocument includes a significant bibliography or literature survey. mention it here)

This report reviews the materials problems related to instrumentation for Fossil Energy Facilities. It discusses requirements for measurement of process parameters (flow, temperature, pressure, chemical composition), of construction material properties, and of fuel characteristics. The main part of the report is a suggested program plan for pertinent materials R\&D. Short descriptions of the various Fossil Energy Processes, listing of present research activities, and a set of 6 "Case Studies" are presented in an. Appendix.

12. KEY WORDS (Six to iwelve entries: alphabetical order: capitalize only proper names; and separate key words by semicolons) Coal;-control; Fossil Energy; materials; process parameters; research recommendations

\section{AVAILABILITY}

U Unlimited

For Official Distribution. Do Not Release to NTIS

Order From Suderintendent of Documents, U.S. Government Printing Office, Washington. D.C. 20402.

X. Order From National Technical Information Service (NTIS), Springfield, VA, 22161
14. NO. OF

PRINTED PAGES

135

15. Price '.-

$\$ \pm 2.50$ 


